\title{
Consequence Evaluation of Radiation Embrittlement of Trojan Reactor Pressure Vessel Supports
}

Manuscript Completed: September 1990

Date I ublished: October 1990

Prepared by

S. C. Lu, S. C. Sommer, G. L. Johnson, Lawrenre Livermore National Laboratory

H. E. Lambert, FTA Associates

Lawrence Livermore National Laboratory

Livermore, CA 9455 !

Subcontractor:

FTA Associates

3728 Brunell Drive

Oakland, CA 94602

Prepared for

Division of Engineering

Ofince of Nuclear Regulatory Research

U.S. Nuclear Regulatory Commission

Washington, DC 20555

NRC FIN B6021 


\begin{abstract}
This report describes a consequence evaluation to address safety concerns raised by the radiation embrittlement of the reactor pressure vessel (RPV) supports for the Trojan nuclear power plant. The study comprises a structural evaluation and an effects evaluation and assumes that all four reactor vessel supports have completely los: the load carrying capability.
\end{abstract}

By demonstrating that the ASME code requirements governing Level D service limits are satisfied, the structural evaluation concludes that the Trojan reactor coolant loop (RCL) piping is capable of transferring loads to the steam generator (SG) supports and the reactor coolant pump (RCP) supports. A subsequent analysis further demonstrates that the SG supports and the RCP supports

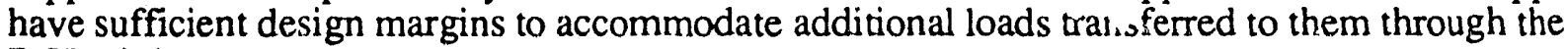
RCi piping.

The effects evaluation, employing a systems analysis approach, investigates initiating events and the reliability of the engineered safeguard systems as the RPV is subject to movements caused by the RPV sunport failure. The evaluation identifies a number of areas of additional safety concems:

(1) The RPV movements could cause multiple rupture of instrumentation thimble tubes or the guide tubes that penetrate the bottom of the RPV and result in a loss of core coolant that may lead to core uncovery.

(2) The deformation of the RCP casing may cause the impelle:s to bind and result in loss of natural circulation; and the tilting of the pump may affect its coastdown ability.

(3) The control rods could bind in the event of tilting of the RPV and the ability to insert control rods during a reactor trip may be affected.

(4) The rupture of the 10-in. safety injection lines could impair the function of the emergency core ccoling system.

Further investigation of the above safety : oncerns, however, concludes that a hypothetical failure of the Trojan RPV supports due to radiation embrittlement will not result in consequences of significant safety concerns. 


\section{CONTENTS}

\section{Page}

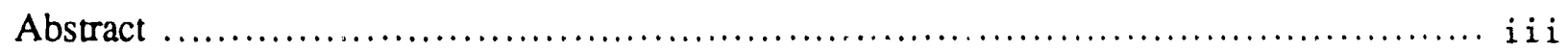

Acknowledgments................................................................ vi

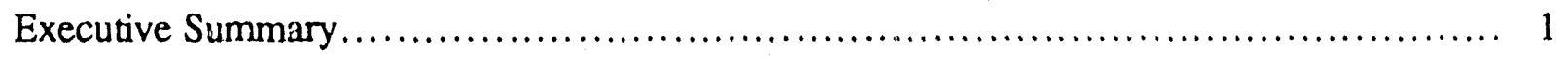

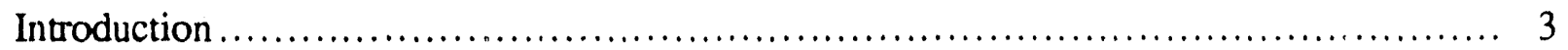

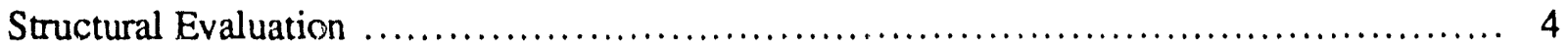

Effects Evaluation .............................................................. 5

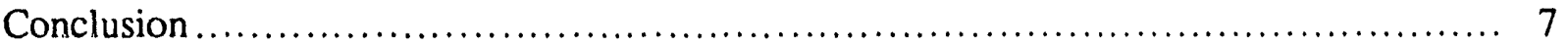

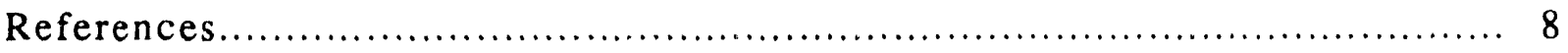

Appendices

1. Structural evaluation of the Trojan reactor coolant loop............................... Al-1

2. Sensitivity study on the variation of steam generator support stiffness $\ldots \ldots \ldots \ldots \ldots \ldots$ A2-1

3. Load capacities of steam generator and reactor coolant pump supports..............A3-1

4. Effects assessment of reactor pressure vessel support failure $\ldots \ldots \ldots \ldots \ldots \ldots \ldots \ldots \ldots$ A4-1

5. Rupture of thimbles and guide tubes ..........................................

6. Effects of pump tilting and casing deformation on reactor coolant pump

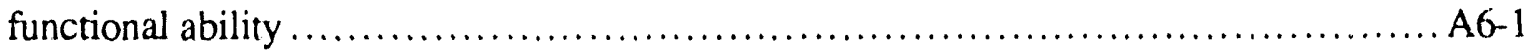

7. The ability to insert control rods with a tilted reactor pressure vessel $\ldots \ldots \ldots \ldots \ldots \ldots \ldots$. $7-1$

8. Structural evaluation of the safety injection lines on the Trojan reactor coolant loop .

Attachment: Preliminary structural evaluation of Trojan RCL

Subject to postulated RPV support failure 


\section{ACKNOWLEDGMENTS}

The authors wish to acknowledge the Office of Nuclear Regulatory Research, U.S. Nuclear Regulatory Commission, for providing the funding, Dr. John O'Brien, the NRC Project Manager, for his technical direction, Dr. John Stevenson of Stevenson and Associates and Mr. Garry Holman of LLNL, for providing technical consultation, and Mr. Ted Bushnell, Mr. Carl Fago and Mr. Marshall Hauck of Portland General Electric Company, for their constant assistance and cooperation during the course of this work. 
The consequence evaluation of radiation embrittlement of reactor pressure vessel (RPV) supports of nuclear power plants offers a more direct and less controversial approach to the safety concerns addressed by Generic Safety Issue 15 (GSI-15) identified by the Nuclear Regulatory Commission (NRC) because this approach depends on more conventional methodologies widely accepted by the engineering community. The success of this evaluation may permit a satisfactory resolution to GSI-15 by demonstrating that even under the most unfavorable circumstances, i.e., complete failure of all RPV supports, there is no undue risk to public safety.

This evaluation is divided into two phases. Phase 1 is a pilot study on a selected nuclear power plant. Phase 2 is a parametric study undertaken in an attempt to generalize the conclusion of the pilot study to other nuclear power plants. The Trojan nuclear power plant was selected for the pilot study because its RPV supports are located in the high radiation zone and are subject to high tensile stresses. The pilot study comprises a structural evaluation and an effects evaluation and assumes that all four RPV supports have completely lost the load carrying capability. The current report addresses Phase 1 results and conclusions.

The structural evaluation considers two load combinations: the combination of dead weight, operating pressure, and the safe shutdown earthquake and the combination of dead weight, pressure, and a loss-of-coolant-accident (LOCA). Both load combinations are classified as Level D Service Limits in accordance with ASME Boiler and Pressure Vessel Code. Rules contained in Subsection NB in conjunction with Appendix F, Division 1, Section III of the ASME Code permit linear elastic analyses and are followed by the structural evaluation.

A preliminary structural evaluation based on an existing computer analysis model of the nuclear steam supply system (NSSS) of the Zion nuclear power plant, which is similar to the Trojan plant, indicates that the ASME Code Appendix F requirements are satisfied by each of the load combinations considered in the analysis, leading to the preliminary conclusion that the Trojan RCL piping is capable of transferring RPV loads to steam generator (SG) and reactor coolant pump (RCP) supports. A subsequent final structural evaluation based on a computer model developed for the Trojan NSSS confirms the preliminary conclusion and, additionally, concludes that the SG and RCP supports have sufficient design margins to accommodate additional loads transferred through the RCL piping.

The effects evaluation, employing a systems analysis approach, investigates initiating events and the reliability of the engineered safeguard systems, which are designed to mitigate some of the initiating events, as the RPV is subject to movements caused by the support failure. As a result, the evaluation identifies the following areas of safety concern:

(1) The multiple rupture of instrumentation thimble tubes or the guide tubes that penetrate the bottom head of the RPV could result in a LOCA that may lead to core uncovery.

(2) The tilting of the flywheel and the deformation of the RCP casing may respectively affect the coastdown ability of the RCP and cause impellers to bind, resulting in loss of natural circulation.

(3) The control rods could bind in the event of tilting of the RPV and the ability to insert control rods during a reactor trip may be affected.

(4) The rupture of two or more of the 10-in. safety injection lines could impair the ECCS function. 
Further investigation, however, concludes that the failure of the Trojan RPV supports will not result in consequences of safety concern because:

(1) A structural analysis of thimble guide tubes indicates that RPV movements will not cause tube rupture.

(2) An assessment of the RCP indicates that the pump should be able to sustain the motion without loss of its function during either the coastdown phase or the natural circulation stage.

(3) Based on information provided by the NSSS vendor, the control rods will not bind as the RPV is subject to the tilting caused by the RPV support failure.

(4) An analysis of the 10-in. safety injection lines demonstrates that the RPV movements will not cause rupture of these lines. 


\subsection{INTRODUCTION}

The reactor pressure vessel (RPV) support embrittlement problem associated with pressurized water reactors (PWRs) in nuclear power plants was identified by the Nuclear Regulatory Commission (NRC) in 1978, designated as a candidate Unresolved Safety Issue in 1981, but assigned a LOW priority in 1983. Based on data and analyses developed by the Oak Ridge National Laboratory (ORNL) in April 1988, [Ref. 1] The NRC staff concluded that the potential for RPV support embrittlement from neutron radiation damage could be greater than predictions based on pre-1988 data. A reevaluation of the issue conducted by the NRC finally concluded in December 1988 that this issue should be given a HIGH priority ranking.

The potential safety significance of this problem is that low-temperature irradiation of structural materials can result in RPV support structure embrittlement, increasing the potential for unstable propagation of flaws that might exist in the materials. The radiation-induced embrittlement may result in failure of the RPV supports and consequent movement of the reactor vessel, given the occurrence of a transient stress or shock such as could be experienced in a loss-of-coolant- accident (LOCA) or severe earthquake. A number of actions are currently funded by the NRC to resolve this generic safety issue. One of the actions is to conduct a consequence evaluation of embrittled RPV support failure.

The objective of the consequence evaluation of embrittled RPV support failure is to provide a sound technical basis for determining whether the failure of reactor pressure vessel supports could prevent safe shutdown or lead to unacceptable consegrences during or following the design basis earthquake or pipe rupture. The work is sponsored by the Division of Engineering, the Office of Nuclear Regulatory Research of the NRC and executed by Lawrence Livermore National Laboratory (LLNL) under an interagency agreement between the NRC and the U.S. Department of Energy.

The evaluation is divided into two phases. Phase 1 is a pilot study on a selected nuclear plant. Phase 2 is a parametric study of critical variables undertaken in an attempt to generalize the pilot results to other nuclear units susceptible to neutron embrittlement damage. The Trojan nuclear power plant has been selected for the pilot study because its RPV supports are located in the high radiation zone and are subject to high tensile stresses.

The pilot study comprises a structural evaluation and an effects evaluation for postulated failure of one or more RPV supports. As a bounding case in the Phase 1 study, all four supports of the Trojan reactor pressure vessel are assumed to have inizially failed. Failure of a RPV support herein means the support has completely lost its load capacity. The structural evaluation determines (1) the ability of the reactor coolant loop (RCL) piping to transfer (or redistribute) the RPV support loads to steam generator (SG) supports, reactor coolant pump (RCP) supports, and, if applicable, the concrete shield wall; and (2) the ability of SG and RCP supports to carry the additional loads transferred by the RCL piping.

The effects evaluation is conducted if the structural evaluation shows that the RPV support loads can be redistributed from the failed supports and that the SG and RCP supports are capable of carrying the additional loads. The effects evaluation then (1; calculates the motions (translations and rotations) of the RPV associated with failure of specified RPV supports; and (2) assesses consequences of the RPV motions such as, but not limited to, the ability to insert control rods for achieving hot shutdown and the ability of the reactor coolant pumps and any instrument lines and small diameter piping attached to the RPV to maintain their integrity. 
This report summarizes the results and conclusion of the Phase 1 pilot study, i.e., the consequence evaluation of embrittled RPV support failure postulated for the Trojan nuclear power plant. Section 2.0 of this report addresses the structural evaluation. Section 3.0 describes the effects evaluation. Section 4.0 summarizes the final conclusion.

\subsection{STRUCTURAL EVALUATION}

The objectives of the structural evaluation are to determine (1) the ability of the RCL piping to transfer the RPV support load to SG and RCP supports, and (2) the ability of SG and RCP supports to carry the additional loads transferred by the RCL piping. The structural evaluation assumes that the RPV has lost all four supports and that the RCL piping is not in contact with the concrete biological shield wall.

\subsection{Load-Transferring Ability of RCL Piping}

The determination of the load-transferring ability of the RCL piping is based on a linear analysis following rules provided by Subsection NB and Appendix F, Division 1, Section III of the ASME Boiler and Pressure Vessel Code. [Ref. 2] The same analysis also produces loads on SG and RCP supports, which can be used to evaluate the load carrying capability of the SG and RCP supports. The evaluation was conducted in two steps, namely, a preliminary evaluation and a final cvaluation.

The preliminary evaluation was conducted based on an existing computer model of the RCL system of Unit 1 of the Zion nuclear power plant (Zion-1), which closely resembles the Trojan RCL system.

Two load combinations were evaluated: (1) the combination of dead weight, operating pressure, and the safe-shutdown earthquake, and (2) the combination of dead weight, operating pressure, and a loss-of-coolant accident. Both load combinations are classified as Level D Service Limits in accordance with the ASME Code. Thermal loads are not considered because thermally induced stresses are classified as secondary stresses by the ASME code and are not required to be considered by Appendix $\mathrm{F}$ evaluation. Static and dynamic linear analyses were conducted to comply with comparable rules specified by Subsection NB in conjunction with Appendix $F$, Division 1, Section III of the ASME Code. Results of this evaluation indicate that ASME Code Appendix $F$ requirements are satisfied by each of the load combinations considered in the analysis, leading to the preliminary conclusion that the Trojan RCL piping is capable of transferring the RPV support loads to the SG and RCP supports. This evaluation is described in detail by Ref. 3, which is included in this report as an attachment.

Although the Trojan RCL system is very similar to the Zion-1, there are differences as noted by Table 1 in Ref. 3 . In order to confirm the results and conclusion of the preliminary structural evaluation, a Trojan RCL model was developed and, accordingly, a final structural evaluation was conducted. The final structural evaluation, which follows the same approach as the preliminary evaluation, generated results very comparable to those of the preliminary evaluation and, therefore, confirms the conclusion that the Trojan RCL piping is capable of transferring loads to the SG and RCP supports in the case of failure of the RPV supports. The detail of the final structural evaluation is described in Appendix 1.

It is noted that support stiffnesses for the Zion SG and RCP are used in the Trojan RCL rnodel because we were not able to obtain the correct information. In order to validate our conclusion, a sensitivity study was conducted and subsequently concluded that the structural response of the 
RCL model is affected very linle by the change in the SG and RCP supports. The sensitivity study is described in Appendix 2.

\subsection{Load-Carrying Capability of the SG and RCP Supports}

A structural analysis was conducted to determine the load-carrying capabilities of th: lower SG supports and the RCP suppors because such information is not available to us. The purpose of the structural analysis is to obtain lower bound estimates in accordance with the design basis loads the SG and RCP supports were originally designed for. The original design basis is a load col ubinal ion which includes the dead load, the norma! operation pressure and temperature, and a LOCA resulting from the rupture of one of the legs of the RCL piping. It is concluded from the structural analysis that the SG and RCP supports should have sufficient load margins because the lower bound load capacities exceed the loads transferred to the SG and RCP supports in case of the RPV support failure. The structural analysis is described in Appendix 3.

\subsection{EFFECTS EVALUATION}

In the case of a postulated RPV support failure, although loads will be transferred by the RCL piping and finally carried by the SG and RCP supports as demonstrated by the structural evaluation, the RPV will undergo movements considerably exceeding those originally restricted by the unfailed RPV supports. The movements consist of primariiy a vertical translation (or drop) and a tilt from the vertical axis (resulting from the failure of three or less of the RPV supports). If the movernents become excessive, they can lead to consequences that include initiating events that may not be mitigated by the engineered safeguard systems (ESS) and damages to the engineered safeguard systems.

The effects evaluation identifies the potential initiating events and examines the engincered safeguard systems. An initial evaluation points out problem areas that were subsequently assessed by the final evaluation.

The initial effects evaluation, based on methodologies commonly employed by systems analysis, constructs several likely accident sequences that would occur as the result of the RPV movements. From the accident sequences, the potential initiating events and required safety systems were identified.

The evaluation identifies two initiating events of safety concern:

(1) The multiple rupture of instrumentation thimble rubes or the guide tubes that penetrate the bottom head of the RPV sould result in a LOCA that may lead to core uncovery.

There are a total of 58 penetrations for high pressure conduits at the bottom head the RPV. These conduits are made of stainless steel with wall thickness of 0.25 in. - 50 of them have a 0.4 -in. inside diameter (DD) and 8 have a 0.6 -in. ID. The conduits are also called thimble guide tubes because stainless steel thimble rubes (with wall thickness of approximately 0.1 in.) are placed inside these guide tubes. Carbon steel drive cables are inserted inside the thimble tubes.

During the normal operation, the annular space formed between the outer guide rube and the inner thimble tube is filled with the reactor coolant. Therefore, both the thimbles and the guide tubes are essentially the extensions of the reactor vessel pressure boundary. A hypothetical RPV support failure results in a downward movement of the vessel, which is normally restricted by the RPV supports. The downward movement could cause the rupture 
of multiple thimble tubes and the guide tubes, leading to core uncovery due to a severe loss of core coolant.

(2) The ilting of the RCP may affect the coastdown ability of the pump and the deformation of the RCP casing may cause the pump impellers to bind, resulting in loss of natural circulation.

The downward movement of the RPV can affect the RCP in two ways: (1) to cause tilting of the pump and (2) to cause deformation of the pump casing.

Tilting of the pump from the vertical axis can cause excessive vibration and in turn cause shutdown of the pump. In this situation, a reactor trip is required to avert core damage. It is important to reactor operation that the reactor coolant continues to flow (or coastdown) for a shor time (approximately one minute) after reactor trip. In order to provide this flow with RCP power being shutdown, each RCP is equipped with a flywheel. Thus, the rotaing inertia of the pump, motor and flywheel is employed during the coastdown period to coninue the reactor coolant flow.

Excessive deformation of the pump casing could bind the pump impellers, resulting in loss of natural circulation.

Other initiating events including LOCAs of various magnitudes, such as a LOCA caused by the rupture of the vent line at the RPV top head, and certain types of transients are possible but they are to be mitigated by the engineered safeguard systems (ESS $s$ ). The required ESS $\mathbf{S}$ are the reactor trip system and the emergency core cooling system (ECCS).

Evaluation of the engineered safeguard systems indicates that the instrumentation that generates the reactor trip signals is excore instrumentation and is not affected by the RPV movement and that the ability of generating signals to actuate the ECCS also will not be affected by the RPV movements. The evaluation, however, identifies the following safety concerns:

(1) The possibility exists that the control rods could bind in the event of tilting of the RPV. The ability io insert control rods during a reactor trip would be adversely affected in this case.

The failure of all four RPV supports is the worst case in terms of loads to be transferred to the RCL piping and the SG and RCP supports, but the failure of three or less of the RPV supports can result in tilting of the RPV that may affect the ability to insen the control rods. The rilting of the RPV is considered to be limited by the concrete shield wall penetrations. The spacing br:ween the RCL pipe and the penetration is approximately 6 in. and the distance from the peiietration to the middle plane that contains the vertical axis of the RPV is about 175 in., resulting in a tilting angle of the RPV from the vertical axis approximately 2 degrees.

(2) Two or more simultaneous ruptures of the safety injection lines could impair the ECCS function and lead to core damage.

Loss-of-coolant accidents other than the ruprure of the main RCL piping and the ruprure of the RPV are assumed to be mitigated by the ECCS. According to the success criteria for accumulator discharge, it is determined that at least two simultaneous ruprures of the 10-in. safety injection lines would have to occur for core damage to occur.

The initial effects eva uation is described in detail in Appendix 4.

Finally, a series of investigations were conducted to address the safety concems identified by the initial effects evaluation as described below: 
(1) A nonlinear structural analysis was conducted to investigate the rupture of thimble guide tubes with $0.25 \mathrm{in}$. wall thickness and $0.6 \mathrm{in}$. inside diameter. These tubes are chosen for the analysis because they are stiffer than the $0.4 \mathrm{in}$. ID tubes and, therefore, most susceptible to rupture due to the RPV movement. The analysis is described in Appendix 5.

(2) The concerns with regard to the tilting of the RCP that may affect the coastdown ability of the pump and the deformation of the pump casing that may cause the impellers to bind are addressed in Appendix 6.

(3) An evaluation was conducted by Westinghouse Electric Corporation to determine the ability to insert control rods for the Trojan nuclear power plant with a tilted reactor vessel system (see Appendix 7).

(4) A structural analysis was conducted to deal with the concern that the 10-in. safety injection lines may rupture as a result of the deformation of the RCL piping. The integrity of safety injection lines is required for the effective operation of the ECCS. The analysis is described in Appendix 8.

\subsection{CONCLUSION}

The Trojan nuclear power plant has been evaluated for the hypothetical failure of reactor pressure vessel supports due to radiation embrittlement. Several safety concerns have been identified by the evaluation. Further investigation, however, concludes that the failure of the Trojan RPV supports will not result in consequences of significant safety concern because:

(1) The results of a structural evaluation indicate that the RCL piping is capable of transferring RPV support loads to the SG and RCP supports and that the SG and RCP supports have sufficient design margins to carry the additional loads transferred through the RCL piping.

(2) A structural analysis of a typical thimble guide tube indicates that tube rupture will not be caused by the RPV movement.

(3) Assessments of the reactor coolant pump indicate that tilting of the pump and the deformation of the casing would not lead to loss of its function during either the coastdown stage or the natural circulation stage.

(4) Based on information provided by the NSSS vendor, the ability to insert control rods will not be affected as the RPV is tilted because of the RPV support failure.

(5) An analysis of the safety injection lines demonstrates that the RPV movements will not cause rupture of these lines to cripple the ECCS function.

It is noted that the scope of this evaluation is limited to consequences that can uniquely occur as the results of a hypothetical failure of the RPV supports. This study does not consider other conseguences such as random failure, of equipment or equipment unavailability due to inappropriate maintenance or testing, or other complications caused by human error factors, which are normally considered in a more complete probabilistic risk assessment of nuclear power plants. 


\subsection{REFERENCES}

(1) R. D. Cheverton, J. G. Merkle, and R. K. Nanstad, Evaluation of HFIR Pressure Vessel Integrity Considering Radiation Embrittlement, Report ORNL/TM -10444, Oak Ridge National Laboratory, April 1988.

(2) ASME Boiler and Pressure Vessel Code, 1986 Edition.

(3) S. C. Lu, Preliminary Structural Evaluation of Trojan RCL Subject to Postulated RPV Support Failure, NUREG/C'R-5506, January 1990. 


\section{APPENDIX 1 \\ STRUCTURAL EVALUATION OF THE TROJAN REACTOR COOLANT LOOP}

\section{Introduction}

The Nuclear Regulatory Commission (NRC) selected the Trojan Nuclear Power Plant for a pilot study of the effects of irradiation embrittlement on reactor precidre vessel (RPV) suppoits. Concern about these supports is due to their location within the belt line, or the high flux region around the pressurized water reactor vessel core. A structural evaluation was performed to investigate the consequenres of RPV support failure with respect to safety. Previous work brsed on an existing finite elenuent model of the Zion Nuclear Power Plant, which is similar to the Trojan plant, demonstrated that the Trojan reactor coolant loop (RCL) system satisfactorily transfers the RPV loads to the sieam generator (SG) and reactor coolant pump (RCP) supports when the RPV supports fail [Ref. A 1-1]. In order to conclude the Trnjan plant consequence evaluation, a Trojan RCL model was developed. This report iescribes major results from the analyses, and compares the Trojan model resuits to those produc ' by the Zion model.

\section{Anailysis}

A preliminary structural ivaluation of the Trojan $\mathrm{RCL}$ system was completed using a finite element model based on the geometry of the Zion Nuclear Power Plant Unit 1 [Ref. A 1-1]. These analyses were done because information about the Zion plant was readily available and the Trojan and Zion plants are geometrically similar. Even though the plants vre similar, a correct RCL model was deemed necessary in orcier to conclude the structural consequence evaluation for the Trojan plant. With a geometrically correct model, a thorough structural evaluation of the Trojan piping and the SG and RCP supports was completed. This evaluation verified the Zion model results and conclusions as well as served as a tool for performing parametric studies of the RCL geometry.

Both the Trojan and Zion plants are typical four-loop Westinghouse pressurized water reactors. Figure A1-1 shows the layout of a typical NSSS. Major components of the NSSS are the reactor pressure vessel, steam generators, reactor coolant pumps, the pressurizer, and the piping. The four loops of the NSSS contain piping which form the hot leg (RPV W SG), the crossover leg (SG to RCP), and the cold leg (RCP to RPV). The pressurizer connects to one of the four hot legs through a surge line.

In order to fully predict the structural behavior of the Trojan NSSS, several load iypes were applied to the model. These loads are combined according with ASME Code definitions [Ref. A 1-2]. Load combination 1 is comprised of dead weight, operating pressure, and the safe shutdown earthquake (SSE), while load combination 2 consists of dead weight, operating pressure, and a small-break loss-of-coolant-accident (SBLOCA) due to a pipe break in the surge line at a location where the pressurizer connects to one of the hot legs. Further description of these load combinations is provided in Ref. A $1-1$.

For the preliminary Trujan structural analysis, a reduced model of the Zion plant was created as detailed in Ref. A 1-1. The original Zion model was made for the Lawrence Livermore National Laboratory's Load Combination Program [Ref A 1-3]. The input format of the morlels is compatible with the finite-element computer code GEMINI [Ref. A1-4]. The piping, RPV, SG, and RCP are modeled with pipe elements, while the supports and nozzle effects are modeled as beam elements and stiffness elements, respectively. The basis of the geometrically correct Trojan 
model ased for the analyses described in this report is the ": " $"$ cecion model, but with some signiricant changes. The Trojan model is shown in Fig. A.1-2.

Table 1 in Ref. A1-1 shows the comparison between the Trojan and Zion plants. The Trojan hot and cold legs are shorter than the respective Zion legs, while the Trojan cold leg is also rotated outward along the crossover leg. Additionally, the Trojan pressurizer is attached to the hot leg of loop 2, although the pressurizer and the surge lise are not included in the Trojan model.

The material descriptions of the piping elements of the Trojan model are as specified in Table A1-1. Two new materials, 8 and 9, were added for the cold leg piping and the RCP casing respectively. The geometric descriptions of the piping elements are also sperified in Table A1 2. Crosssectional dimensions are the same as those given for the Trojan plant in Table 1 of Rel A1-1. The Trojan plant does not have loop isolation valves on the hot or cold li:gs.

The Trojan RPV horizontal and vertical supports are less stiff than those in the Zion plant. This effect is included by decreasing the axial area of the supports to $61 \%$ of the Zion values. The Zion vertical support stiffness is $63700 \mathrm{kips} / \mathrm{in}$., while the Trojan vertical support stiffness is only $38800 \mathrm{kips} / \mathrm{in}$. [Ref. A1-5] which is $61 \%$ of the Zion vi, ue. No further information is available about the other Trojan RPV vertical and horizontal supports, thus the $61 \%$,elationship between the Zion and Trojan supports is assumed for all the RPV supports.

Finally, the Trojan RPV is heavier than the Zion RPV [Ref. A1-1], thus the nodal mass applied for the RPV mass at node 168 is increased from $48326 \mathrm{lbs}$. $-\mathrm{sec}^{2} / \mathrm{ft}$. to $52643 \mathrm{lbs}$. $-\mathrm{sec}^{2} / \mathrm{ft}$. In static load analyses, the weight is increased from $1556100 \mathrm{lbs}$. to $1695100 \mathrm{lbs}$. The remaining weight of the RPV, 424900 lbs., is applied at node 169.

With a geometrically correct Trojan model, structural analyses performed with GEMINI [Ref. A 1-4] predict the forces, moments, and stresses in the Trojan RCL. The structural evaluation follows guidelines specified in the ASME Boiler and Pressure Vessel Code [Ref. A1-2] for linear analyses. Two series of analyses provide detailed results about the structural response. The first series of analyses consider the NSSS as fully supported with no embrittlement degradation of the RPV supports in order to predict the structural response of the RPV, SG, and RCP supports under various loading conditions. This information is useful to other NRC funded resears $h$ projects related to the RPV support embrittler.aent problem. As the worst case, the second series $\therefore$ analyses assume all four RPV supports have failed. Allowing for the RPV supports failure requires modifications of the material and geometric descriptions of the Trojan beam elements which model the RPV horizontal and vertical supports. At failure, these elements have negligible stiffness which is modeled with drastically reduced elastic modulus, mass density, and axial area. By reducing these beam properties, these elements have no effect on the structural response of the Trojan plant. The supported and unsupported RPV finite element models bound the effects of irradiation embrittlement of the support structures.

Using GEMINI [Ref A1-4], the predicted frequency response of the Trojan plant with and without RPV supports is determined. Table A 1-3 lists the first 30 modes of the free vibration analysis and it can be clearly seen that the supported RPV has higher frequency vibrational modes. This is reasonable since the supported structure is stiffer than the unsupported one. The first three unsupported RPV modes, corresponding to frequencies of $3.78 \mathrm{~Hz}, 4.30 \mathrm{~Hz}$, and $5.97 \mathrm{~Hz}$, are pictured in Figs. A1-3 to A1-5. As expected, the dominant motion of the first mode is vertical displacement, while the dominant motions of the second and third modes are rocking displacements in the two horizontal directions.

The first type of loading applied to the Trojan RCL is the SSE ground motion. For base ground accelerations of $0.25 \mathrm{~g}$ horizontally and $0.17 \mathrm{~g}$ vertically, the floor response spectra for the Trojan 
plant is provided in Fig. 7 of Ref. Al-1. The structural analyses in GEMINI use the response spectrum method. This method uses the mode shapes extracted from the previous frequency analyses. Figure 12 in Ref. Al-1 contains the appropriate damping factors for the 30 mode shapes. Linear interpolation finds the damping values for $f$-quencies between $10 \mathrm{~Hz}$ and $20 \mathrm{~Hz}$. The damping factors for the 30 modes are listed in Table A $1-4$.

Supplemental analyses using $\mathbf{5 0}$ modes of the free vibration analysis demonstrate that using only the furst 30 modes is adequate for the dynamic load cases. Even though use of only 30 modes does not capture all of the mass participation in the horizontal di: ections, the dominant structural response in the vertical direction is effectively determined by the 30 modes. For thes SSE load case, the predicted forces and moments in the elements being studied differ by less than $1 \%$ berween the 30 and 50 mode analyses.

A SBLOCA is assumed by the NRC [Ref. Al-1] to occur at the joint between the surge line and hot leg. This accident causes a forcing function to be applied on the hot leg at the surge line connection. Further description of the forcing function parameters is provideil in Ref $A \mid-1$. In the Trojan mndel, this second type of dyrarnic loading is applied on loop 2 at node 5 using the modal time history integration method available in GEMINI.

The additional loading types applied to the Trojan model are the static loads of operating pressure, dead weight, and operating temperature.

The operating pressure of the Trojan is 321800 psf. (2235 psi.), while thie operating temperanre is approximately 600 degrees Fahrer:heit. Thermal effects due to the operating temperature are deteranined by a static thermal analysis. The operating temperature is also used to evaluate the iemperature-def andent material properties. One series of static analyses modeled the effects of both the operating pressure on the piping and the dead weight on the entire structure. Another series of analyses studied only the effects of dead weight on the Trojan plant. The results of the dead weight analyses are used only to determine the berding stresses in the RPV nozzles.

\section{Results}

The major safety concern of radiation-induced embrittlement is the possible loss of RPV support if the supports fail. Upon failure, the RPV must be supported by the remaining components of the NSSS, specifically the RCL piping and SG supports. While the piping will transfer and redi stribute the loads, the SG and RCP supports will carry the additional loads due to RPV support failure. Since the study in Ref. Al-1 only determined the capability of the RCL piping to transfer the loads, this report also focuses on the RCL piping. The structural evaluation of the SG and RCP supports is presented in Appendix 3.

Table A1-5 lists the predicted vertical forces in the RPV supports from the first series of analyses. The Westir.ghouse values are reproduced from Ref. A1-5 and they are conservative relative to the forces predicted by GEMINI. The SBLOCA forcing function used in GEMINI is a more recently developed load uime history and it contains sophistications that Westinghouse may not have included in their analyses. Overall though, the GEMINI and Westinghouse results compare reasonably. For the SBLOCA loading, the vertical support force is largest in the loop 2 support since that is the loop upon which the surge line is attached.

The stiffness oi the Trojan SG supports is different than that for the Zion SG supports, but this difference is not modeled in the analyses described in this repor because the exact Trojan stiffness values are unknown. In onder to verify that the conclusions drawn from the Trojan model in this report, a sensitivity study in which the stiffness of the SG supports is increased and decreased by 
$30 \%$ to account for any reasonable difference in the Trojan and Zion SG supports is described in Appendix 2.

The vertical displacements at the outlet nezzles of the RPV with assumed RPV suppon failure are given in Table A1-6. Except for the SBLOCA loading, the displacements are comparable bet ween the four loops. With RPV suppor failure, the main NSSS support comes from the SG supports. The predicted response of these supports to RPV support failure is detailed in Tables A1-7 and A1-8.

Appendix F and Subsection NB of the ASME Boiler and Pressure Vessel Code [Ref. A1-2] provide rules for limiting the consequences of specified events. These rules provide assurance of pressure boundary integrity, however, they do not necessarily assure component reliability during or after the ient. For piping, the following equation rasst be satisfied using a stress limit of 3 * $S_{m}\left[\right.$ Ref. $\left.A_{i} \cdot 1\right]$ :

$$
\begin{aligned}
& \left(B_{1} *\left(P * D_{0} / 2 * t\right)\right)+\left(B_{2}^{*}\left(D_{0} * M_{i} / 2 * I\right)\right)<3 * S_{m} \\
& \text { where } \quad B_{1}, B_{2} \quad \text { - primary stress indices with values of } 0.5 \text { and } 1.0 \\
& P \quad \text { - pressure } \\
& \text { Do - outside pipe diameter } \\
& \text { t - pipe wall thickness } \\
& \text { I - moment of inertia of the pipe section } \\
& \mathrm{M}_{\mathrm{i}} \quad \text { resulting moment due to a combination of mechanical loads } \\
& S_{m} \quad \text { - allowable stress intensity value }
\end{aligned}
$$

As determined in the analyses using the Zion finite element model, the critical piping location is at the RPV outlet nozzles [Ref. A $1-1$ ]. The dead weight load case produces the largest bending moments in the RCL piping. A careful study of the piping results from the dead weight analysis with the Trojan model demonstrates that the RPV outlet nozzle is still the critical piping location since that piping has the largest bending moments. Table A $1-9$ lists the predicted bending stresses in the piping due to a yariety of load conditions. Using the ASME piping failure criteria the ability of the RCL piping to survive the consequences of RPV suppor failure is determined. The results of the ASME failure criteria investigation are given in Table Al-10. As demonstrated, the RCL piping does not violate the pressure-retaining boundary under RPV support failure.

To validate the structural analyses based on the Trojan $\mathrm{RCl}$ model described in this reporh, comparisons are made between the results in Tables Al-3 through Al-10 to those in Tables 2 through 8 in Ref. Al-1 Both the Zion and Trojan based RCL models have similar mode shapes for the suppored and unsupported RPV analvses. With RPV supporn failure, the Trojan model is slightly stiffer than the Zion model. This results in slightlv smaller predicted forces and moments than those detailed in Ref. A1-1 (when comparing the Zion and Trojan results, except for the SBLOCA case, loops 1, 2, 3, and 4 of the Trojan model respectively correspond to loops 4,1 , 2 , and 3 of the Zion model). Trends which were evident with the Zion model are reproduced. Zion and Trojan results are within $5 \%$ to $20 \%$ of each other. For the SBLOCA case, the two models do not directly correlate except that the maximum forces and inoments $\propto c c u r$ on the same hot leg as the pipe break.

The RPV vertical forces in Table A1-5 reflect the major differences between the Trojan and Zion models. Due to the stiffer Trojan piping and reduced Trojan RPV supporn stiffness, the RPV forces are less than those for the Zion model. The exception is the operating pressure and dead 
weight analysis because the Trojan RPV is heavier than the Zion RPV. Both models predict that the maximum RPV vertical forces of about $1000 \mathrm{kips}$. will result from the load combination of weight, pressure and SSE loading.

\section{Conclusion}

Given a postulated failure of RPV supports due to irradiation embrittlement effects, the finite element analyses predict that the RCL piping will transfer the loads to the SG and RCP supports. Results of structural evaluations demonstrate that the ASME Code Appendix F requirements are satisfied by the Trojan piping at the RPV outlet nozzles. Table A1-10 indicates that the maximum stress levels occur with load combination 1 . This corresponds well with the results described in Ref. A1-1, which stated that the SSE load combination is more damaging for plants in high seismic zones like the Trojan plant. Both the Zion and Trojan models produce similar conclusions about the structurai response of the RPV with possible support failure. These conclusions are detailed in Ref. A1-1. Since the piping successfully transfers the RPV loads, analyses are needed to determine the load capacity of the other component supports (namely, SG and RCP supports). These analyses are presented in Appendix 3.

\section{References}

A1-1. Lu, Stephen C., Preliminary Structural Evaluation of Trojan RCL Subject to Postulated RPV Support Failure, Lawrence Livermore National Laboratory, Livermore, California, NUREG/CR - 5506, UCID - 21831, November 1989.

A1-2. ASME Boiler and Pressure Vessel Code, 1986 Edition.

A1-3. Eberhardt, A. C., Probability of Pipe Fracture in the Primary Coolant Loop of a PWR Plant, Volume 2: Primary Coolant Loop Model, NUREG/CR-2189, Vol. 2, September 1981.

A 1-4. Murray, Robert C., GEMINI - A Computer Program for Two and Three Dimensional Linear, Static, and Seismic Structural Analysis, Lawrence Livermore National Laboratory, University of California, Livermore, California, UCID - 20338, October 1984.

A1-5. Cheverton, R.D., et al., Impact of Radiation Embrittlement on Integrity of Pressure Vessel Supports for Two PWR Plants, Oak Ridge National Laboratory, NUREG/CR5320, ORNL/TM-10966, January 1989. 
Table A1-1. Piping element material descriptions.

\begin{tabular}{lccc}
\hline Description & E(109) & $\nu$ & $\alpha\left(\mathbf{1 0}^{-6}\right)$ \\
\hline & & & \\
Steam Generator & 3.80 & 0.25 & 7.83 \\
RPV Shell & 3.80 & 0.25 & $\mathbf{7 . 8 3}$ \\
Hot Leg Piping & 3.64 & 0.25 & $\mathbf{7 . 8 3}$ \\
Loop Valves & 3.80 & 0.25 & $\mathbf{7 . 8 3}$ \\
SG Inlet Nozzle & 3.80 & 0.25 & 9.60 \\
Crossover Piping & 3.64 & 0.25 & 6.19 \\
RC Pump Motor & 4.02 & 0.25 & 9.60 \\
Cold Leg Piping & 3.64 & 0.25 & 7.83 \\
RC Pump Casing & 3.80 & 0.25 & \\
\hline
\end{tabular}

$E=$ elastic modulus (psf.)

$v=$ Poisson's ratio

$\alpha=$ thermal expansion coefficient (ft./ft./deg. F) 
Table A1-2. Piping element section properties.

\begin{tabular}{|c|c|c|c|c|}
\hline Description & $d_{0}$ & $\mathbf{t}$ & $w / l$ & $\mathbf{m} / \mathbf{l}$ \\
\hline Hot Leg Piping & 2.825 & 0.2042 & 1073 & 33.354 \\
\hline Crossover Piping & 3.017 & 0.2167 & 1197 & 37.209 \\
\hline Cold Leg Piping & 2.678 & 0.1933 & 945 & 29.375 \\
\hline Hot Leg Elbow & 2.956 & 0.2693 & 1405 & 43.669 \\
\hline Crossover Elbow & 3.125 & 0.2710 & 1487 & 45.223 \\
\hline Cold Leg Elbow & 2.786 & 0.2475 & 1204 & 37.426 \\
\hline
\end{tabular}

$d_{0}=$ outside diameter (ft.)

$t=$ wall thickness (ft.)

$w / l=$ weight per unit length (lbs./ft.)

$m / l=$ mass per unit length (lbs.-sec. ${ }^{2} /$ ft. $^{2}$ ) 
Table A1-3. Frequencies of first 30 modes, Trojan RCL Model.

\begin{tabular}{|c|c|c|}
\hline \multirow[b]{2}{*}{ Number } & \multicolumn{2}{|c|}{ Erequency (Hertz) } \\
\hline & With Support Failure & Without Support Failure \\
\hline 1 & 3.776 & 7.239 \\
\hline 2 & 4.304 & 7.280 \\
\hline 3 & 5.974 & 7.285 \\
\hline$\Leftrightarrow$ & 7.101 & 7.301 \\
\hline 5 & 7.202 & 9.089 \\
\hline 6 & 7.283 & 9.095 \\
\hline 7 & 7.302 & 9.098 \\
\hline 8 & 9.087 & 9.110 \\
\hline 9 & 9.098 & 9.266 \\
\hline 10 & 9.099 & 9.315 \\
\hline 11 & 9.112 & 9.325 \\
\hline 12 & 9.198 & 9.331 \\
\hline 13 & 9.298 & 9.629 \\
\hline 14 & 9.340 & 9.637 \\
\hline 15 & 9.385 & 9.659 \\
\hline 16 & 9.449 & 9.664 \\
\hline 17 & 9.644 & 13.742 \\
\hline 18 & 9.657 & 13.773 \\
\hline 19 & 9.692 & 14.014 \\
\hline 20 & 10.443 & 14.022 \\
\hline 21 & 12.911 & 14.117 \\
\hline 22 & 13.519 & 14.516 \\
\hline 23 & 14.018 & 17.873 \\
\hline 24 & 14.026 & 19.540 \\
\hline 25 & 14.043 & 20.051 \\
\hline 26 & 14.074 & 20.467 \\
\hline 27 & 20.466 & 20.469 \\
\hline 28 & 20.470 & 20.476 \\
\hline 29 & 20.474 & 20.491 \\
\hline 30 & 20.483 & 20.967 \\
\hline
\end{tabular}


Table A1-4. Damping factors of first 30 modes, Trojan RCL Model.

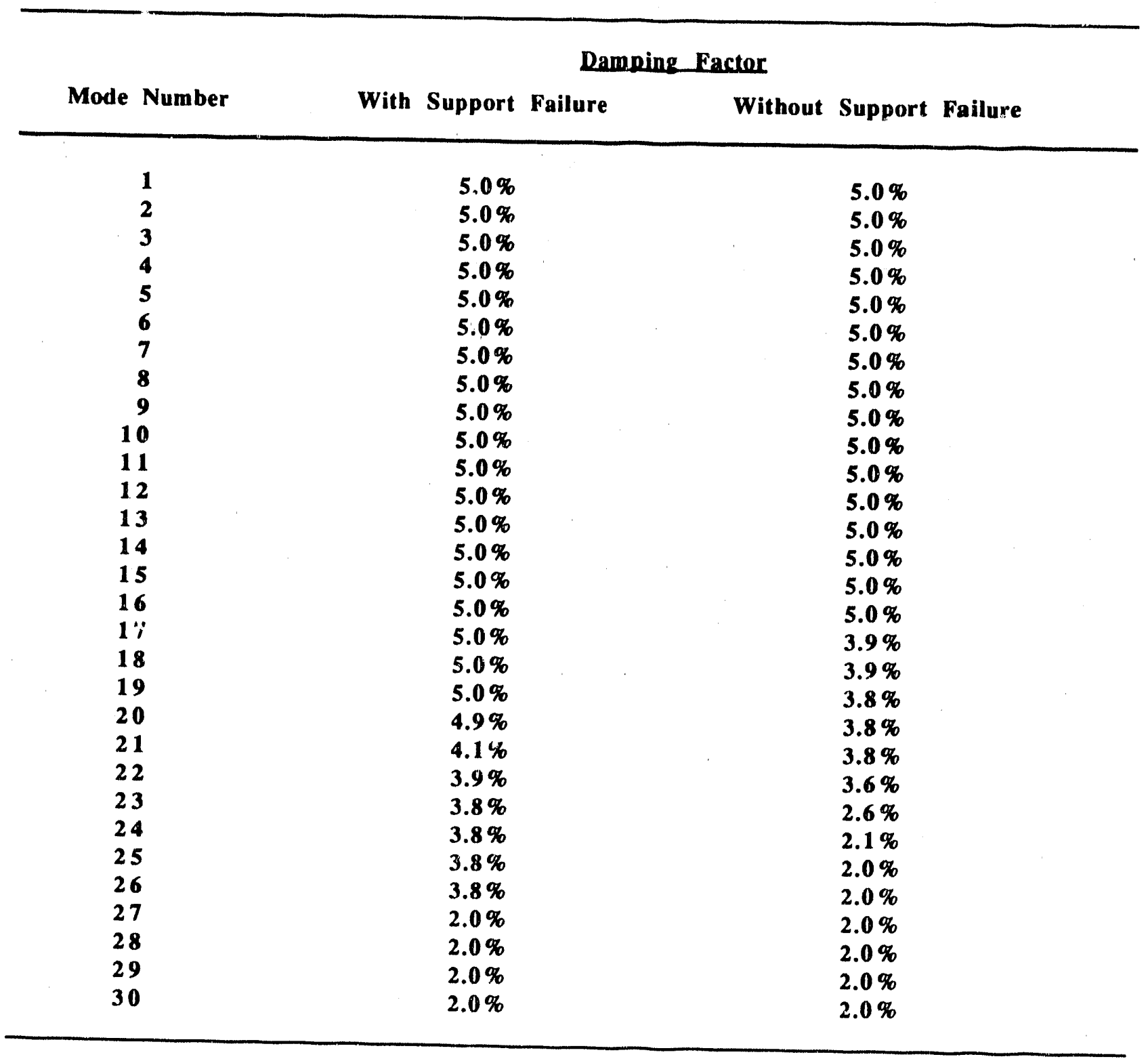


Table A1-5. Vertical forces in RPV supports.

\begin{tabular}{|c|c|c|c|c|c|}
\hline \multirow[b]{2}{*}{ Load Case } & \multicolumn{4}{|c|}{ Supeort Force (kips) } & \multirow[b]{2}{*}{ West } \\
\hline & $\begin{array}{l}\text { Loop } 1 \\
\text { BE } 45\end{array}$ & $\begin{array}{c}\text { Loop } 2 \\
\text { BE } 42\end{array}$ & $\begin{array}{c}\text { Loop } 3 \\
\text { BE } 43\end{array}$ & $\begin{array}{c}\text { Loop } 4 \\
\text { BE } 44\end{array}$ & \\
\hline SSE & 308 & 337 & 311 & 337 & 394 \\
\hline SBLOCA & 23 & 138 & 22 & 103 & 740 \\
\hline Thermal & 89 & 86 & 57 & 102 & 288 \\
\hline PW & 577 & 579 & 574 & 581 & \\
\hline $\mathbf{W}$ & 567 & 571 & 568 & 571 & 530 \\
\hline PWT & 666 & 665 & 631 & 683 & \\
\hline PWT + SSE & 974 & 1002 & 942 & 1020 & 1212 \\
\hline PWT + SBLOCA & 689 & 803 & 653 & 786 & 1558 \\
\hline
\end{tabular}

BE = beam element in Trojan model

West $=$ Westinghouse results

(Note: The PWT + SSE and PWT + SBLOCA results do not

include pressure effects, thus they are actually WT + SSE and

WT + SBLOCA, respectively. WT - dead weight and thermal)

SSE = safe shutdown earthquake

SBLOCA $=$ small-break loss-of-coolant accident

$P W=$ operating pressure and dead weight

$W=$ dead weight

PWT $=$ operating pressure and dead weight (PW) plus thermal 
Table A1-6. Vertical displacements at PRV nutlet nozzles.

\begin{tabular}{lcccc}
\hline & \multicolumn{3}{c}{ Displacement_ind } \\
Load Case & Loop 1 & Loop 2 & Loop 3 & Loop 4 \\
& ND 301 & ND 1 & ND 101 & ND 201 \\
\hline SSE & 0.228 & 0.228 & 0.228 & 0.228 \\
SBLOCA & 0.084 & 0.114 & 0.096 & 0.068 \\
Thermal & 0.128 & 0.120 & 0.117 & 0.123 \\
PW & 0.816 & 0.815 & 0.815 & 0.816 \\
PWT & 0.944 & 0.935 & 0.932 & 0.939 \\
PWT + SSE & 1.172 & 1.164 & 1.160 & 1.167 \\
PWT + SBLOCA & 1.028 & 1.049 & 1.028 & 1.007 \\
\hline
\end{tabular}

ND = node number in Trojan model

SSE = safe shutdown earthquake

SBLOCA = small-break loss-of-coolant accident

$\mathbf{P W}=$ operating pressure and dead weight

PWT = operating pressure, dead weight, and thermal 
Table A1-7. Vertical forces in SG supports.

\begin{tabular}{|c|c|c|c|c|}
\hline \multirow[b]{2}{*}{ Load Case } & \multicolumn{4}{|c|}{ Support_forces_(kips) } \\
\hline & $\underset{B E}{\text { Loop }} 1$ & $\begin{array}{c}\text { Loop } 2 \\
\text { BE } 1\end{array}$ & $\begin{array}{c}\text { Loop } 3 \\
\text { BE } 2\end{array}$ & $\begin{array}{c}\text { Loop } \\
\text { BE } 3\end{array}$ \\
\hline SSE & 306 & 368 & 429 & 426 \\
\hline SBLOCA & 63 & 357 & 79 & 47 \\
\hline Thermal & 71 & 12 & 70 & 92 \\
\hline PW & 1264 & 1283 & 1287 & 1294 \\
\hline PWT & 1335 & 1295 & 1357 & 1387 \\
\hline PWT + SSE & $16+1$ & 1663 & 1786 & 1813 \\
\hline PWT + SBLOCA & 1398 & 1652 & 1436 & 1434 \\
\hline
\end{tabular}

\footnotetext{
$\mathrm{BE}=$ beam element ir Trojan model

SSE = sufe shutdown earthquake

SBLOCA = small-break loss-of-coolant accident

PW = operating pressure and dead weight

PWT = operating pressure, dead weight, and thermal
} 
Table A1-8. Overturning moments in SG supports.

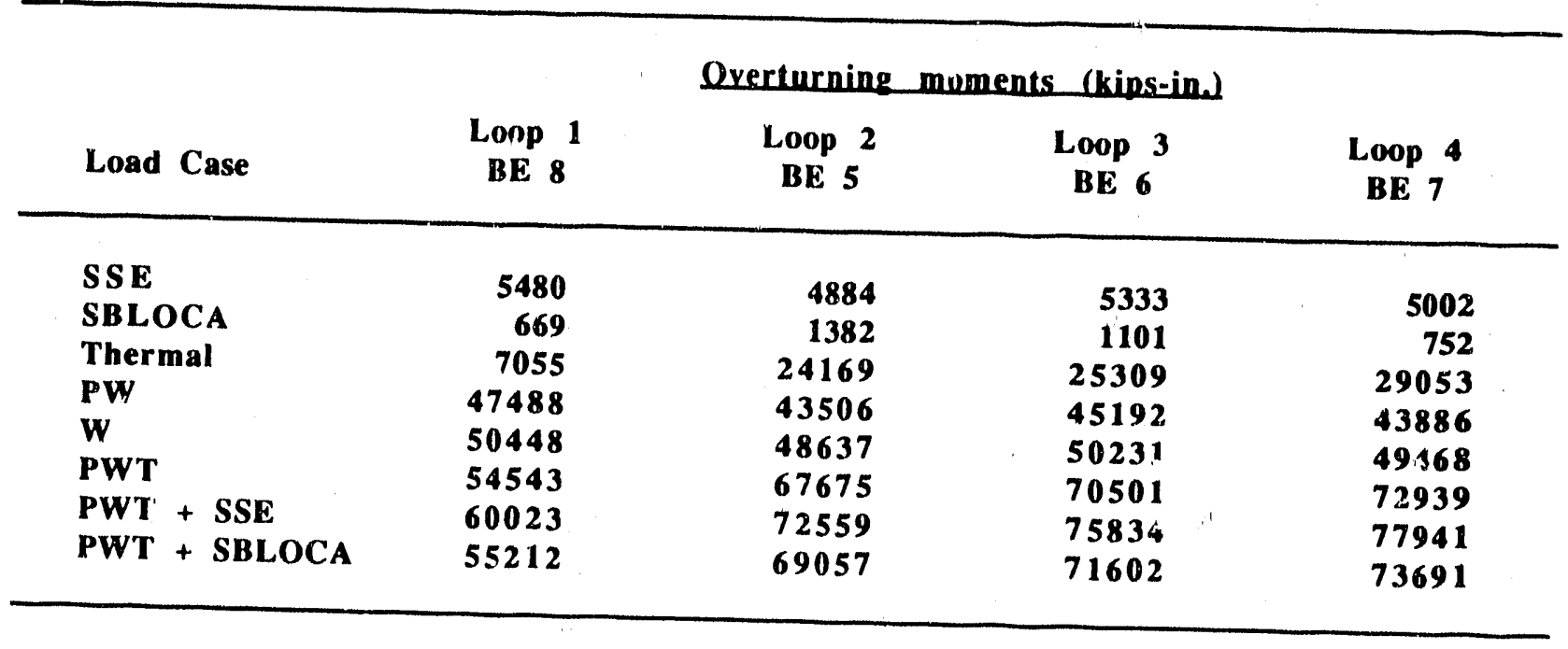

\footnotetext{
BE = beam element in Trojan model

SSE = safe shutdown earthquake

SBLOCA = small-break loss-of-coolant accident

PW = operating pressure and dead weight

$W=$ dead weight

PWT = opera'ing pressure and dead weight (PW) plus thermal
} 
Table A1-9. Bending stresses in RCL piping at RPV outlet nozzles.

\begin{tabular}{|c|c|c|c|c|}
\hline \multirow[b]{2}{*}{ Load Case } & \multicolumn{4}{|c|}{ Bending_Stress_(psi) } \\
\hline & $\begin{array}{l}\text { Loop } 1 \\
\text { PE } 151\end{array}$ & $\begin{array}{c}\text { Loop } \\
\text { PE } 1\end{array}$ & $\begin{array}{c}\text { Loop } 3 \\
\text { PE } 51\end{array}$ & $\begin{array}{l}\text { Loop } 4 \\
\text { PE } 101\end{array}$ \\
\hline SSE & 9606 & 9620 & 9634 & $y 628$ \\
\hline SBLOCA & 3216 & 5361 & 4359 & 2636 \\
\hline Thermal & 2611 & 2205 & 2445 & 1744 \\
\hline PW & 23781 & 23930 & 23788 & 23970 \\
\hline $\mathbf{w}$ & 23801 & 23875 & 23781 & 23869 \\
\hline
\end{tabular}

$$
\begin{aligned}
\text { PE } & =\text { pipe element in Trojan model } \\
\text { SSE } & =\text { safe shutdown earthquake } \\
\text { SBLOCA } & =\text { small-break loss-of-coolant accident } \\
\mathbf{P W} & =\text { operating pressure and dead weight } \\
\mathbf{W} & =\text { dead weight }
\end{aligned}
$$


Table A1-10. ASME code evaluation.

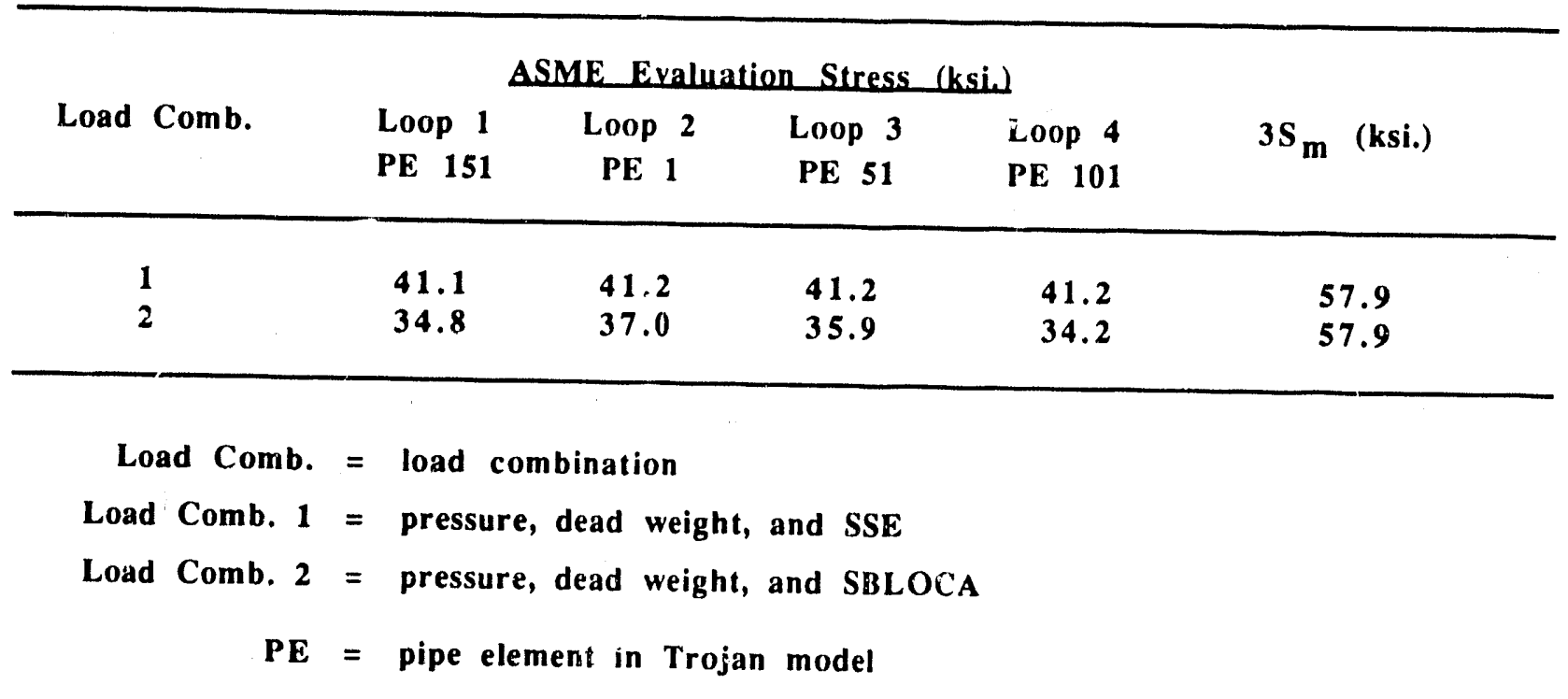




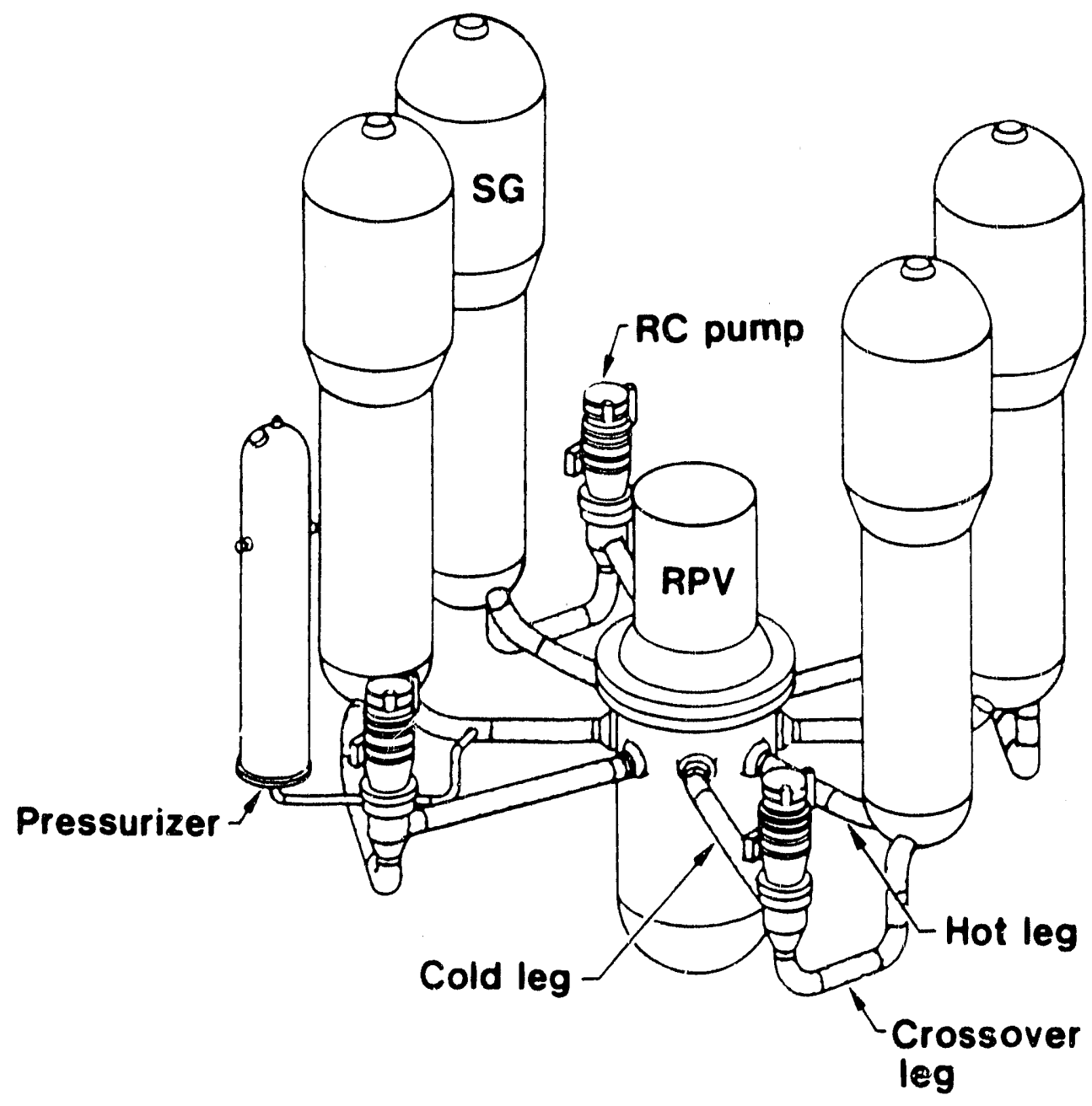

Figure A1-1 A typical Westinghouse nuclear steam supply system (NSSS). 


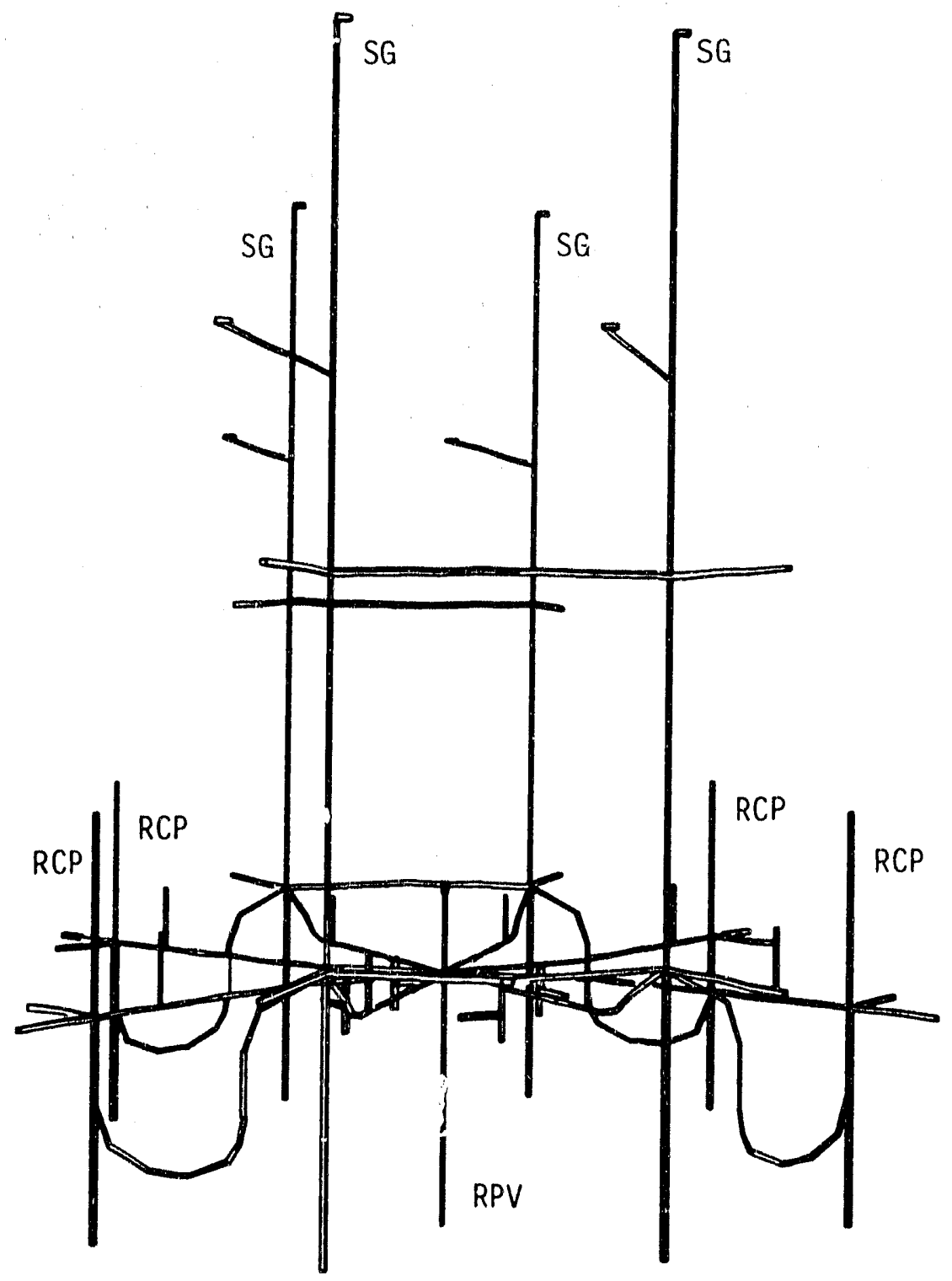

$\stackrel{1}{2}^{2}$

Figure A1-2 Trojan finite element model. 

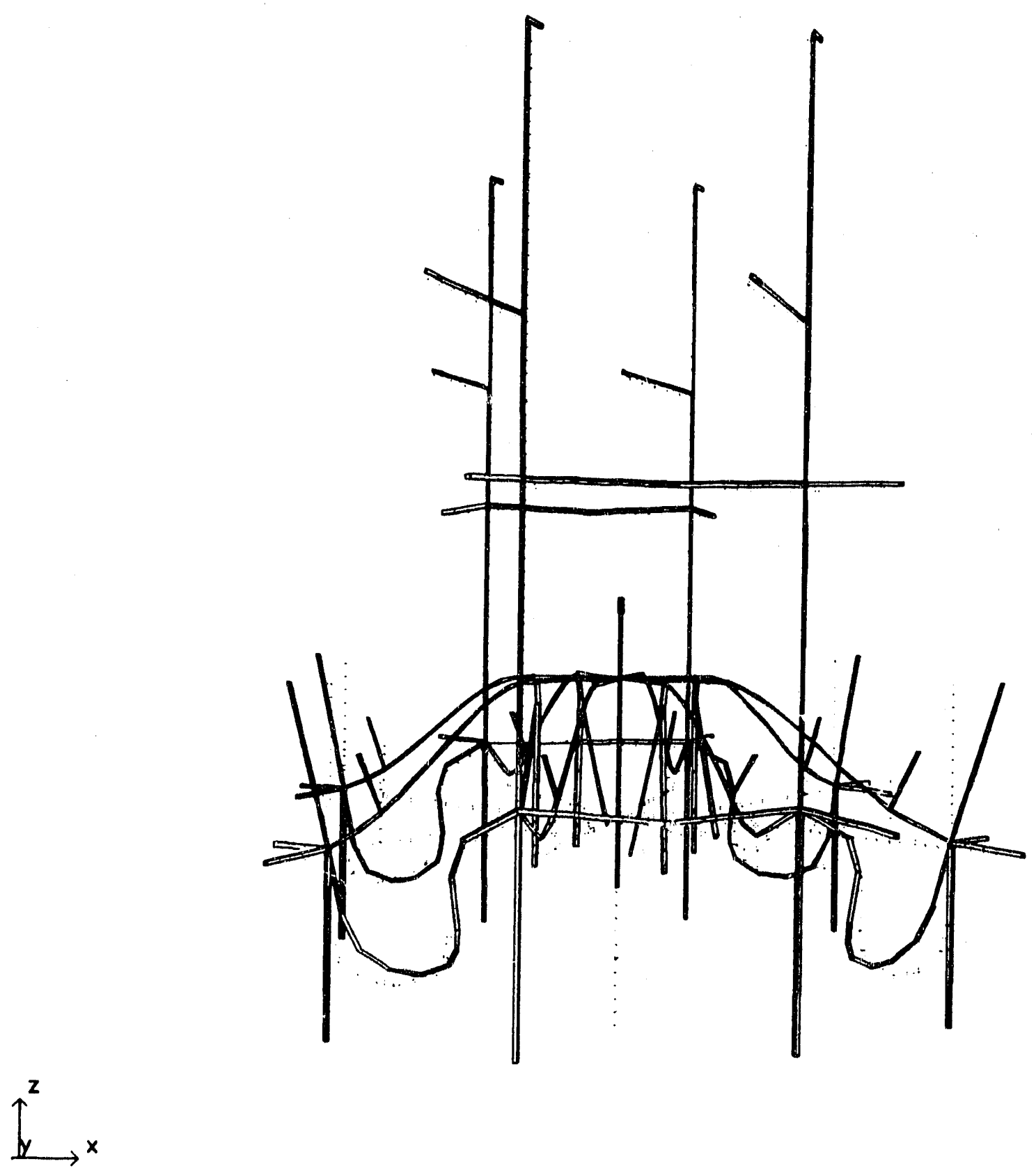

Figure A1-3 3.78 Hertz mode shape

A $1-18$ 


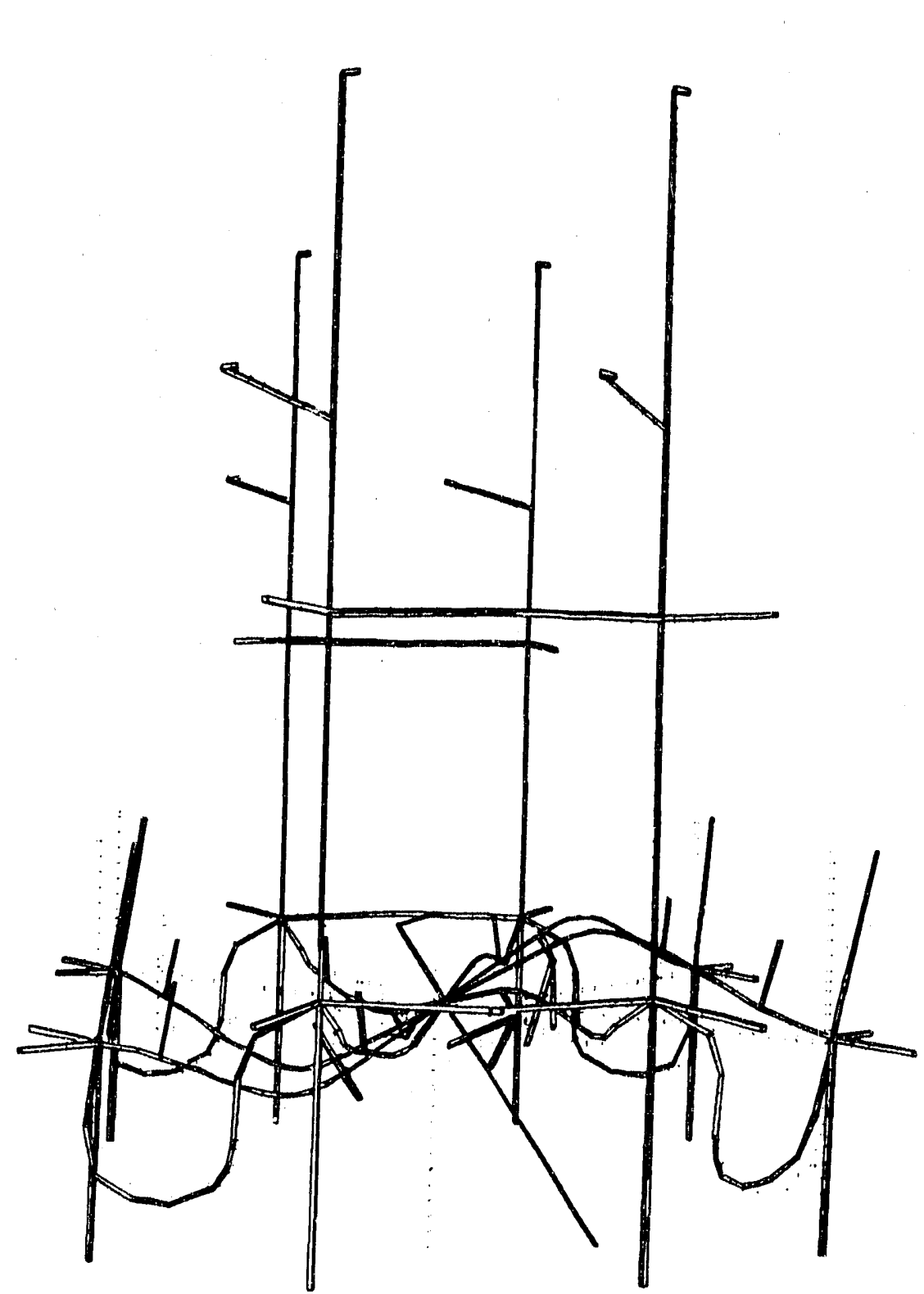



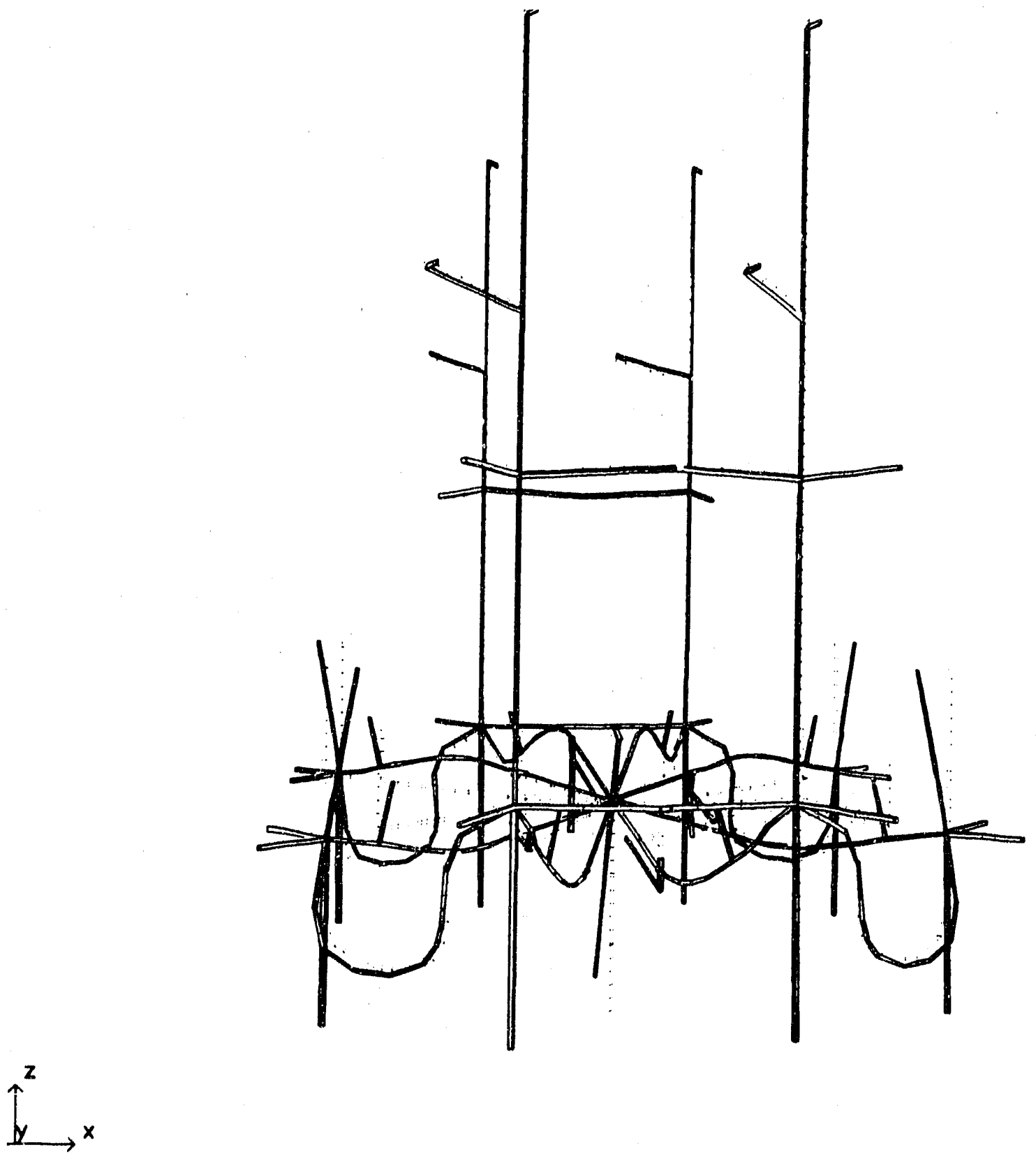

Figure A1-5 5.97 Hertz mode shape

A1-20 


\section{APPENDIX 2 \\ SENSITIVITY STUDY ON THE VARIATION OF STEAM GENERATOR SUPPORT STIFFNESS}

It is noted in the structural evaluation of the Trojan reactor coolant loop (as described in Appendix 1) that the stiffness of the Trojan steam generator supports is different from that for the Zion steam generator supports but the difference is not modeled in the analysis because the exact Trojan stiffness values are unknown. In order to validate the results of the structural analysis, a sensitivity study in which the stiffness of the steam generator supports is increased and decreased by $30 \%$ to account for any reasonable difference in the Trojan and Zion steam generator supports is conducted.

The results of the sensitivity study are summarized by Tables A2-1, A2-2 and A2-3, respectively, for vertical forces in steam generator supports, overturning moments in steam generator supports, and resuits of ASME code evaluation. It can be seen that the variation in the stiffness of the steam generator supports has little effect on the results of the structural evaluation. It is anticipated that the same conclusion is also applicable to the effect of variation of the stiffness of the reactor coolant pump supports. 
Table A2-1. Vertical forces in SG supports.

\begin{tabular}{|c|c|c|c|c|c|}
\hline \multirow[b]{2}{*}{ Load Case } & \multirow[b]{2}{*}{ Stif } & \multicolumn{4}{|c|}{ Support Forces (kips) } \\
\hline & & $\begin{array}{c}\text { Loop } 1 \\
\text { BE } 4\end{array}$ & $\begin{array}{c}\text { Loop } 2 \\
\text { BE } 1\end{array}$ & $\begin{array}{c}\text { Loop } 3 \\
\text { BE } 2\end{array}$ & $\begin{array}{c}\text { Loop } 4 \\
\text { LE } 3\end{array}$ \\
\hline SSE & Ori & 306 & 368 & 429 & 426 \\
\hline SSE & + & 352 & 361 & 442 & 428 \\
\hline SSE & - & 417 & 462 & 451 & 456 \\
\hline SBLOCA & Ori & 63 & 357 & 79 & 47 \\
\hline SBLOCA & + & 63 & 353 & 75 & 47 \\
\hline SBLOCA & - & 61 & 338 & 84 & 53 \\
\hline Thermal & Ori & 71 & 12 & 70 & 92 \\
\hline Thermal & + & 71 & 13 & 71 & 92 \\
\hline Thermal & $\cdot$ & 72 & 11 & 69 & 94 \\
\hline $\mathbf{P W}$ & Ori & 1264 & 1283 & 1287 & 1294 \\
\hline $\mathbf{P W}$ & + & 1276 & 1292 & 1297 & 1303 \\
\hline PW & - & 1245 & 1266 & 1268 & 1277 \\
\hline PWT & Ori & 1335 & 1295 & 1357 & 1387 \\
\hline PWT & + & 1347 & 1305 & 1368 & 1395 \\
\hline PWT & - & 1317 & 1277 & 1337 & 1371 \\
\hline PWT + SSE & Ori & 1641 & 1663 & 1786 & 1813 \\
\hline PWT + SSE & + & 1699 & 1666 & 1810 & 1823 \\
\hline PWT + SSE & - & 1734 & 1739 & 1788 & 1827 \\
\hline PWT + SBLOCA & Ori & 1398 & 1652 & 1436 & 1434 \\
\hline PWT + SBLOCA & + & 1410 & 1658 & 1443 & 1442 \\
\hline PWT + SBLOCA & - & 1378 & 1615 & 1421 & 1424 \\
\hline
\end{tabular}

\footnotetext{
Stif $=$ stiffness values (original, $+30 \%$, or $-30 \%$ )

BE = beam element in Trojan model

SSE = safe shutdown earthquake

SBLOCA = small-break loss-of-coolant accident

PW $=$ operating pressure and dead weight

PWT = operating pressure, dead weight, and thermal
} 
Table A2-2. Overturning moments in SG supports.

\begin{tabular}{|c|c|c|c|c|c|}
\hline \multirow[b]{2}{*}{ Load Case } & \multirow[b]{2}{*}{ Stif } & \multicolumn{4}{|c|}{ Everturning moments (kips-in.) } \\
\hline & & $\begin{array}{c}\text { Loop } 1 \\
\text { BE \& }\end{array}$ & $\begin{array}{c}\text { Loop } 2 \\
\text { BE } 5\end{array}$ & $\begin{array}{l}\text { Loop } 3 \\
\text { BE } 6\end{array}$ & $\begin{array}{c}\text { Loop } 4 \\
\text { BE } 7\end{array}$ \\
\hline SSE & Ori & 5480 & 4884 & 5333 & 5002 \\
\hline SSE & + & 6910 & $\mathbf{5 8 8 0}$ & 6652 & 6073 \\
\hline SSE & - & 3760 & 3465 & 3692 & 3531 \\
\hline SBLOCA & Ori & 669 & 1382 & 1101 & 752 \\
\hline SBLOCA & + & 892 & 1741 & 1423 & 909 \\
\hline SBLOCA & - & 433 & 1052 & 781 & 615 \\
\hline Thermal & Ori & 7055 & 24169 & 25309 & 29053 \\
\hline Thermal & + & 7134 & 25651 & 26644 & 30872 \\
\hline Thermal & - & 6831 & 21839 & 23144 & 26215 \\
\hline PW & Ori & 47488 & 43506 & 45192 & 43886 \\
\hline $\mathbf{P W}$ & + & 50058 & 46085 & 47639 & 46338 \\
\hline $\mathbf{P W}$ & - & 43330 & 39415 & 41244 & 39962 \\
\hline $\mathbf{W}$ & Ori & 50448 & 48637 & 50231 & 49468 \\
\hline $\mathbf{w}$ & + & 53111 & 51510 & 52920 & 52236 \\
\hline $\mathbf{w}$ & - & 46127 & 44080 & 45884 & 45038 \\
\hline PWT & Ori & 54543 & 67675 & 70501 & 72939 \\
\hline PW'T & + & 57192 & 71736 & 74283 & 77210 \\
\hline PWT & - & 50161 & 61254 & 64388 & 66177 \\
\hline PWT + SSE & Ori & 60023 & 72559 & 75834 & 77941 \\
\hline PWT + SSE & + & 64102 & 77616 & 80935 & 83283 \\
\hline PWT + SSE & - & 53921 & 64719 & 68080 & 69708 \\
\hline PWT + SBLOCA & Ori & 55212 & 69057 & 71602 & 73691 \\
\hline PWT + SBLOCA & + & 58084 & 73477 & 75706 & 78119 \\
\hline PWT + SBLOCA & - & 50594 & 62306 & 65169 & 66792 \\
\hline
\end{tabular}

\footnotetext{
Stif $=$ stiffness values (original, $+30 \%$, or $-30 \%$ )

BE = beam element in Trojan model

SSE = safe shutdown earthquake

SBLOCA = small-break loss-of-coolant accident

PW = operating pressure and dead weight

$W=$ weight

PWT = operating pressure, dead weight (PW) plus thermal
} 
Table A2-3. ASME cod? evaluation.

\begin{tabular}{|c|c|c|c|c|c|c|}
\hline \multirow[b]{2}{*}{ Load } & \multirow[b]{2}{*}{ Stif } & \multicolumn{4}{|c|}{ ASME "rvaluation Load (ksi) } & \multirow[b]{2}{*}{ 3Sm (ksi. } \\
\hline & & $\begin{array}{l}\text { Loop } 1 \\
\text { PE } 151\end{array}$ & $\begin{array}{c}\text { Loop } 2 \\
\text { PE } 1\end{array}$ & $\begin{array}{l}\text { Loop } 3 \\
\text { PE } 51\end{array}$ & $\begin{array}{l}\text { Loop } 4 \\
\text { PE } 101\end{array}$ & \\
\hline 1 & Ori & 41.1 & 41.2 & 41.2 & 41.2 & 57.9 \\
\hline 1 & + & 41.1 & 41.2 & 41.1 & 41.2 & 57.9 \\
\hline 1 & - & 41.2 & 41.3 & 41.2 & 41.3 & 57.9 \\
\hline 2 & Ori & 34.8 & 37.0 & 35.9 & 34.2 & 57.9 \\
\hline 2 & + & 34.8 & 37.0 & 35.9 & 34.2 & 57.9 \\
\hline 2 & - & 34.6 & 37.2 & 35.8 & 34.2 & 57.9 \\
\hline
\end{tabular}

Load Comb. = load combination

Load Comb. 1 = pressure, dead weight, and SSE

Load Comb. 2 = pressure, dead weight, and SBLOCA

Stif $=$ stiffness values (original, $+30 \%$, or $-30 \%$ )

PE $=$ pipe element in Trojan model 


\section{APPENDIX 3}

\section{LOAD CAPACITIES OF STEAM GENERATOR AND REACTOR COOLANT PUMP SUPPORTS}

\section{A. Load Capacity of Steam Generator Lower Supports}

Each steam generator lower support consists of four vertical columns and is subject to an axial force and an overturning moment. The forces and moments for various loading conditions are listed in Tables A1-7 and A1-8, Appendix 1. The maximum values of the forces and moments are summarized below:

$\begin{array}{ccc}\text { Loading Condition } & \text { Axial Force } & \begin{array}{c}\text { Overturning Moment } \\ \text { (kips) }\end{array} \\ \text { PWT + SSE } & \text { 1813(or 927) } & 77,941\end{array}$

Note: (1) The value in the parentheses results from uplift forces due to SSE and is to be used to compute tension in the support column.

(2) PWT $=$ Pressure + Weight + Thermal.

Thus, the maximum compression in the column is

$$
1813 / 4+77,941 /(2 \mathrm{~d}) \text { or } 843 \mathrm{kips},
$$

where, $d$ (the distance between two columns) is approximately $100 \mathrm{in}$. for the Trojan steam generator supports, and the maximum tension in the column is 158 kips.

To determine the load capacity of the steam generator column, we consider the "original" reactor coolant loop system, i.e., no failure of the RPV supports, but subject to the "original" design basis load combination of pressure, weight, thermal, and a large-break loss-of-coolant accident (LBLOCA). An LBLOCA is a double-ended guillotine break (DEGB) of one of the three legs of the reactor coolant loop piping. To evaluate the forces and moments generated by LBLOCA at the steam generator supports, it is assumed that a slot DEGB is located at the inlet (hot leg) nozzle of the steam generator. The slot break is chosen such that it creates a vertical downward or upward jet force at the break location. An equivalent static analysis is conducted. To obtain a lower bound estimate of the steam generator support load capacity, the magnitude of the jet force is assumed to be the product of the internal pressure ( $2235 \mathrm{psi})$ and the pipe flow area $(660 \mathrm{sq}$. in.) although normally twice this value is recommended. In other words, we conservatively ignore the factor of two in this estimation of SG support capacity. The axial force and overturning moment generated by a LBLOCA load at the steam generator support are, respectively, 932 kips and 18,868 kip- in..

To obtain compression capacity for the SG support column, the axial force and overturning moment are, respectively, $2403 \mathrm{kips}$ and 66,243 kip-in. for the combined loading conditions of pressure, weight, thermal, SSE, and LBLOCA. The compression capacity is, therefore, 932 kips. The axial force and moment for calculating the tension capacity are $523 \mathrm{kips}$ (in tension) and 24,498 kip-in., respectively. The tension capacity is found to be $273 \mathrm{kips}$. It can be seen that both 
the compression and tension load capacities of the SG support columns exceed the column loads of 843 kips in compression and 158 kips in tension resulting from the failure of RPV supports.

\section{B. Load Capacity of Reactor Coolant Pump Supports}

To obtain the forces and moments in the RCP supports, a slot DEGB is assumed at the inlet (cold leg) nozzle of the pump. The RCP support forces and moments that produce maximum compression in support columns are summarized below:

$\begin{array}{lccc}\text { Loading Condition } & \text { RPV Support Failure } & \text { Force } & \text { Moment } \\ & & (\mathrm{kips}) & (\mathrm{k}-\mathrm{in} .) \\ \text { PWT + SSE } & \text { yes } & 596 & 40,691 \\ \text { PWT + SSE + LBLOCA } & \text { no } & 1614 & 51,785\end{array}$

Similarly, the RCP support forces and moments that produce maximum tension in support columns are shown below:

$\begin{array}{lccc}\text { Loading Condition } & \text { RPV Support Failure } & \text { Force } & \begin{array}{c}\text { Moment } \\ \text { (k-in.) }\end{array} \\ \text { PWT + SSE } & & \text { (kips) } & 40,691 \\ \text { PWT + SSE + LBLOCA } & \text { no } & 399 & 50,207\end{array}$

It can be seen that the maximum forces and moments in the RCP supports for the case of failed RPV supports do not exceed those in the RCP columns resulting from the original design basis loading combination. 


\section{APPENDIX 4 \\ EFFECTS ASSESSMENT OF REACTOR PRESSURE VESSEL SUPPORT FAILURE}

\section{Introduction}

The study presented in this Appendix is an "effects evaluation" to determine the potential effect that RPV motions would have on the ability to place the plant in a safe shutdown condition. Sprecific issues to be addressed include:

- the effect of pipe ruptures in small diameter lines attached to the reactor pressure vessel on the ability to shut down the reactor

- the ability to insert control rods and to achieve a hot shutdown

- rupture of piping attachment to the $\mathrm{RCL}$ piping

- the performance of the four reactor vessel coolant pumps, e.g., due to departure of rotating axis from true vertical; issues such as natural recirculation through a stopped pump or through a seized pump

- the behavior of instrument lines, such as those controlling safety systems which themselves may not be directly (i.e., physically) affected by vessel motions but could suffer indirect steam damage.

The study concludes by making recommendations as to what events should be analyzed further.

In this study, we use a systems analysis approach to identify the important events from an accident initiation and mitigation viewpoint. The SSMRP seismic risk assessment of Zion (see Ref. A4-1) identified initiating events and gerierated reactor accident sequences in terms of event trees and fault trees. We use this information concerning the important accident sequences to define the accident sequences and systems of concern in the event of a movement of the RPV. However, we limit the scope of this study to include failures that can occur as the result of RPV movement, such as rupture of RCS piping attached to the RCS. We do not consider additional failures such as random failures of equipment or equipment unavailability due to maintenance or testing, which are considered in a complete probabilistic risk assessment.

\section{Systems Analysis Perspective}

In this effects assessment, we employ a systems analysis approach to identify the failure modes in addition to those considered in Ref. A4-2 that can either cause an initiating event and/or fail engineered safeguard systems (ESS) as the result of reactor vessel movement, i.e., events which can lead to a core-melt accident.

Initiating events cause insufficient heat removal from the fuel rods in the core and in turn cause core melt and radioactive relcase if mitigation of the initiating event does not occur. Initiating events typically considered in a probabilistic risk assessment are of three basic categories:

- rupture of the reactor pressure vessel or the equivalent

- loss of coolant accidents (LOCAs) (other than RPV rupture events) 
- transients.

RPV rupture events are LOCAs which cannot be mitigated by the ECCS or causes failure of the ECCS.

Initiating events considered in the seismic probabilistic risk assessment of Zion [Ref. A4-1] are listed in Table A4-1. Reference A4-1 identified the following five basic accident-mitigating functions that occur sequentially following an initiating event:

1) Reactor Shutdown

2) Emergency Core Cooling

3) Post-Accident Radioactivity Removal

4) Post-Accident Heat Removal

5) Containment Integrity.

The accident-mitigating systems which perform these functions are called engineered safeguard systems and are briefly described below. One purpose of this study is to ascertain whether damage to ESS can occur when RPV movement occurs.

\section{I) Engineered Safety Feature Actuation System}

The signal actuation logic which activates the ESS is called the Engineered Safety Feature Actuation System (ESFAS). As shown in Fig. A4-1, the purpose of this system is to perform safety system actuation based upon values of selected unit parameters.

\section{2) Reactor Shutdown}

The system which performs the rapid shutdown of the reactor to limit core heat production is the Reactor Protection System.

\section{3) Emergency Core Cooling}

The emergency core cooling systems (ECCS) prevent the release of radioactivity from the fuel by performing coolant makeup and heat removal functions. These systems include:

- accumulators

- $\quad$ safety injection

- charging

- auxiliary feedwater

- residual heat removal.

It is important to note that there are breaks in the reactor coolant system that can negate the effectiveness of the ECCS. These breaks are categorized as reactor vessel rupture events listed in Table A4-1. In this case, RCS coolant loss through the break exceeds ECCS makeup resulting in core uncovery. Examples of RPV rupture events include: 
(2) multiple ruptures of high pressure conduits (called flux thimble guide tubes) used for flux mapping that penetrate the bottom of the RPV.

\section{4) Post-Accident Radioactivity Removal}

Post-accident radioactivity removal refer to systems which remove radioactivity from the containment atmosphere. These systems include:

- containment spray injection

- containment spray recirculation

- containment fan cooling

- chemical volume and control.

\section{5) Post-Accident Heat Removal}

Post-accident heat removal refers to systems which remove heat from the containment. These systems include:

- containment spray injection

- containment spray recirculation

- containment fan cooling

- residual heat removai.

\section{6) Containment Integrity}

Containment integrity refers to those sustems that prevent dispersal of radioactivity to the environment and that isolate the containment.

Containment isolation will be initiated by means of a containment isolation signal (CIS). A CIS occurs on containment high pressure as sensed by two out of three containment highpressure switches or on a safety injection signal (SIS).

The containment isolation systems provide the means of isolating fluid systems that pass through containment penetrations so as to confine to the containment any radioactivity that may be released in the containment fullowing a design basis event. The containment isolation systems are required to function following a design basis event to isolate nonsafety-related fluid systems penetrating the containment. 


\section{Accident Sequences}

The purpose of this effects evaluation is not to construct detailed event trees and fault trees for the initiating events listed in Table A4-1. However, it is useful to consider the likely sequences that would occur as the result of RPV movement. This evaluation identified four types of accident sequences:

- $\quad$ Accident Sequences - Type 1 (RPV rupture events) - RPV rupture events caused by events such as (1) catastrophic RCS pipe rupture due to collapse of the steam generator or reactor coolant pump supports, (2) rupture of the thimble guide tubes which penetrate the bottom of the RPV or (3) multiple ruptures of ECCS penetrations. RPV rupture events result in an inability of the ECCS to reflood the core. In this case, the only mitigating safety systems are those in the containment (Containment Spray Injection and Containment Fan Cooling).

- Accident Sequences - Type 2 (ECCS inoperability) - Rupture of piping attached to the RCS piping (not considered as a RPV rupture event) causes a LOCA and ECCS fails to operate for reasons such as:

1) Safety Injection Signal, (SIS), which starts the ECCS pumps and opens valves in the ECCS injection lines, is not generated.

- Accident Sequences - Type 3 (Reactor Trip Failure) - Transient event occurs (such as loss of forced circulation in the primary coolant loop due to trip of the reactor coolant pumps caused by excessive RCS pump vibration) and reactor trip failure for reasons such as:

i) Reactor trip signal not generated

2) Failure to insert the control rods due to tilting of the control rod drive.

- Accident Sequence - Type 4 (Loss of RCS Flow) - Transient event occurs and failure to remove decay heat (e.g., loss of forced and natural circulation in the primary coolant loop due to RCS pump impellers binding).

From the accident sequences described above, the initiating events identified are:

- RPV Rupture Events (breach of the primary reactor coolant boundary that cannot be mitigated by ECCS)

- LOCAs (breach of the primary reactor coolant boundary that can be mitigated by ECCS)

- Transients (not a breach of the reacror coolant boundary, the reactor is generating more heat than is removed, reactor trip and secondary heat removal is required) and the systems identified are:

- Reactor Trip System

- ECCS

- $\quad$ RCS pumps.

We discuss each of these systems below. 


\section{Reactor 'Trip System}

Reactor trip is a required safety function for all initiating events listed in Table A4-1 except for the large LOCA. During a large LOCA, the blowdown is rapid and the replacement of the coolant (and moderator) with highly borated water would bring the reactor to a subcritical point. In this section we first describe the instrumentation that generates a reactor trip and discuss whether this instrumentation would be affected by RPV movement. Later we discuss the possibility of tilting the control rod drive resulting in a failure to scram.

Instrumentation that generates a reactor trip are of three types:

(1) Excore instrumentation which measures neutron flux.

(2) Process instrumentation which measures temperature, pressure, flow or reactor coolant pump status in the four primary loops of reactor coolant system.

(3) Process instrumentation which measure temperature, pressure or flow in the four loops of the secondary heat removal system, i.e., main steam, turbine, condensatc and feedwater systems.

The Reactor Trip System uses sensors which feed analog circuitry consisting of two to four redundant channels which monitor various plant parameters. The Reactor Trip System also contains the digital logic circuitry necessary to automatically open the reactor trip breakers. The digital circuitry consists of two redundant logic trains which receive inputs from the analog protection channels.

Each of the two trains is capable of opening a separate and independent reactor trip breaker, RTA and RTB, respectively. The two trip breakers in series connect three-phase AC power from the rod drive motor generator sets to the rod drive power cabinets. During plant power operation, a DC undervoltage coil on each reactor trip breaker holds a trip plunger out against its spring, allowing the power to be available at the rod control power supply cabinets. For reactor trip, a loss of DC voltage to the undervoltage coil releases the trip plunger and trips open the breaker. When either of the trip breakers opens, power is interrupted to the rod drive power supply, and the control rods fall, by gravity, into the core. The rods cannot be withdrawn until an operator resets the trip breakers. The trip breakers cannot be reset until the bistable (an on-off electrical switch) which initiated the trip re-energizes. Bypass breakers BYA and BYB are provided to permit testing of the trip breakers.

The core protection system philosophy is to define a region of permissible operation in terms of power, flow, axial power distribution, and primary coolant temperature and pressure so that the reactor is tripped when the limits of this region are approached.

The following are plant conditions requiring reactor trip.

(1) Departure from Nucleate Boiling Ratio (DNBR) approaching 1.30.

(2) Power density (kilowatts per foot) approaching rated value for Condition II faults (fuel rod maximum linear power $=21.1 \mathrm{KW} / \mathrm{ft}$ ).

(3) Reactor Coolant System overpressure creating stresses approaching the limits. The ASME code pressure limit is 110 percent of the design pressure, which is 2485 psia for Trojan. 
Table A4-2 lists the signals which will generate a reactor trip and the instrumentation which generates these signals. The instrumentation which generates these signals are excore instrumentation which does not penetrate the RPV and would not be affected by RPV movement. All instrumentation has been nuclear qualified for Class $1 \mathrm{E}$ Service and instruments required to mitigate a LOCA can survive a steam environment and blowdown forces created by a LOCA.

The variables that are monitored for reactor trip include neutron flux, reactor coolant temperature, reactor coolant pressure and pressurizer level, reactor coolant flow, reactor coolant pump operational status, steam generator feedwater flow, steam generator water level and turbinegenerator operational status.

A reactor trip occurs when the Safety Injection System is actuated. This trip protects the core against a loss of reactor coolant or a steam line break.

In the event of a reactor trip, the control rods fall into the core by gravity. Each absorber rod in a rod cluster control moves vertically in its own tubular guide thimble. In their fully withdrawn position, the absorber rods do not leave the upper end of their guide thimbles which assures that the rods are always properly aligned. In the event of RPV movement, the control rod drive, control rods and guide thimbles should move all in the same direction. However, the possibility does exist that the control rods could bind in the event of tilting of the RPV.

\section{Lmergency Core Cooling System}

The emergency core cooling system (ECCS) is required if there is a rupture in the RCS boundary which causes loss of RCS coolant inventory.

In this study we are excluding (1) the possibility of rupture of the main reactor coolant loop piping and (2) rupture of the RPV itself.

In addition, we describe all the penetrations to the RCS. In the event that any of these penetrations rupture, a LOCA is generated.

\section{ECCS Operation}

The Emergency Core Cooling System (ECCS) is provided to suppiy dilute borated water to cool the reactor core in the event of a loss of reactor coolant, and to supply concentrated boric acid to maintain the reactor in a shutdown condition during the cooldown accompanying a steam line break.

During a large Loss Of Coolant Accident (LOCA), the reactor core and coolant system may be jlown dry. It is the function of the ECCS to initially refill the reactor vessel and to provide long term cooling for the reactor core. The operation of the ECCS, following a LOCA, may be divided into two distinct phases:

(1) The injection phase in which the coolant lost from the reactor coolant system, is replenished, initial core cooling is accomplished, and any reactivity increase accompanying the accident is nullified. 
(2) The recirculation phase in which long term core cooling is provide during the accident recovery phase.

During a steam break accident, the problem is not a loss of reactor coolant, but a reduction in reactor coolant temperature due to the removal of energy from the affected steam generator. This cooldown, due to the effects of negative moderator temperature coefficient, will cause a positive reactivity addition. The ECCS provides a supply of concentrated boric acid solution, which can be injected at high reactor coolant system pressures, to counteract this positive reactivity.

The ECCS consists of the following systems:

- charging system

- $\quad$ safety injection system

- accumulators

- low pressure injection, RHR pumps.

The success logic for the ECCS as a function of break size is shown in Table A4-3. During the injection mode, the flow of water is from the refueling water storage tank to the injection lines in each of the four cold legs.

Other ECCS modes include recirculation and hot leg injection. Recirculation occurs approximately 45 minutes after injection, hot leg injection occurs approximately 17 hours after injection.

\section{ECCS Actuation}

Table A4-4 lists the ESS actuation signals for the Trojan Nuclear Power Plant. As shown in Fig. A4-1, ESFAS generates a safety injection signal which actuates the ECCS. An SIS is actuated by the following signals:

(1) high containment pressure (4 psig)

(2) low pressurizer pressure (1765 psig)

(3) high differential pressure between steam gencrators

(4) high steam line flow in two of the four steam generator lines with either low-low Tave or low steam pressure.

A break size greater than $9 "$ in diameter generates high containment pressure. Three pressure detectors, located outside the containment building, are used to develop the containment high pressure signal. These detectors would not be affected by RPV movement.

The pressure transmitters for pressurizer pressure would not be affected by RCS movement. The pressure taps for these detectors could rupture; however, a low pressure signal would be generated in this case, a fail-safe condition.

High differential steam pressure or high steam line flow is caused by a steam break which is not considered in this study. 
An important conclusion of this section is that given a LOCA, movement of the RPV would not hinder generation of a SIS.

\section{RCS Penetrations}

A major focus of this study is to identify all the possible ruptures of the RCS penetrations that can occur as the result of RPV movement. The primary coolant loop pressure boundary includes these penetrations. Rupture of an RCS penetration causes a LOCA and ECCS actuation is required to prevent core uncovery. This means that rupture of a penetration is an initiating event in the LOCA accident sequence for the accident sequence:

- $\quad$ RPV rupture events (Type 1 accident sequence)

- $\quad$ ECCS inoperability (Type 2 accident sequence).

There are three types of RCS penetrations:

(1) Penetrations to reactor coolant loop piping (includes ex-core instrumentation)

(2) Penetrations to the top of the reactor vessel head (includes incore instrumentation, i.e., thermocouples)

(3) Penetrations at the bottom of the RPV (includes incore instrumentation, i.e. neutron flux detectors in thimble tubes).

A simplified diagram of the reactor coolant system with penetrations is shown in Fig. A4-2. Penetrations to the RCL piping are listed below, with the number of penetrations indicated in parenthesis and the outside diameter indicated in brackets.

\section{Penetrations to RCS piping}

Major penetrations include:

(1) Surge line from loop 2 to the pressurizer, (1), [14" OD].

(2) The Safety Injection-accumulator penetrations on the cold leg of loops 1, 2, 3, and 4 used mainly for injection of borated water during a safety injection. They are also used for RHR system return during normal cooling operation of the Reactor Coolant System, (4), [10" OD].

(3) Safety injection - hot leg recirculation penetration on the hot leg of loops 1, 2,3 , and 4 . RHR hot leg recirculation shares penetrations on loops 2 and $4,(4),\left[6^{\prime \prime}\right.$ ID].

(4) Spray scoops on loops 2 and 3 cold legs allow the pressurizer spray flow to be assisted by reactor coolant pump (RCP) discharge velocity, (2), [4" OD]. (5) Charging and alternate charging penetrations on loops 1 and 4 respectively,

(6) Drains are on each loop crossover leg low point. (4)

(7) Nuclear sampling lines on loops 1 and 3 hot legs have a sample scoop that extends into the coolant stream for a representative sample, (2), [2" OD]. 
(8) Normal and excess letdown penetrations on loop 3 crossover leg low point and cold leg, respectively, (2), [3" OD].

(9) Residual Heat Removal (RHR) System penetrations on cold leg of loops 1, 2,3 , and 4 that are used for cooldown operation, (4), [6" OD].

(10) One RHR penetration on \#4 hot leg, (1), [4" OD].

Smaller penetrations include:

(11) The R'TD hot-leg bypass connections are scoops which extend into the reactor coolant to collect a representative temperature sample for the RTD manifold. (20)

(12) The wide range tempriature detectors are located in thermowells that extend into the reactor coolant pipes. (8)

(13) Elbow Taps for flow measurement, (16), [3/8" OD].

(14) Reactor Coolant Pump Seals, $(3 \times 4=12)$.

Penetrations for incore instrumentation are show/n in Fig. A4-3.

\section{Penetrations at the top of the RPV}

There are a total of 79 penetrations from the top of the $r$ actor vessel head. These penetrations include:

- 1 vent head penetration

- 5 thermocouple drives

- 61 control rod drive mechanisms

- 12 spare penetrations including one for the reactor vessel level instrumentation system (RVLIS).

Penetrations at the bottom of the RPV

There are a total of 58 penetratior.s for high pressure conduits at the bottom of the RPV (see Fig. A4-3).

\section{Flux Detector Insertion System}

A cross section of the detector, its drive cable, guide thimble and conduit is shown in Fig. A4-4. The guide thimble can be thought of as a thin tube within a thick tube, with the outer thick tube (the thimble guide tube) being the high pressure conduit. There are a total of 58 thimble guide tubes with wall thickness of $0.25^{\prime \prime}$ - fifty have a .4 " inside diameter and eight have a .6" inside diameter. The guide thimble has a wall thickness of approximately .1".

Fifty-eight retractable thimbles are insered into the reactor through thimble guide tubes extending from the bottom of the reactor vessel through the concrete shield area and then up to a thimble seal table. Since the movable detector thimbles are closed at the leading (reactor) ends, they will normally be dry inside. They will thus serve as the pressure 
boundary between the reactor water pressure and the atmosphere. Mechanical seals between the retractable thimbles and the thimble guide tubes are provided at the seal table. The thimble guide tubes are essentially extensions of the reactor vessel with the thimbles allowing the insertion of the incore instrumentation movable miniature detectors (i.e., the inner side of the thimble guide tube and the outer side of the flux thimble are pressurized and represent an extension of the reactor coolant system). During normal operation the thimbles are inserted in the core and are retracted only during refueling or for maintenance.

\section{RPV Rupture Events}

Ruptures of the RCS that are beyond the design basis of the ECCS are called RPV rupture events. There are two areas of concern:

- rupture of RCS penetrations

- failure of either steam generator or RCS pump supports.

Ruptures of RCS penetrations identified for this study that are beyond the ECCS design basis include the following:

- multiple rupture of ECCS penetrations

- rupture of the thimble guide tubes that penetrate the bottom of the RPV.

\section{Rupture of ECCS penetrations}

The outside diameter of the charging injection lines is 1.5"; the outside diameter of the safety injection lines is 10". As described in Table A4-1, rupture of one of the charging lines causes a small LOCA; rupture of one safety injection line causes a large LOCA. Assuming that all the ECCS pumps start and all injection valves open, at least two simultaneous ruptures of safety injection lines would have to occur for core damage to occur. The conclusion is based upon the success criteria (3-out-of-4) for accumulator discharge as stated in Table A4-3 This assumes that there are no other failures such as (1) random equipment failure and (2) equipment unavailable due to maintenance or testing. Furthermore, the success criteria in Table A4-3 states that if all four 10" safety injection lines do not rupture, then successful emergency cone cooling is achieved.

\section{Rupture of the thimble guide tubes used for flux mapping}

The high pressure conduits used in the flux detector system are 60 feet long and extend from the RPV to the seal Table. Movement of the RPV causes bending stresses to be placed on these conduits with the possibility of rupture. It is unlikely that the inside thimble tube would rupture since it is free to move within the thimble guide tube. Rupture of the thimble guide tubes results in a LOCA at the bottom of the RPV. According to an NRC staff presentation to the Advisory Committee on Reactor Safety [Ref. A4-3] core uncovery would occur if more than six conduits ruptured, corresponding to a break size of $.0006326 \mathrm{ft}^{2}$ and an RCS pressure of 1225 psia. In this case, the high pressure injection system can not pump enough water into the core, i.e., the leak rate exceeds the makeup rate, and core uncovery results.

Appendix 1 indicates that the RCS piping could withstand loss of the RPV supports and that the resultant loads could be adequately transferred to the steam generator and reactor coolant pump supports. However, if either the SG or RCP supports fail as the result of RPV support failure, then rupture of the RCS piping could occur. Appendix 3 demonstrates that the SG and RCP supports will not fail as a result of RPV support failure. 


\section{Reactor Coolant Pumps}

The function of the reactor coolant pumps (RCPs) is to circulate coolant (water) through the reactor core and steam generators. A trip of one or more RCPs results in inadequate heat removal and reactor trip is required.

The reactor coolant pump is a vertical, single-stage, centrifugal, controlled-leakage shaft seal pump designed to pump large volumes of reactor coolant at high temperatures and pressures. The reactor coolant pump consists of a hydraulic section, a shaft seal section, and a motor section. The reactor coolant pump and its supports are described by Figs. A4-5.

The hydraulic section consists of an impeller, turning vane-diffuser, casing, thermal barrier, heat exchanger, and lower radial bearing. The shaft seal section consists of three devices. They are the No. 1 controlled-leakage, film-riding face seal and the Nos. 2 and 3 rubbing face seals. These seals are contained within the main flange and seal housing. The motor section consists of a vertical solid shafi, squirrel cage induction motor, an oil-lubricated double Kingsbury thrust bearing, two oil-lubricated radial bearings, and a flywheel with an anti-reverse rotation device.

Attached to the bottom of the pump shaft is the impeller. The reactor coolant is drawn up through the impeller and discharged through the discharge nozzle in the side of the casing. Above the impeller is a thermal barrier which contains a heat exchanger. The thermal barrier limits heat transfer between the hot reactor coolant system water and the pump radial bearing and seals.

High pressure seal injection water from the chemical and volume control system harging pumps is introduced through the thermal barrier wall. A portion of this water flows up the shaft to the seal area, while the remainder flows down the shaft past the pump radial bearing and through the thermal barrier where it acts as a buffer to prevent reactor coolant system water from entering the radial bearing and seal section of the unit. The heat exchanger provides a means of cooling the reactor coolant system water to an acceptable level in the event injection flow is lost. The seals would continue to provide controlled leakage, which depends only on pressure. Since there would be no injection water, the reactor coolant water would leak through the normal seal path. Mounted above the thermal barrier is the pump radial bearing which is a water-lubricated journal with a spherical seat for self-alignment. The seal system controls the upward flow of the high pressure injection water. The No. 1 seal leakoff is channeled to the Seal Water Heat Exchanger and to the Volume Control Tank outlet of the Chemical and Volume Control System. The leakoff from No. 2 seal is channeled to the reactor coolant drain tank (RCDT) of the Liquid Waste Processing System for processing and eventual reuse. No. 3 seal leakoff overflows to the containment sump.

The motor is an air-cooled, Class B Thermoplastic Epoxy-insulated, squirrel cage induction motor. The rotor and stator are of standard construction and are cooled by air. Six resistance temperature detectors are located troughout the stator to sense the winding temperature. A double Kingsbury thrust bearing and upper radial guide bearing are lubricated by oil which is circulated through the bearings and cooled in an external vertical heat exchanger by component cooling water. The heat exchanger is attached to the side of the motor. Below the stator is a lower radial bearing which is submerged in oil, for lubrication and cooling. This oil is cooled by an integral heat exchanger, also cooled by component cooling water. At the top of the motor is a flywheel and an anti-reverse rotation device. A removable coupling between the motor is a flywheel and an anti-reverse rotation device. A removable coupling between the motor and pump allows work on the shaft seals without the necessity of lifting the motor out of the way. 
Each pump is supported on three two-hinged columns. Each column attaches to a flange on the casing. One column is on the opposite side of the discharge of the pump. The other two columns flank the discharge at $\pm 45^{\circ}$ positions. The columns attach to the containment floor. The rods at the upper end of the column are attached to the missile barrier wall. These tie rods provide lateral support. Lateral stability is provided by the unbroken primary piping, a ring girder on the upper part, and tension tie rods attached to the support feet. The ring girder which circles the pump is supported by two hydraulic suppressors.

The pump is vertically mounted and is arranged with a bottom suction and a radial side discharge nozzle. The hydraulic parts consist of a casing, impeller, turning vane-diffuser, diffuser adanter, pump bearing, thermal barrier and heat exchanger.

Movement of the RPV can cause the RCS pump to tilt in the direction of the cold leg (see Fig. A45) and result in the following possible RCS pump failure modes:

\section{Loss of Forced Circulation}

Tilting of the pump from true vertical can cause excessive vibration of the flywheel that is attached to the pump shaft and in turn cause shutdown of the pump and loss of forced circulation in the $\mathrm{RCS}$ pumps should fail. In this case, a reactor trip is required to avert core damage.

The purpose of the flywheel is to provide coastdown capability so that flow and decay heat removal will occur for a period of 60 seconds following trip of the reactor coolant pumps. Following the coastdown period, successful heat removal can be accornplished by natural recirculation as a result of heat convection. The FSAR states that 3 out of 4 pumps must operate for successful heat removal during the coastdown period.

It is essential to show that the coastdown capability of the pump will not be affected by the tilting of the pump and excessive vibration of the flywheel.

In the event of RCP shutdown, there are numerous trip signals that could be produced to scram the reactor. These signals include reactor coolant overtemperature, insufficient RCS coolant flow and RCP breaker position. Reactor coolant temperature is detected by RTDs in each loop; reactor coolant flow is continuously monitored by three differential pressure measurements in each loop. It is felt that there is enough redundancy in the trip logic that a reactor trip would occur in the event of an RCP shutdown.

\section{Loss of Natural Circulation}

Furthermore the tilting of the pump could cause deformation of the pump casing. It is possible that the pump impeller could bind resulting in loss of natural circulation in the RCS pump. Loss of natural circulation in the RCS causes insufficient heat removal and core melt. There is not enough time for the operator to mitigate this accident by feed-and-bleed operation, i.e., coolant makeup by the charging system followed by release of coolant through the power operated relief valves on the pressurizer.

Tilting of the pump could cause bending or rupturing of the pipes used for (1) high pressure seal injection (supplied from the chemical and volume control system) and (2) for cooling the thermal barrier/heat exchanger (supplied from the component cooling water system). Failure of these two systems can eventually result in loss of seal integrity and in turn cause a LOCA within several hours. 


\section{Recommendations and Conclusions}

In this section we identify (1) potential problem areas (vulnerabilities affecting plant safety) that w/arrant further study (2) concerns initially identified that we believe are not problems. We discuss potential vulnerabilities in terms of the accident sequences. In the discussion below, we assume that all of the RPV supports have failed.

\section{(1) RPV Rupture Events}

Appendix 1 has identified that a structural failure of SG/RCP supports could cause a catastrophic collapse of the reactor coolant loop piping. Appendix 3, however, demonstrates that failure of SG/RCP supports will not occur. This study has identified the following additional RPV rupture events.

\section{Rupture of the Thimble Guide Tubes at the Bottom of the RPV}

Rupture of more than six thimble guide tubes causes a LOCA that can not be mitigated by the ECCS. This is definitely a problem area that warrants further investigation. Appendix 5 indicates, however, that rupture of thimble tubes will not take place due to RPV support failure.

\section{Multiple Ruptures of ECCS Penetrations}

Multiple ruptures of ECCS penetrations are beyond the design basis of the ECCS and is a problem area that warrants further investigation. This study indicates that successful emergency core cooling can not be achieved if all four 10" safety injection lines rupture. Appendix 8, however, concludes that the safety injection lines will not fail for a given RPV support failure.

\section{(2) ECCS Inoperability}

ICCS operability refers to the successful actuation and operation of the ECCS given a LOCA that ian be mitigated by the ECCS. The only potential problem area identified was the inability to generate a safety injection signal (SIS) given a LOCA. Low pressurizer pressure is one signal that generates as SIS. Rupture of the pressure taps causes low pressure which is a fail safe condition. Hence, we believe that ECCS inoperability is not a safety issue in this study.

\section{(3) Reactor Trip Failure}

There are two issues regarding reactor trip failure:

(1) Failure to insert the control rods due to tilting of the control rod drive.

(2) Failure to generate reactor trip signal.

\section{Control Rod Drive Failure}

We believe that given failure of the RPV supports, that there is a strong likelihood the reactor shutdown will be required, e.g., we believe that one or more reactor coolant pumps will be shut down which in turn requires reactor trip. Tilting of the control rod drive is potentially a very 
serious problem and warrants further investigation. Appendix 7 demonstrates that the tilting which occurs at Trojan due to RPV support failure does not lead to the inability to insert the control rods.

\section{Eailure to Generate a Reactor Trip Signal}

Generation of a reactor trip signal is required for two types of initiating events:

- transients, e.g., trip of one or more RCPs,

- LOCAs.

Trip of one or more RCPs causes low RCS coolant flow and high RCS coolant temperature. As described in Section 6.4, there are numerous trip signals that would be generated and there is enough redundancy in the trip logic that a reactor trip would occur in the event of RCP shutdown.

A LOCA causes low pressurizer pressure which generates a reactor trip signal as well as a SIS. As described earlier, movement of the RPV would not hinder generating a low pressure signal.

Hence we feel that failure to generate a reactor trip signal is not a problem warranting further investigation.

\section{(4) Loss of RCP Functional Ability}

Following trip of the reactor coolant pumps, RCS flow is still required during the coast down period as well as during natural recirculation. Below, we discuss the failure modes of the RCPs that could cause loss of RCP function following RCP trip.

Tilting of the pumps during coastdown could conceivably cause excessive vibration and in turn cause the RCP to lose coast down capability.

In addition, deformation of the RCP casing could cause the pump impeller to bind resulting in loss of natural recirculation.

We believe the issue of RCP functional ability warrants further investigation. Appendix 6 subsequently concludes that natural circulation will $\alpha$ ccur in the hypothetical case of RPV support failure at Trojan.

In summary, we believe that the following events are of highest priority and should be analyzed further due to the fact that these events can directly lead to core melt:

- Rupture of the thimble guide tubes (this includes rupture of the RVLIS instrumentation: line).

- Failure to scram due to tilting of the control rod drive.

- Loss of RCP functional ability during coast down or natural recirculation.

- ECCS connection failures.

However, various appendices of this document address these issues and conclude in each case that safety can be maintained when RPV supports fail at Trojan. 


\section{REFERENCES}

A4-1. J. E. Wells, L. L. George and G. E. Cummings, Seismic Safety Margins Research Program, Phase I Final Report - Systems Analysis, Lawrence Livermore National Laboratory, NUREG/CR-2015, Vol. 8, UCRL-5302, Vol. 8 (1983).

A4-2. S. C. Lu, Preliminary Structural Evaluation of Trojan RCL Subject to Postulated RPV Support Failure, Lawrence Livermore National Laboratory, UCID 21831, NUREG/CR5506 (1990).

A4-3. Advisory Committee on Reactor Safety Meeting Transcripts, July 31 (1985). 
Table A4-1. Definitions of event tree initiating events.

\section{Reactor Vessel Rupture (RVR)}

A vessel rupture large enough to negate the effectiveness of the ECC systems required to prevent core melt or a rupture of sufficient primary coolant piping in a pattern that negates the effectiveness of those same ECC systems.

\section{Large LOCA (LLOCA)}

A rupture of primary coolant piping equivalent to the break of a single pipe whose inside diameter is greater than 6" but which does not negate the effectiveness of the ECC systems required to prevent core melt.

\section{Medium LOCA (MLOCA)}

A rupture of primary coolant piping equivalent to the break of a single pipe whose inside diameter is greater than 3 " but less than or equal to 6".

\section{Small LOCA (SLOCA)}

A rupture of primary coolant piping equivalent to the break of a single pipe whose inside diameter is greater than 1.5 " but less than or equal to 3 ".

\section{Small-small LOCA (SSLOCA)}

A rupture of primary coolant piping equivalent to the break of a single pipe whose inside diameter is greater than $0.5^{\prime \prime}$ but less than or equal to $1.5^{\prime \prime}$.

\section{Class 1 Transient (T1)}

Any abnormal condition in the plant which requires that the plant be shut down but which does not directly affect the operability of the PCS and does not qualify as a LOCA or vessel rupture.

\section{Class 2 Transient (T2)}

Any abnormal condition in the plant which requires that the plant be shut down and does not qualify as a LOCA or vessel rupture but which causes the PCS to become inoperative. 
Table A4-2. List of reactor trips.

\begin{tabular}{|c|c|c|}
\hline Reactor Trip & Setpoint & $\begin{array}{l}\text { Coincidence } \\
\text { logic }\end{array}$ \\
\hline Source range Hi flux & $\geq 10^{5} \mathrm{cps}$ & 1 of 2 \\
\hline $\begin{array}{l}\text { Intermediate range } \mathrm{Hi}^{\mathrm{i}} \text { flux } \\
\text { power }\end{array}$ & amps $\geq 25$ percent & 1 of 2 \\
\hline $\begin{array}{l}\text { Power range Hi flux } \\
\text { (low setpoint) }\end{array}$ & $\geq 25$ percent & 2 of 4 \\
\hline $\begin{array}{l}\text { Power range Hi flux } \\
\text { (high setpoint) }\end{array}$ & $\geq 108$ percent & 2 of 4 \\
\hline $\begin{array}{l}\text { Power range Hi flux rate } \\
\text { Positive } \\
\text { Negative }\end{array}$ & $\begin{array}{l}+5 \operatorname{percent} / 2 \sec \\
-5 \operatorname{percent} / 2 \sec \end{array}$ & $\begin{array}{l}2 \text { of } 4 \\
2 \text { of } 4\end{array}$ \\
\hline Overtemperature $\Delta \mathrm{T}$ & Variable ( 132 percent \pm penalties) & 2 of 4 \\
\hline Overpower $\Delta T$ & Variable (108 percent - penalties) & 2 of 4 \\
\hline Pressurizer low pressure & $\leq 1865 \mathrm{psig}$ & 2 of 4 \\
\hline Pressurizer high pressure & $\geq 2385$ psig & 2 of 4 \\
\hline Pressurizer high level & $\geq 92$ percent of span & 2 of 4 \\
\hline Single loop loss of flow & $\leq 90$ percent flow & 2 of 3 on 1 of 4 \\
\hline Two loop loss of flow & $\leq 90$ percent flow & 2 of 3 on 2 of 4 \\
\hline $\begin{array}{l}\text { Reactor coolant pump bus } \\
\text { undervoltage }\end{array}$ & $\begin{array}{l}\leq 68 \text { percent bus } \\
\text { voltage }\end{array}$ & $\begin{array}{l}1 \text { of } 2 \text { on } \\
2 \text { of } 2 \text { buses }\end{array}$ \\
\hline $\begin{array}{l}\text { Reactor coolant pump bus } \\
\text { underfrequency }\end{array}$ & $\leq 57.5 \mathrm{~Hz}$ & $\begin{array}{l}1 \text { of } 2 \text { on } \\
2 \text { of } 2 \text { buses }\end{array}$ \\
\hline $\begin{array}{l}\text { Reactor coolant pump } \\
\text { breakers }\end{array}$ & Breaker opening & 2 of 4 breakers \\
\hline $\begin{array}{l}\text { Steam generator low-low } \\
\text { level }\end{array}$ & $\begin{array}{c}\leq 15 \text { percent of } \\
\text { span }\end{array}$ & $\begin{array}{c}2 \text { of } 3 \text { on } \\
1 \text { of } 4\end{array}$ \\
\hline Low feedwater flow & $\begin{array}{l}\text { (level) } 25 \text { percent } \\
\text { of span } \\
\text { (flow) } 1.5 \times 10^{6} \\
\text { lbs/hr mismatch }\end{array}$ & $\begin{array}{l}1 \text { of } 2 \text { on } \\
1 \text { of } 4 \\
1 \text { of } 2 \text { on } \\
1 \text { of } 4\end{array}$ \\
\hline
\end{tabular}


Table A4-2. List of reactor trips. (continued)

\begin{tabular}{lcc}
\hline Reactor Trip & Setpoint & $\begin{array}{c}\text { Coincidence } \\
\text { logic }\end{array}$ \\
\hline $\begin{array}{l}\text { Turbine trip } \\
\text { Oil pressure } \\
\text { Turbine stop valves }\end{array}$ & $\begin{array}{c}</ 4 \text { stop valves } \\
\text { shut }\end{array}$ & 2 of 3 \\
Safety injection & SI actuation & 4 of 4 \\
Manual & Manual switches & 1 of 2 trains \\
SSPS general warning & General waming & 1 of 2 \\
\hline
\end{tabular}


Table A4-3. Definition of ECCS equipment success requirements for LOCA events at the Trojan Nuclear Power Plant.

\begin{tabular}{|c|c|c|}
\hline $\begin{array}{l}\text { LOCA size } \\
\text { (Equivalent diam.) }\end{array}$ & $\begin{array}{l}\text { Injection mode } \\
\text { (ECI) }\end{array}$ & $\begin{array}{l}\text { Recirculation mode } \\
\text { (ECR) }\end{array}$ \\
\hline $\begin{array}{l}\text { Large } \\
\text { Breaks }>6 "\end{array}$ & $1 / 2$ LPIS * 3/4 ACC & 1/2 LPIS \\
\hline$\frac{\text { Medium }}{6^{\prime \prime} \geq \text { Breaks }>3 "}$ & $\begin{array}{c}1 / 2 \mathrm{CP} * 1 / 2 \mathrm{SIP} * 3 / 4 \mathrm{ACC} \\
\mathrm{OR} 2 / 2 \mathrm{SIP} * 3 / 4 \mathrm{ACC}\end{array}$ & $\begin{array}{l}1 / 2 C P * 1 / 2 \\
\text { SIP OR } 2 / 2 \text { SIP } \\
\text { OR 1/2 LPIS }\end{array}$ \\
\hline$\frac{\text { Small }}{3^{\prime \prime} \geq \text { Breaks }>1.5^{\prime \prime}}$ & $\begin{array}{c}1 / 2 \mathrm{CP} * 1 / 2 \mathrm{SIP} \mathrm{QR} \\
2 / 2 \mathrm{SIP}\end{array}$ & $\begin{array}{c}1 / 2 \mathrm{CP} * 1 / 2 \\
\operatorname{SIP} \mathrm{OR} 2 / 2 \text { SIP }\end{array}$ \\
\hline$\frac{\text { Small-small }}{1.5^{\prime \prime} \geq \text { Breaks }}>0.5^{\prime \prime}$ & $\begin{array}{l}1 / 2 \mathrm{CP} * 1 / 2 \mathrm{SIP} \frac{\mathrm{OR}}{2 / 2 \mathrm{SIP} Q \mathrm{OR} 2 / 2 \mathrm{CP}}\end{array}$ & $\begin{array}{c}1 / 2 C P * 1 / 2 \\
\text { SIP OR } 2 / 2 \text { SIP } \\
\text { OR } 2 / 2 C P\end{array}$ \\
\hline
\end{tabular}

Notation:

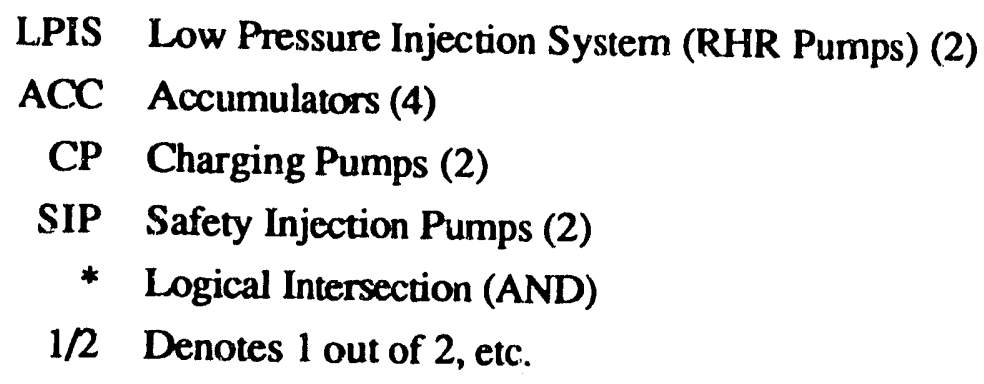


Table A4-4. List of safeguard actuations.

\begin{tabular}{|c|c|c|}
\hline Safeguard actuation & Setpoint & Coincidence \\
\hline $\begin{array}{l}\text { Containment high pressure } \\
\text { safety injection signal }\end{array}$ & 4 psig & 2 of 3 \\
\hline $\begin{array}{l}\text { Pressurizer low pressure } \\
\text { safety injection signal }\end{array}$ & 1765 psig & 2 of 3 \\
\hline $\begin{array}{l}\text { Containment high-high } \\
\text { pressure containment } \\
\text { spray actuation signal } \\
\text { and steam line isolation } \\
\text { signal }\end{array}$ & 30 psig & 2 of 4 \\
\hline \multirow[t]{3}{*}{$\begin{array}{l}\text { High steam flow safety } \\
\text { injection signal and } \\
\text { steam line isolation } \\
\text { signal }\end{array}$} & $\begin{array}{l}\text { Flow: } \\
\text { from } 0 \text { percent load } \\
\text { to } 20 \text { percent load, } \\
\text { setpoint is } 40 \text { percent } \\
\text { of design flow; } \\
\text { from } 20 \text { percent load } \\
\text { to } 100 \text { percent load, } \\
\text { setpoint is } 110 \\
\text { percent of design flow }\end{array}$ & $\begin{array}{c}1 \text { of } 2 \text { on } \\
2 \text { of } 4 \text { S/G } \\
\text { AND }\end{array}$ \\
\hline & $\frac{\text { Temperature: }}{553^{\circ} \mathrm{F}}$ & 2 of 4 \\
\hline & $\frac{\text { Steam Pressure: }}{600 \text { psig }}$ & 2 of 4 \\
\hline $\begin{array}{l}\text { High steamline differential } \\
\text { pressure safety injection } \\
\text { signal }\end{array}$ & $100 \mathrm{psig}$ & 2 of 3 \\
\hline \multirow[t]{3}{*}{ Feedwater isolation signals } & $\begin{array}{l}\text { 1) P-4 AND LO - TAVG } \\
\text { of } 564^{\circ} \mathrm{F}\end{array}$ & 2 of 4 \\
\hline & 2) Safety injection & \\
\hline & $\begin{array}{l}\text { 3) } 75 \text { percent steam } \\
\text { generator level }\end{array}$ & $\begin{array}{l}2 \text { of } 3 \text { on } \\
1 \text { of } 4 \mathrm{~S} / \mathrm{G}\end{array}$ \\
\hline \multirow[t]{4}{*}{ Auxiliary feed pump } & $\begin{array}{l}\text { 1) } 15 \text { percent steam } \\
\text { generator low-low } \\
\text { level }\end{array}$ & $\begin{array}{l}2 \text { of } 3 \text { on } \\
1 \text { of } 4 \mathrm{~S} / \mathrm{G}\end{array}$ \\
\hline & $\begin{array}{l}\text { 2) Trip of both main } \\
\text { feed pumps }\end{array}$ & 2 of 2 \\
\hline & 3) Safety injection & \\
\hline & 4) Loss of normal power & \\
\hline
\end{tabular}


Table A4-4. List of safeguard actuations. (Continued)

\begin{tabular}{llc}
\hline Safeguard actuation & Setpoint & Coincidence \\
\hline $\begin{array}{l}\text { Manual safety injection } \\
\text { signal }\end{array}$ & $\begin{array}{l}\text { Manual switches } \\
(\text { C-02, C-19) }\end{array}$ & 1 of 2 \\
$\begin{array}{l}\text { Manual steam line } \\
\text { isolation signal }\end{array}$ & $\begin{array}{l}\text { Individual pushbuttons } \\
(\text { C-02) }\end{array}$ & 4 of 4 \\
$\begin{array}{l}\text { Manual containment spray } \\
\text { actuation signal }\end{array}$ & $\begin{array}{l}\text { Two switches } \\
\text { (C-19) }\end{array}$ & 2 of 2 \\
$\begin{array}{l}\text { Manual containment } \\
\text { isolation signal }\end{array}$ & Two switches & Simultaneously \\
\hline
\end{tabular}




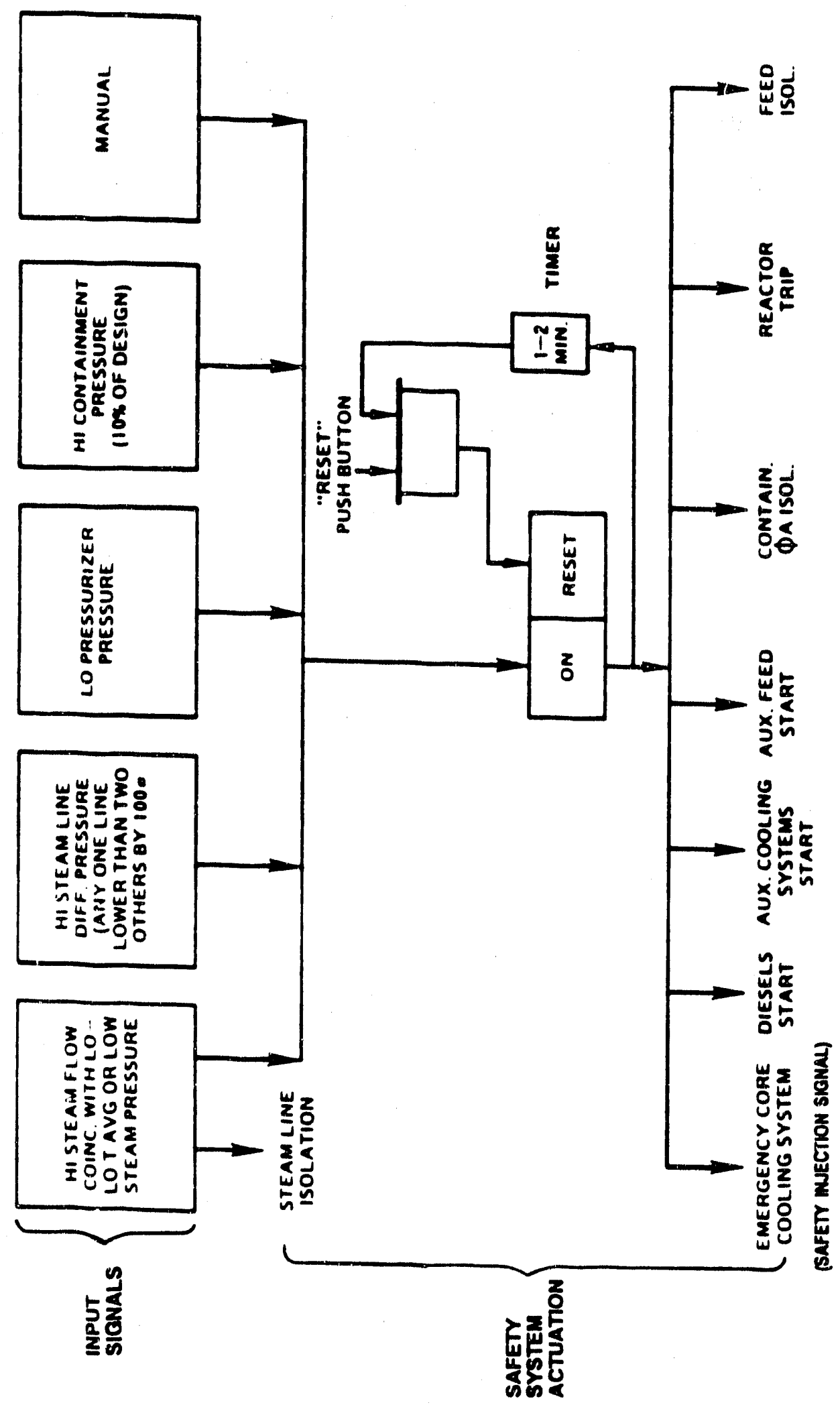

Figure A4-1 Engineered safety features actuation logic. 


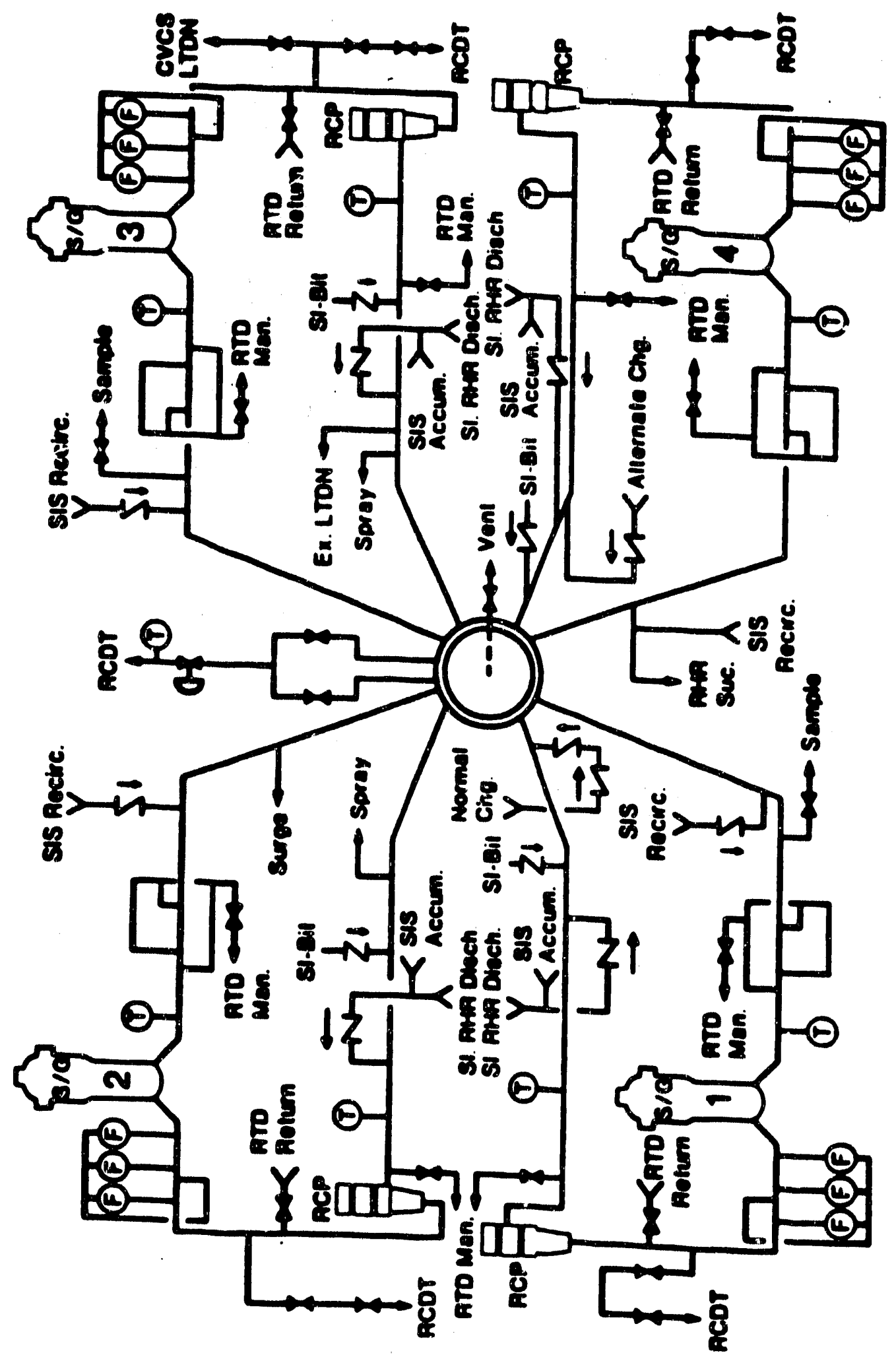

Figure A4-2 Simplified flow diagram - reactor coolant system. 


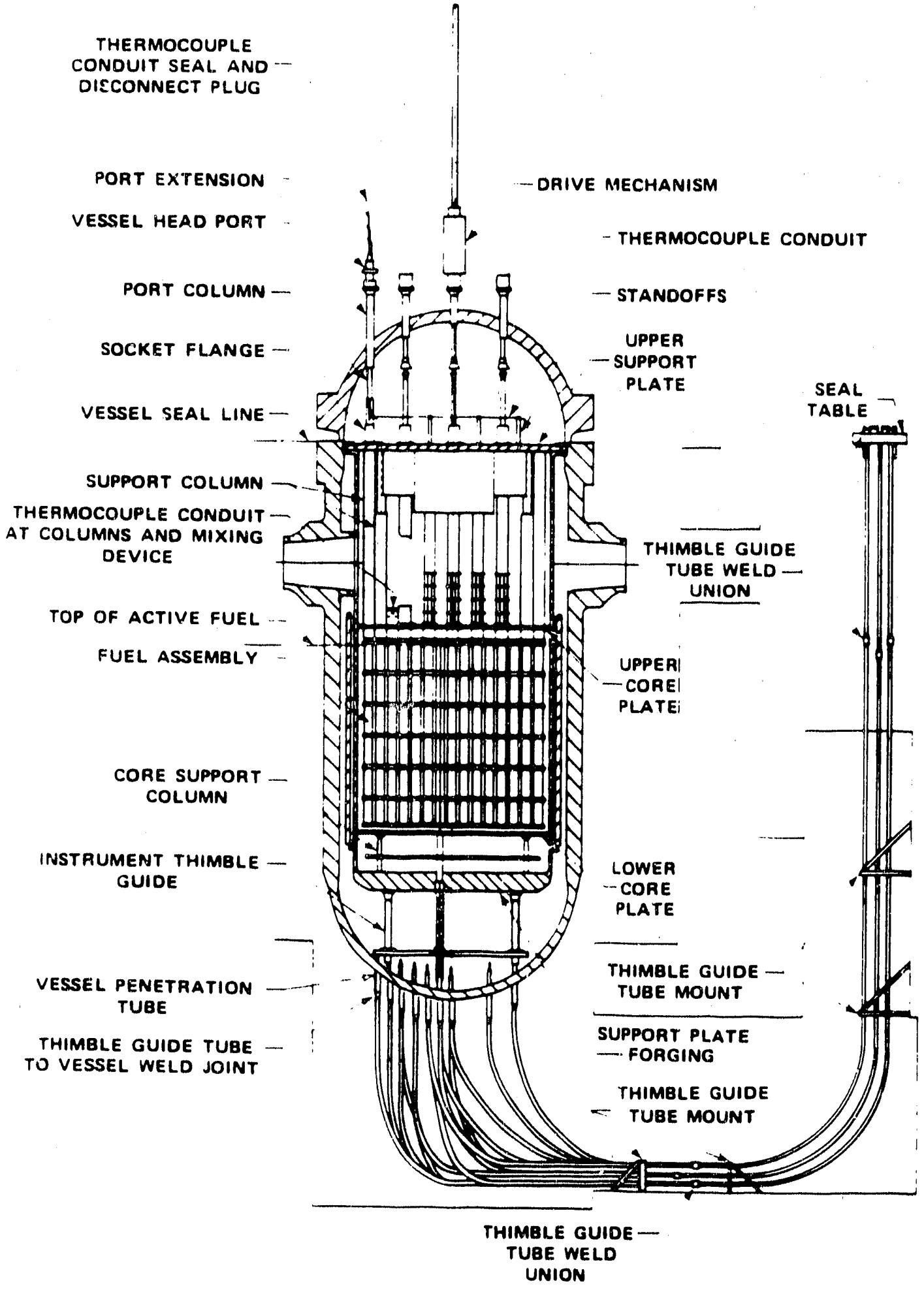

Figure A4-3 Incore instrumentation. 


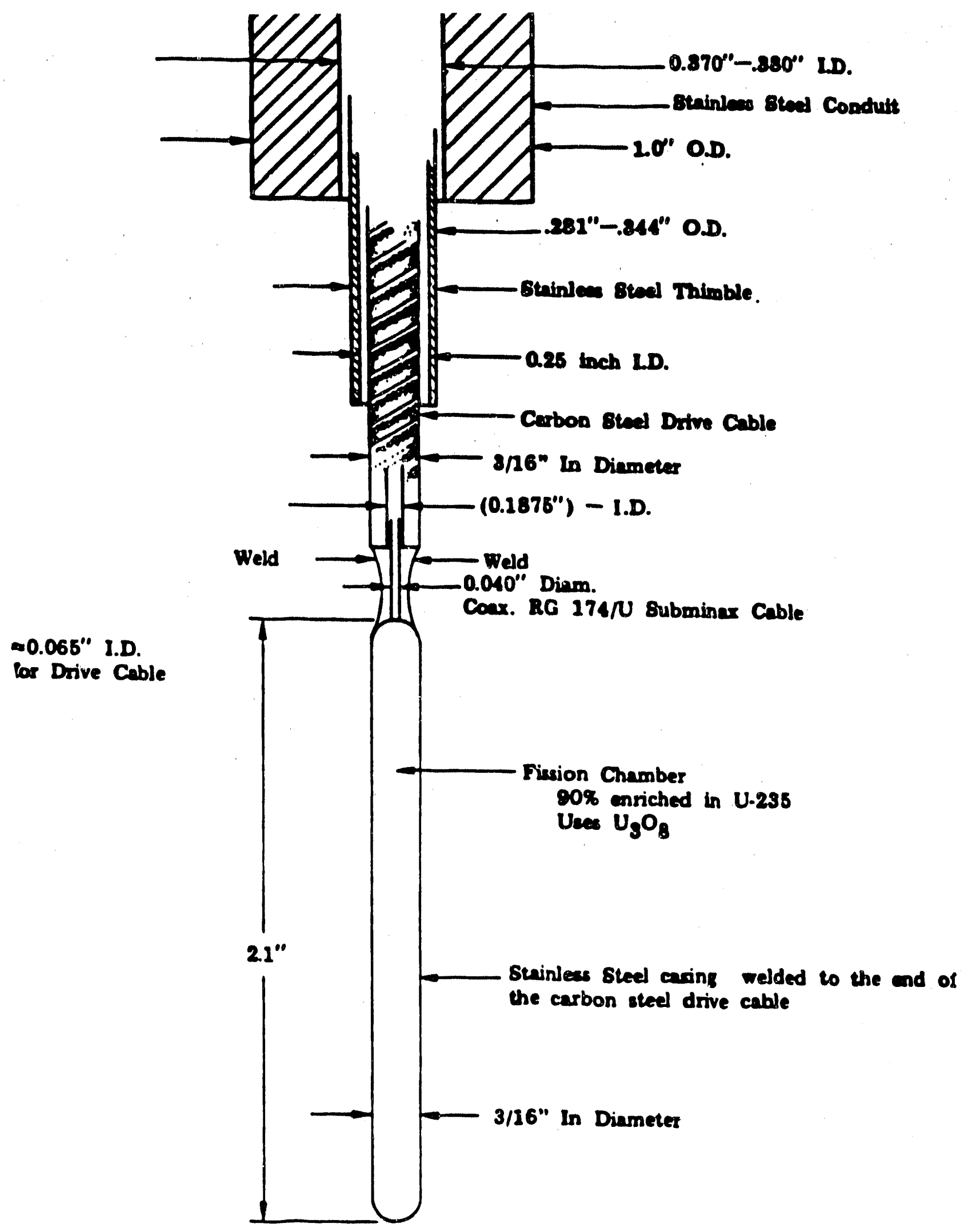

Figure A4-4 Cross section of detector, drive cable, guide thimble, and conduit. 


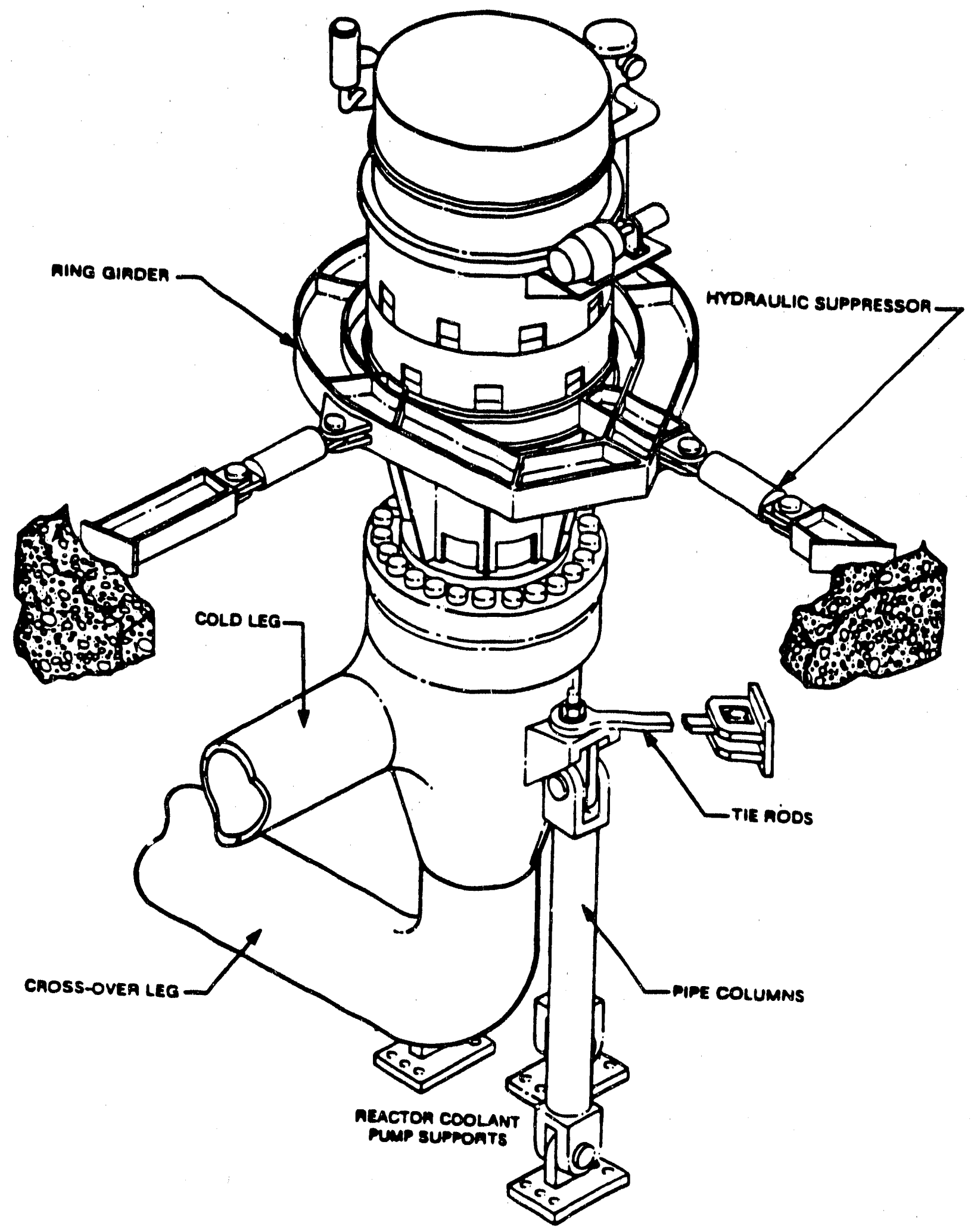

Figure A4-5 Reactor coolant pump and supports. 


\section{APPENDIX 5}

\section{RUPTURE OF THIMBLES AND GUIDE TUBES}

It is indicated in Appendix 4 that there are a total of 58 penetrations for high pressure conduits at the bottom of the reactor pressure vessel. These conduits are made of stainless steel with wall thickness of $0.25 \mathrm{in}$.- fifty of them have a $0.4 \mathrm{in}$. inside diameter (ID) and eight have a $0.6 \mathrm{in}$. ID. The conduits are also called thimble guide tubes because stainless steel thimble tubes with wall thickness of approximately $0.1 \mathrm{in}$. are placed inside these guide tubes. Carbon steel drive cables are insurted inside the thimble tubes. Figure A5-1 shows the thimble guide tubes as a part of the typical arrangement for in-core instrumentation.

During the normal operation, the annular space formed between the outer guide tube and the inner thimble thithe is filled with the reactor coolant. Therefore, both the thimbles and the guide tubes are essentially ihe extensions of the reactor vessel pressure boundary.

A postulated RPV support failure results in a downward movement of the vessel which is normally restricted by the RPV supports. The downward movement could cause the rupture of the thimbles and the guide tubes, resulting in core uncovery due to loss of core coolant. In order to investigate this possibility, a nonlinear structural analysis of the thimble guide tubes with a $0.6 \mathrm{in}$. ID was conducted. The guide tubes with a 0.6 in. ID are stiffer than either the guide tubes with a 0.4 in. ID or the much smaller thimble tubes and, therefore, are more susceptible to rupture.

A thimble guide tube between the bottom of the RPV and the first anchor point is typically composed of a vertical straight section followed subsequently by a 90-degree circular arc and, finally, a horizontal straight section. The lengths of the vertical and the horizontal sections vary from tube to tube but the circular sections have a fixed radius for all guide tubes. In the structural analysis the lengths of the vertical and horizontal sections of the guide tube are conservatively assumed to be zero and the radius of the circular section of the tube is estimated to be 12 feet.

The analysis was accomplished through the use of a general purposed finite element computer code ANSYS developed and maintained by Swanson Analysis Systems Inc. The approximately 18.8 feet arc-shaped guide tube is modeled by eight curved pipe elements. The lower end of the curved pipe is fixed in motion and the upper end is allowed to move only in the vertical direction. This movement was estimated to be about 1.2 in. as reported in Appendix 1 based on a linear structural analysis of the RCL system. The actual movement may be greater but should not exceed 6 in. which represents the spacing between the RCL pipe and the penetration in the concrete shield wall (see Fig. A5-2).

The results of the analysis are summarized by Figs. A5-3 and A5-4 which show, respectively, the equivalent stress vs. equivalent strain curve at the lower fixed end of the guide tube up to a 6-in. vertical displacement applied at the upper end of the tube and the strain-displacement relationship. The analysis indicates that the maximum equivalent strain in the tube occurs at the lower end of the tube and reaches a value of approximately $0.006 \mathrm{in}$./in. if the upper end of the tube moves downward 6 in. Since stain!ess steel can easily be stretched to a strain of 0.2 in./in. or greater without rupture, it is concluded that the vertical movement of the RPV will not cause the rupture of the guide tubes or the much more flexible thimble tubes.

It is known that the wall degradation or thinning were observed on the thimble tubes in Westinghouse nuclear steam supply systems. We were advised by the NRC to consider a $0.005 \mathrm{in}$. wear in both the thimble tubes and the guide tubes in this evaluation. However, in view of the small strain predicted by the structural analysis, it is concluded that the wall thinning will have negligible effect on the rupture of the thimble tubes or the guide tubes. 


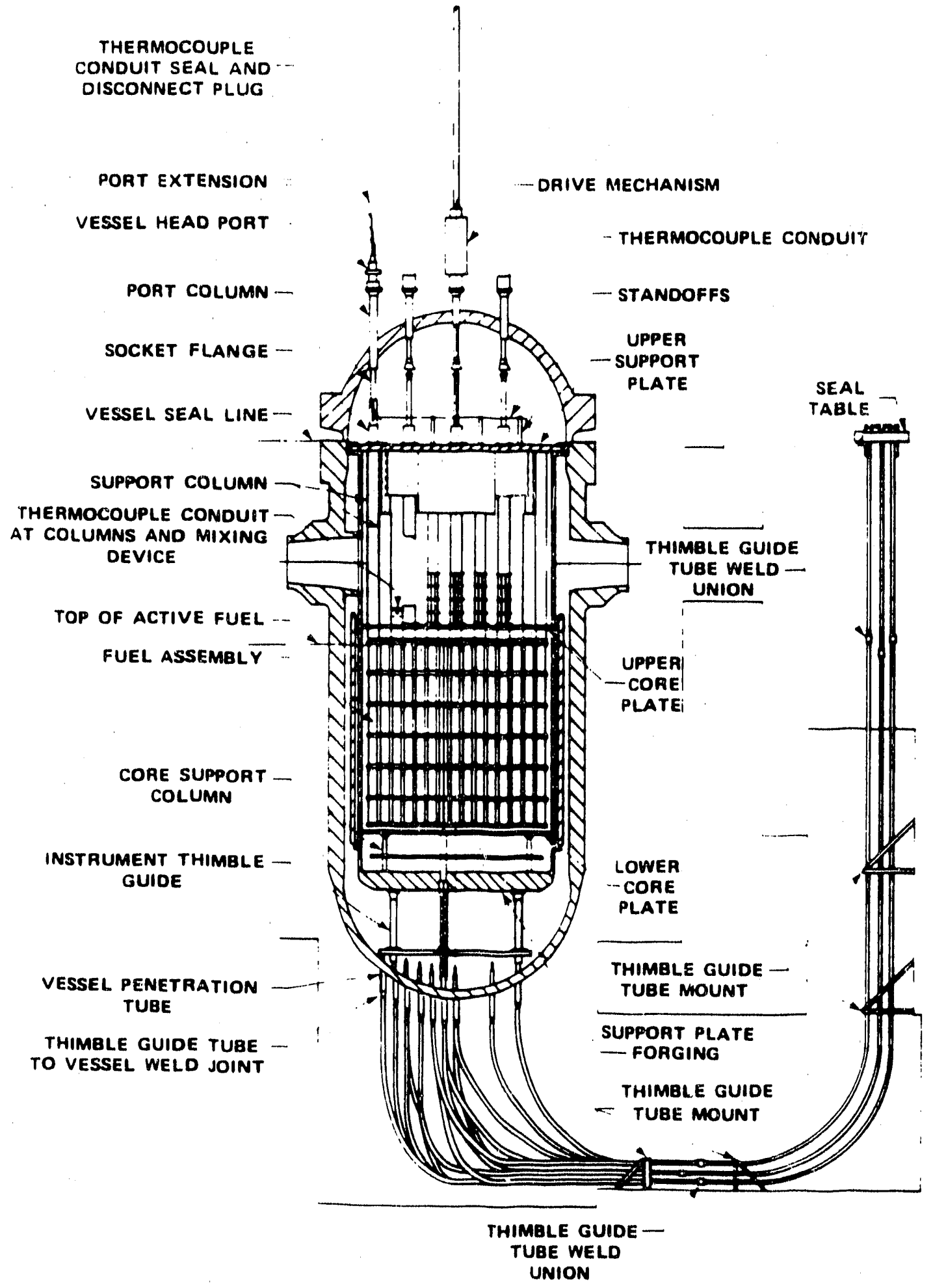

Figure A5-1 Typical arrangement for in-ı., ore instrumentation. 


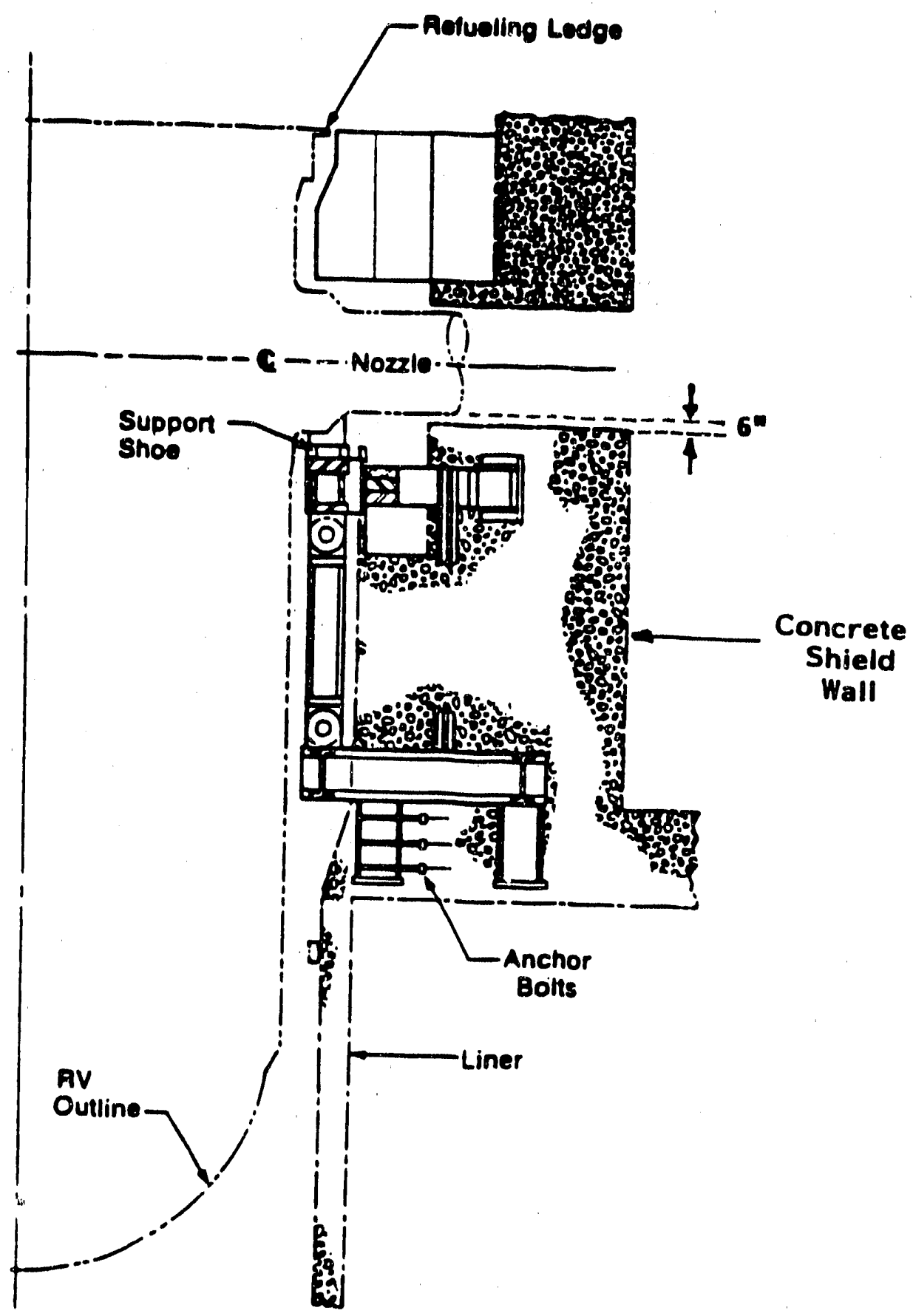

Figure A5-2 Reactor vessel supnnort. 


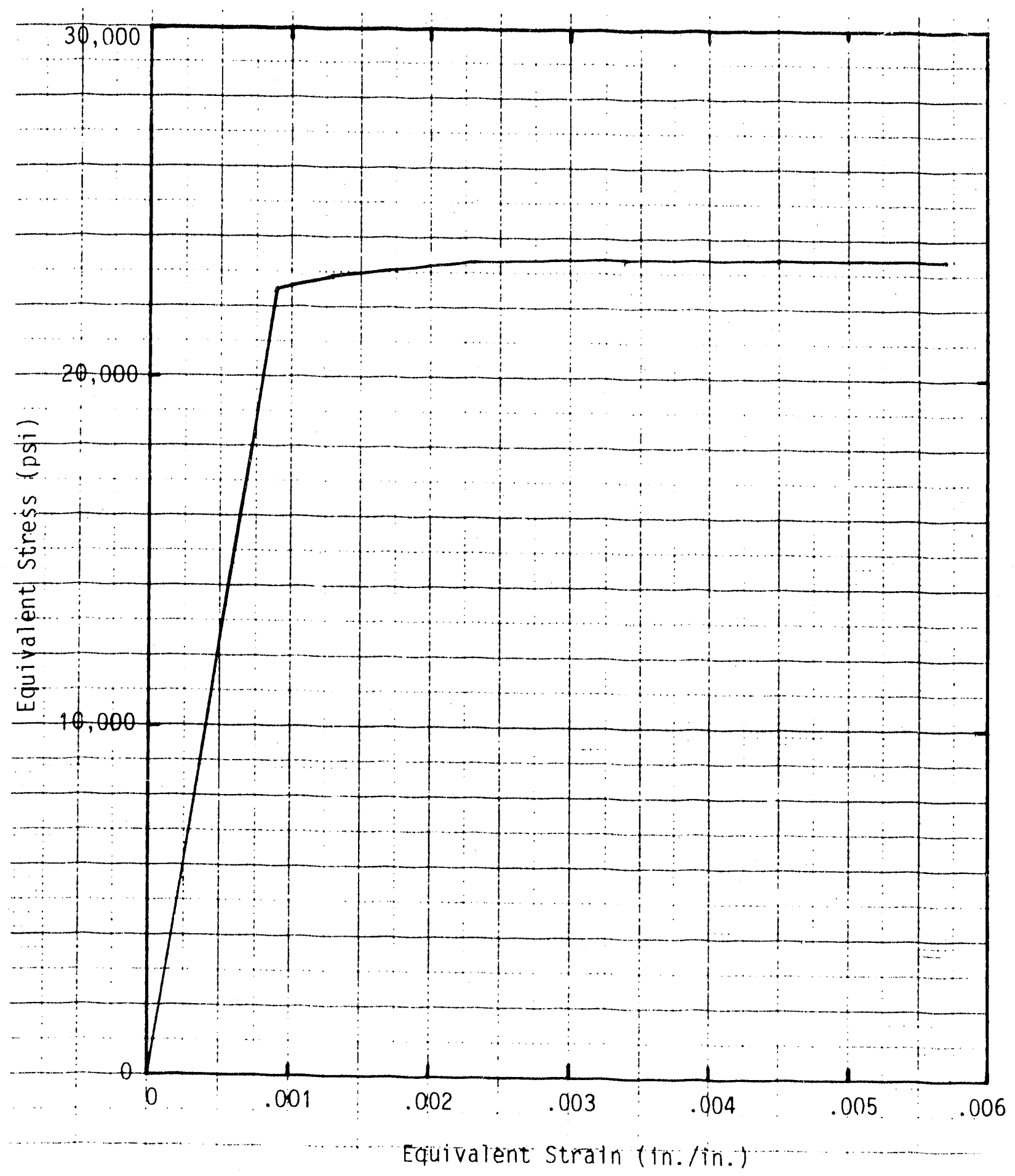

Figurê A5-3 Equivaient stress vs. strain at lower tixed end of the tube. 


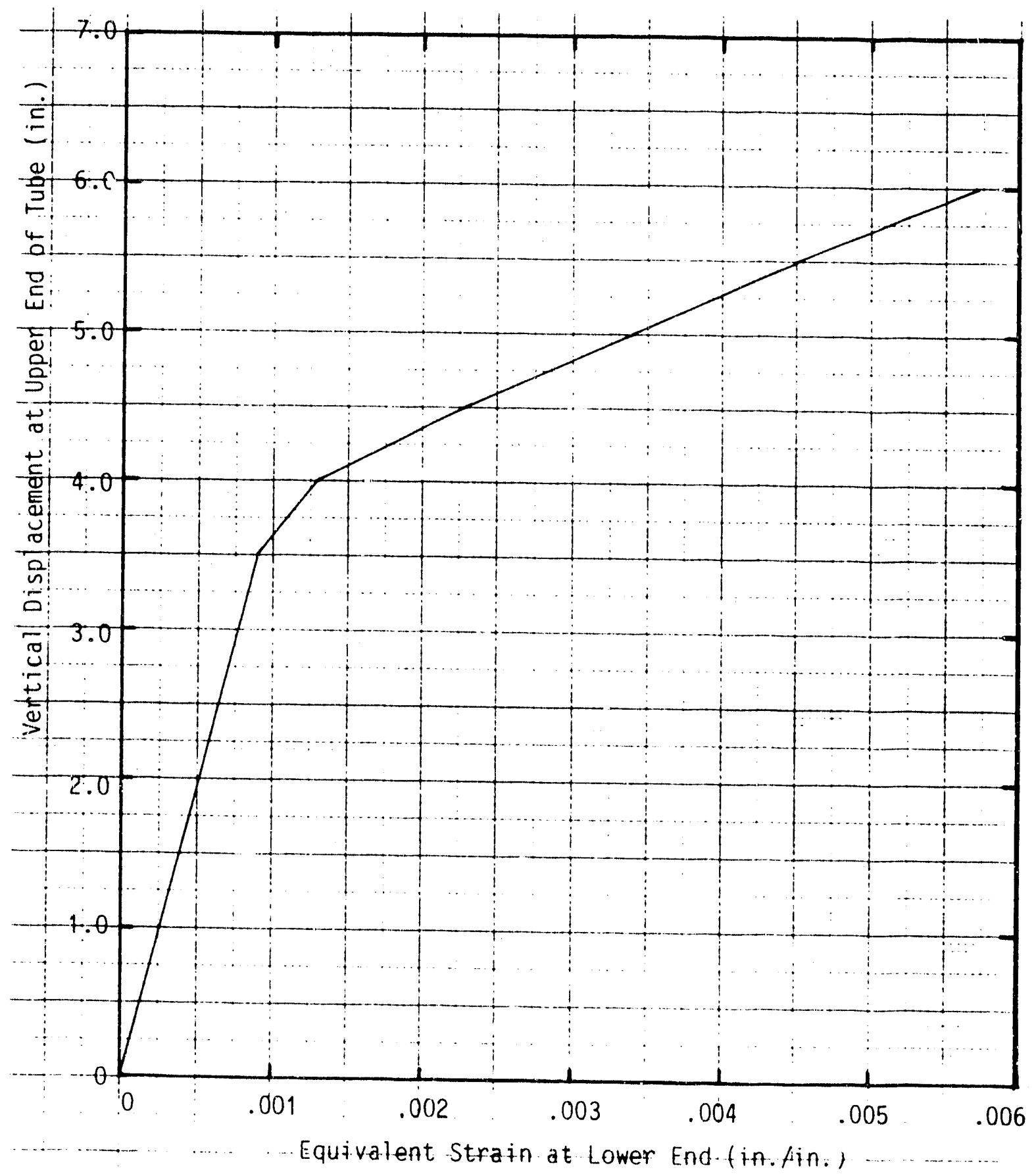

Figure A5-4 Vertical displacement at upper end vs. ea. strain at lower end 


\section{APPENDIX 6 \\ EFFECTS OF PUMP TILTING AND CASING DEFORMATION ON REACTOR COOLANT PUMP FUNCTIONAL ABILITY}

In the case of a hypothetical support failure of the reactor pressure vessel (RPV), although loads will be transferred by the reactor cooling loop (RCL) piping and finally carried by the steam generator (SG) and the reactor coolant pump (RCP) supports as demonstrated by the structural evaluation (Appendix 1), the RPV will undergo movements considerably exceeding those originally restricted by the unfailed RPV supports. The primary movement will be a vertical translation (drop) in the worst case of the RPV support failure, i.e., loss of all four RPV supports. An upperbound of this downward movement is estimated to be 6 in. as reported in Appendix 5.

The downward movement of the vessel could affect the reactor coolant pumps in two ways: (1) to cause the tilting of the pump from its vertical axis and (2) to cause deformation of the pump casing.

Tilting of the pump from its vertical axis could cause excessive vibration and in turn cause shutdown of the pump. In this situation, a reactor trip is required to avert core damage. It is important to reactor operation that the reactor coolant continues to flow due to flywheel coastdown for a short time (approximately 60 seconds) after a reactor trip. In order to provide this flow with pump power already shutdown, each reactor coolant pump is equipped with a flywheel. Thus, the rotating inertia of the pump, motor and flywheel is employed during the coastdown period to continue the reactor coolant flow.

Based on an extrapolation scheme applied to the resuits of the structural analysis described in Appendix 1, the angle of tilting of the reactor coolant pump from its vertical axis is estimated to be about 0.6 degrees for the upperbound drop of $6 \mathrm{in}$. of the reactor pressure vessel. The reactor coolant pumps used at the Trojan nuclear power plant are manufactured by the Westinghouse Electric Corporation. In accordance with a facsimile transmitai from W. W. Hicks, Westinghouse Site Services Manager at Trojan Nuclear Power Plant, to S. C. Lu of LLNL dated June 19, 1990 , Westinghouse's position on the RCP coastdown with one degree tilt is that they think the RCP will coasidown under the proposed tilt, however, they would have to perform some bearing loading calculations and other analysis before they would certify to the NRC that the pump would indeed coast down as required. The transmittal also indicates that similarly designed Westinghouse reactor coolant pump units have been approved for normal operation for an equivalent tilting angle of about 0.32 degree at the Asco Units operated by Asociacion Nuclear Asco in Spain. In conclusion, it is felt that there exist very strong indications that the reactor coolant pump will maintain its coastdown ability in the case of a hypothetical RPV support failure.

In order to investigate the possibility of the binding of pump impellers due to the deformation of the casing, the stresses in the pump casing were calculated from the forces and bending moments obtained from the structural evaluation reported in Appendix 1. The pump casing has an outside diameter of $70 \mathrm{in}$. and thickness of $6 \mathrm{in}$.. The calculated stresses were found to be very small in the pump casing, i.e., approximately $7 \mathrm{ksi}$. Therefore, it is concluded that such small stresses will not cause significant pump casing deformation to bind the impellers. 


\section{APPENDIX 7}

\section{THE ABILITY TO INSERT CONTROL RODS WITH A TITLED REACTOR PRESSURE VESSEL}

In order to investigate the potential consequences of a hypothetical failure of reactor vessel supports of the Trojan nuclear power plant, the Westinghouse Electric Corporation was requested by the Portland General Electric Company, the owner of the Trojan plant, to perform an evaluation of the effects of a postulated 2 degree tilt of the reactor vessel on the ability to insert the control rods. The detail of the evaluation was reported in "Evaluation of the Ability to Insert Control Rods for the Trojan Nuclear Power Plant with a Tilted Reactor Vessel System", prepared by A. I. Fakhri, D. R. Forsyth and C. H. Boyd of Westinghouse Electric Corporation. This appendix is a brief summary of the Westinghouse evaluation.

The control rods rely on the force of gravity to insert the control rods. As long as the sum of the various drag forces acting on the control rod assemblies is less than the downward force of gravity acting on the rods, the rods will fall into the core. The downward moiion of the control rods is resisted to some extent by a number of retarding forces. In particular:

- The dry weight of the control rods is reduced by the buoyancy forc: generated by the water which is displaced by the control rod.

- Mechanical friction exists between the various stationary guideways and the moveable control rods. Pull tests have been performed during fabrication and plant startup to ensure that mechanical friction due to surface condition, tolerance effects and misalignments is not significant. A typical force is on the order of 10 pounds.

- Hydraulic drag forces are generated by the axial flow through the core and the control rod guide tubes. The magnitude of these forces is a function of the fuel assembly hydraulic characteristics and geometry as well as the plant flowrate, temperature and pressure.

- Viscous drag due to skin friction is generated by the motion of the control rods through the water. This force roughly increases with the square of the rod speed.

- There is also an added mass effect due to the fact that as the rod falls, it must displace water out of its path. This effectively increases the mass of the control rod.

Over the years, a number of developmental tests have been performed in order to demonstrate the ability of the control rods to function under adverse conditions. Although no testing has been explicitly performed for the case where the entire drive line is tilted by a few degrees, there has been a substantial amount of testing for conditions which are expected to be much more severe and this testing has confirmed that the slender configuration of the control rods alows them to be inserted even when subjected to substantial bow, geometrical misalignment or dynamic excitation. In addition, the in-plant rod drop time measurements show that a substantial margin exists between actual drop times at Trojan and the time assurned in accident analyses.

If the driveline of the control rod drive is tilted, the control rods will still be driven into the core by the force of gravity but instead of falling vertically, they will fall along a line which is inclined by some angle. This means that the downward force is reduced and is in fact equivalent to increasing the mechanical friction by the same amount. In addition, the movable control rod and the 
stationary guideways can be idealized to now be in contact and a normal force exists. This leads to an additional frictional drag force.

The effect of various assumptions on the friction factor (a) and the tilt angle on the weight reduction, the added friction force and the total equivalent friction force is shown by the following table:

\begin{tabular}{|c|c|c|c|c|c|c|c|}
\hline \multirow{2}{*}{$\begin{array}{c}\text { TILT } \\
\text { ANGLE } \\
\text { (DEGREE) }\end{array}$} & \multirow{2}{*}{$\begin{array}{c}\text { EQ. WEIGHT } \\
\text { REDUCTION } \\
\text { (LB) }\end{array}$} & \multicolumn{3}{|c|}{$\begin{array}{c}\text { ADDED FRICTION FORCE } \\
(\mathrm{LB})\end{array}$} & \multicolumn{3}{|c|}{$\begin{array}{l}\text { TOTAL EQ. FRICTION } \\
\text { (LB) }\end{array}$} \\
\hline & & $a=.4$ & $a=.6$ & $a=1.0$ & $a=.4$ & $a=.6$ & $a=1,0$ \\
\hline $\begin{array}{r}0 \\
2 \\
4 \\
6 \\
8 \\
10 \\
\end{array}$ & $\begin{array}{l}0.00 \\
0.16 \\
0.63 \\
1.42 \\
2.53 \\
3.95 \\
\end{array}$ & $\begin{array}{r}0.00 \\
4.05 \\
8.09 \\
12.13 \\
16.14 \\
20.14 \\
\end{array}$ & $\begin{array}{r}0.00 \\
5.07 \\
12.14 \\
18.19 \\
24.22 \\
30.21 \\
\end{array}$ & $\begin{array}{r}0.00 \\
10.12 \\
20.23 \\
30.31 \\
40.36 \\
50.36 \\
\end{array}$ & $\begin{array}{l}10.00 \\
14.21 \\
18.73 \\
23.55 \\
28.67 \\
34.09\end{array}$ & $\begin{array}{l}10.00 \\
16.23 \\
22.77 \\
29.61 \\
36.75 \\
44.16\end{array}$ & $\begin{array}{l}10.00 \\
20.28 \\
30.68 \\
41.74 \\
52.89 \\
64.31\end{array}$ \\
\hline
\end{tabular}

For the case of a 2-degree tilt of the reactor vessel, even conservatively assuming a friction coefficient of unity, the total increased friction force due to the tilt is only 10.3 pounds. If we assume a 10-degree tilt, the total increased friction force is 54 pounds. Since the normal friction force in the case of zero tilt angle is expected to be on the order of 10 pounds so the totals for the above cases become 20.3 and 64.3 pounds. Each control rods weighs roughly 290 pounds which is much larger than either of these friction forces.

In order to demonstrate that the control rods can be inserted with this additional drag force, calculations were performed to determine the variation in rod drop time with increased friction force. The calculations were performed by using a Westinghouse Proprietary Computer Code, DROP, which integrates the equation of motion for the control rods. A series of calculations was performed for a range of assumed friction drag forces (10 to 100 pounds). The results show that the average (and even worst case) rod can be inserted for this range of drag forces. For the 2degree and even 10-degree cases discussed, the corresponcing 20.3 and 64.3 pound drag forces lead to rod drop times which are much less than the 2.2 second drop limit for Trojan for the average and even the slowest rods. Thus this basic evaluation leads to the conclusion that a 2degree tilt dces not impact the ability to insert the control rods.

As a parallel effort, a direct investigation of the effect of small ( 0 to 6 degrees) tilts was performed by modifying the previously discussed drop time model to directly evaluate the rod drop time corresponding to a particular tilt. The results of this evaluation confin $\mathrm{m}$ the results obtained in the previous parametric study. For a tilt of 2 degrees, it is concluded that there is no adverse impact on the ability to insert the control rods for the Trojan plant. 


\section{APPENDIX 8}

\section{STRUCTURAL EVALUATION OF THE SAFETY INJECTION LINES ON THE TROJAN REACTOR COOLANT LOOP}

\section{Introduction}

An effects assessment of the failure of reactor pressure vessel (RPV) supports in the Trojan Reactor Cooling Loop (RCL) has determined that the rupture of safery injection lines which atiach to the cold legs may render the emergency core coolant system inoperable (See Appendix 4). The injection lines are critical for safety because they provide coolant to the reactor core when the piping experiences a loss-of-coolant accident. The analysis of RPV support failure was part of an effort sponsored by the Nuclear Regulatory Commission in which the Trojan Nuclear Power Plant was selected for a pilot study of the effects of irradiation embrittlement on RPV supports. By modifying the finite element model of the Trojan plant that is described in Appendix 1, a structural evaluation was performed to investigate the behavior of the injection lines with RPV support failure. This report details the modifications to the Trojan model, describes major results from the analyses, and discusses the conclusions reached by the analyses.

\section{Analysis}

As detailed in Appendix 1, upon the postulated failure of RPV supports due to irradiation embrittlement effects, the finite element analyses predict that the RCL piping will transfer loads to the SG and RCP supports. These analyses did not account for any RPV support from branch lines which attach to the hot, cross-over, and cold legs. If the loads are successfully transferred by the $\mathrm{RCL}$ piping, then the branch lines, for example the safety injection lines, will carry some of these loads. In order to predict the behavior of the injection lines under these additional loads, the Trojan model used in Appendix 1 must be modified.

Figure A8-1, taken from Trojan piping drawing RC-2501R-2-2, shows the attachment of the injection lines to the cold legs. The lines are stainless steel ASTM A375-TP316 and have an outer diameter (OD) of 10.75 in., a thickness of 1.0 in., and a weight per length of 104.13 pounds per foot. As displayed in Fig. A8-1 and in Trojan piping drawing RC-2501R-2-1, the lines are fitted to the cold leg by a nozzle which is 1.0775 feet long and they are initially parallel to the RPV centerline. After a $15 \mathrm{in}$. elbow, the lines are perpendicular to the RPV centerline. The first injection line whip restraint is 3.875 feet from the 15 in. elbow.

The injection lines are modeled with piping elements. The nozzle is also modeled with piping elements with the same stiffness as the injection lines because little detailed information is available about the nozzle. The connection between the cold leg and the injection lines is stiffer than the $10.75 \mathrm{in}$. OD injection line piping directly attaching to the $32.14 \mathrm{OD}$ in. cold leg piping, but this direct type of connection is consistent with the attachment between the 14 in. OD pressurizer line and the $33.9 \mathrm{in.}$ OD hot leg in the model described in Appendix 1.

It is conservatively assumed that the safety injection line is supported at the first pipe whip restraint which is modeled with fixed displacements and rotations except in the axial direction. This is conservative because the restraints have 3/4 in. gaps around the pipe cross-section which allow for significant motion. By assuming fixed motion, higher stresses are obrained at the piping elements near the restraints. Figure A8-2 shows the RCL model with the injection lines, while Fig. A8-3 displays a close-up view of an injectionn linie. The resi uf itie injection line beyond the rirst pipe 
restraint is not included in the finite element model due to the fixed support condition at the first pipe whip restraint. This condition makes the modeled section of the injection line the stiffest part.

With the modifications of the Trojan model, structural analyses predict the forces, moments, and stresses in the Trojan RCL. The structural evaluation follows the same guidelines considered in Appendix 1. Since it was confirmed in Appendix 1 that the safe shutdown earthquake (SSE) load combination is more damaging for plants (such as Trojan) in high seismic zones, the injection lines are studied with the same load combination. Similar to analyses in Appendix 1, the structural evaluation is of the worst-case condition in which all four RPV supports have failed.

Table A8-1 lists the first 30 modes of the free vibration analysis as compared to the first 30 modes of the Trojan plant without injection lines. In addition, the associated damping factors for the mode shapes are given in Table A8-1. As expected, the injection lines provide additional support to the RCL which makes the system stiffer. The slightly stiffer system has hi RCL model without the injection lines because it takes more energy to excite the stiffer system. Even though use of only 30 modes does not capture all of the mass participation in the horizontal directions, the dominant structural response in the vertical direction is effectively determined by the 30 modes. Almost all of the vertical mass $(99.75 \%)$ participates in the first 30 modes.

As detailed in Appendix 1 the first type of loading applied to the Trojan RCL is the SSE ground motion with the response spectrum method. The SSE load combination also requires dead weight loading which is a static analysis. With the predicted structural response from the SSE and dead weight analyses, the Trojan injection lines are reviewed with the applicable ASME criteria.

\section{Results}

The main safety concern for the safety injection lines is that they may rupture due to the RCL piping motion resulting from failure of the RPV supports. As described in Appendix 1 the RCL piping successfully transfers the RPV support loads to other RCL components so the injection lines become part of the load path at their attachments to the cold legs.

Appendix F and Subsection NB of the ASME Boiler and Pressure Vessel Code provide rules for limiting the consequences of specified events. These rules do not allow the pressure-retaining boundary to support stresses which are higher than the allowable stress limit. For piping, the following equation must be satisfied using a stress limit of $3 * \mathrm{~S}_{\mathrm{m}}$ :

$$
\begin{aligned}
& \left(B_{1} *\left(P * D_{o} / 2 * t\right)\right)+\left(B_{2} *\left(D_{0} * M_{i} / 2 * I\right)\right)<3 * S_{m} \\
& \text { where } \quad \mathrm{B}_{1}, \mathrm{~B}_{2} \quad \text { - primary stress indices with values of } 0.5 \text { and } 1.0 \\
& \text { P - pressure } \\
& \text { Do - outside pipe diameter } \\
& \text { t - pipe wall thickness } \\
& \text { I - moment of inertia of the pipe section } \\
& M_{i} \quad-\text { resulting moment due to a combination of mechanical loads } \\
& \mathrm{S}_{\mathrm{m}} \quad \text { - allowable stress intensity value }
\end{aligned}
$$

As expected, Table A8-2 shows that the critical piping location in the injection lines is at the pipe whip restraint. Since the four loops have nearly symmetrical results, only loop 2 results are listed in Tabic A $8-2$. Similar to the anaiyses in Appendix $i$ the dead weight load case produces the 
largest bending moments in the injection lines. The results of the ASME failure criteria are given in Table A8-3. Even though the predicted stress levels are about $93 \%$ of the allowable limit, the injection lines do not violate the pressure-retaining boundary under RPV support failure. The actual stresses in the lines are definitely lower than those in Table A8-3 because the analyses detailed in this report have conservative assumptions for the pipe whip restraints.

By including the injection lines and their supports, the structural behavior of the Trojan RCL changed. As mentioned earlier, the Trojan model with the injection lines has slightly higher modes than the less stiff model without the lines. Comparison of the results given in Appendix 1 are made between the two models. Both the predicted SG vertical support forces and the moments in RCL piping at RPV outlet nozzles due to SSE loading are lower in the model with the injection lines than those in the model without the lines. The Trojan model without the support from all the non-branch lines, like the safety injection lines, is the most conservative one because it predicts the highest loads. Without the additional support from the non-branch lines, the RCL branch components must support more of the forces and moments.

\section{Conclusion}

Given a postulated failure of RPV supports due to irradiation embrittlement effects, the finite element analyses predict that the safety injection lines will not fail. Results of structural evaluations demonstrate that the ASME Code Appendix F requirements are satisfied by the Trojan injection lines for load combination 1 as listed in Table A8-3. 
Table A8-1. Frequencies of first 30 modes, Trojan RCL Model.

\begin{tabular}{lccc}
\hline & \multicolumn{2}{c}{ Erequency $($ Hertz $)$} & \\
Mode & No injection lines & Injection lines & Damping \\
\hline 1 & & & \\
2 & 3.776 & 3.810 & $5.0 \%$ \\
3 & 4.304 & 4.363 & $5.0 \%$ \\
4 & 5.974 & 5.986 & $5.0 \%$ \\
5 & 7.101 & 7.101 & $5.0 \%$ \\
6 & 7.202 & 7.203 & $5.0 \%$ \\
7 & 7.283 & 7.283 & $5.0 \%$ \\
8 & 7.302 & 7.302 & $5.0 \%$ \\
9 & 9.087 & 9.090 & $5.0 \%$ \\
10 & 9.098 & 9.105 & $5.0 \%$ \\
11 & 9.099 & 9.108 & $5.0 \%$ \\
12 & 9.112 & 9.120 & $5.0 \%$ \\
13 & 9.198 & 9.270 & $5.0 \%$ \\
14 & 9.298 & 9.303 & $5.0 \%$ \\
15 & 9.340 & 9.396 & $5.0 \%$ \\
16 & 9.385 & 9.437 & $5.0 \%$ \\
17 & 9.449 & 9.485 & $5.0 \%$ \\
18 & 9.644 & 9.651 & $5.0 \%$ \\
19 & 9.657 & 9.665 & $5.0 \%$ \\
20 & 9.692 & 9.707 & $4.9 \%$ \\
21 & 10.443 & 10.473 & $4.1 \%$ \\
22 & 12.911 & 12.927 & $3.9 \%$ \\
23 & 13.519 & 13.537 & $3.8 \%$ \\
24 & 14.018 & 14.019 & $3.8 \%$ \\
25 & 14.026 & 14.026 & $3.8 \%$ \\
26 & 14.043 & 14.043 & $2.8 \%$ \\
27 & 14.074 & 14.075 & $2.0 \%$ \\
28 & 20.466 & 20.612 & $2.0 \%$ \\
29 & 20.470 & 20.617 & $2.0 \%$ \\
30 & 20.474 & 20.621 & \\
\hline
\end{tabular}


Table A8-2. Resultant moments in the injection line piping of Loop 2.

\begin{tabular}{llcc}
\hline & & \multicolumn{2}{c}{ Resultant Moments (kips - in.) } \\
Pipe & Loading & i- end & j-end \\
\hline 225 & SSE & 275.8 & 189.5 \\
225 & DW & 613.1 & 482.1 \\
226 & SSE & 189.5 & 164.4 \\
226 & DW & 482.1 & 448.8 \\
227 & SSE & 164.4 & 101.6 \\
227 & DW & 448.8 & 264.4 \\
228 & SSE & 101.6 & 57.9 \\
228 & DW & 264.4 & 175.7 \\
229 & SSE & 57.9 & 161.3 \\
229 & DW & 175.7 & 485.7 \\
230 & SSE & 161.3 & 438.3 \\
230 & DW & 485.7 & 1294.5 \\
231 & SSE & 438.3 & 716.3 \\
231 & DW & 1294.5 & 2106.5 \\
& & & \\
\hline
\end{tabular}

Pipe $=$ Piping element in Trojan model

- Pipe count starts from the cold leg attachment point ( $\mathrm{i}$ - end of 1 ) and proceeds to the pipe whip :estraint $(j-$ end of 7$)$.

- Elements 3 and 4 are the bend pipe.

DW $=$ Dead weight

SSE $=$ Safe shutdown earthquake

Resultant Moment (Mi) is calculated from the following formula:

$$
\begin{aligned}
\mathrm{Mi}^{2}= & \mathrm{My}^{2}+\mathrm{Mz}^{2} \\
& \mathrm{My} \text { - moment in y-direction } \\
& \mathrm{Mz} \text { - moment in z-direction }
\end{aligned}
$$


Table A8-3. ASME code evaluation.

\begin{tabular}{cccccc}
\hline \multirow{2}{*}{ Load Comb. } & \multicolumn{5}{c}{ ASME Evaluation Load (ksi.) } \\
& Loop 1 & Loop 2 & Loop 3 & Loop 4 & 3S $_{\mathbf{m}}$ (ksi.) \\
& PE 252 & PE 231 & PE 238 & PE 245 & \\
1 & 47.31 & 47.26 & 47.31 & 47.33 & 51.0 \\
\hline
\end{tabular}

Load Comb. = load combination

Load Comb. 1 = pressure, dead weight, and SSE

$\mathrm{PE}=$ pipe element in Trojan model

$\mathrm{S}_{\mathrm{m}}=\mathrm{ASME}$ stress intensity (NUREG/CR-5506) 


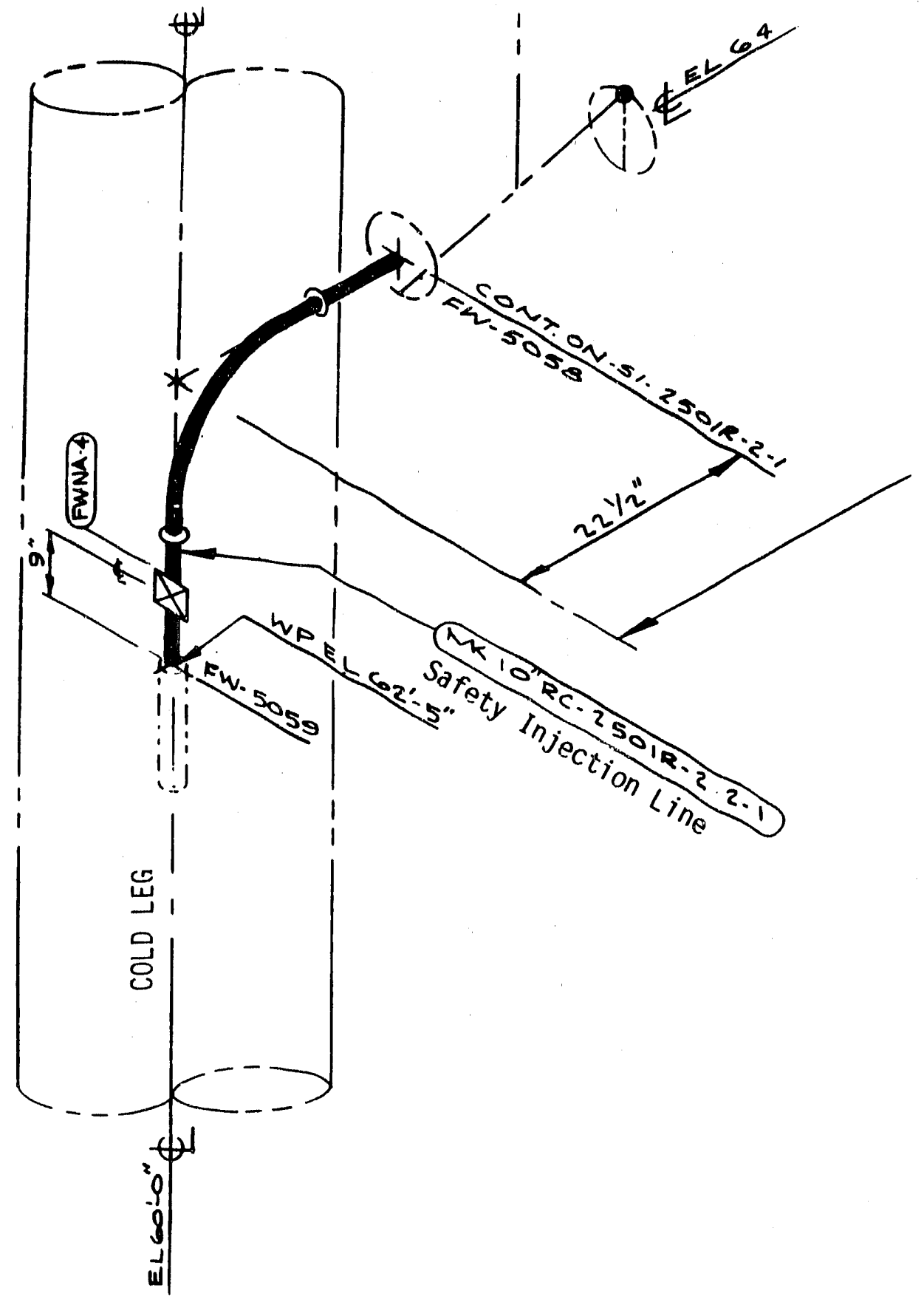

Figure A8-1 Safety injectiuon line attached to the cold leg. 


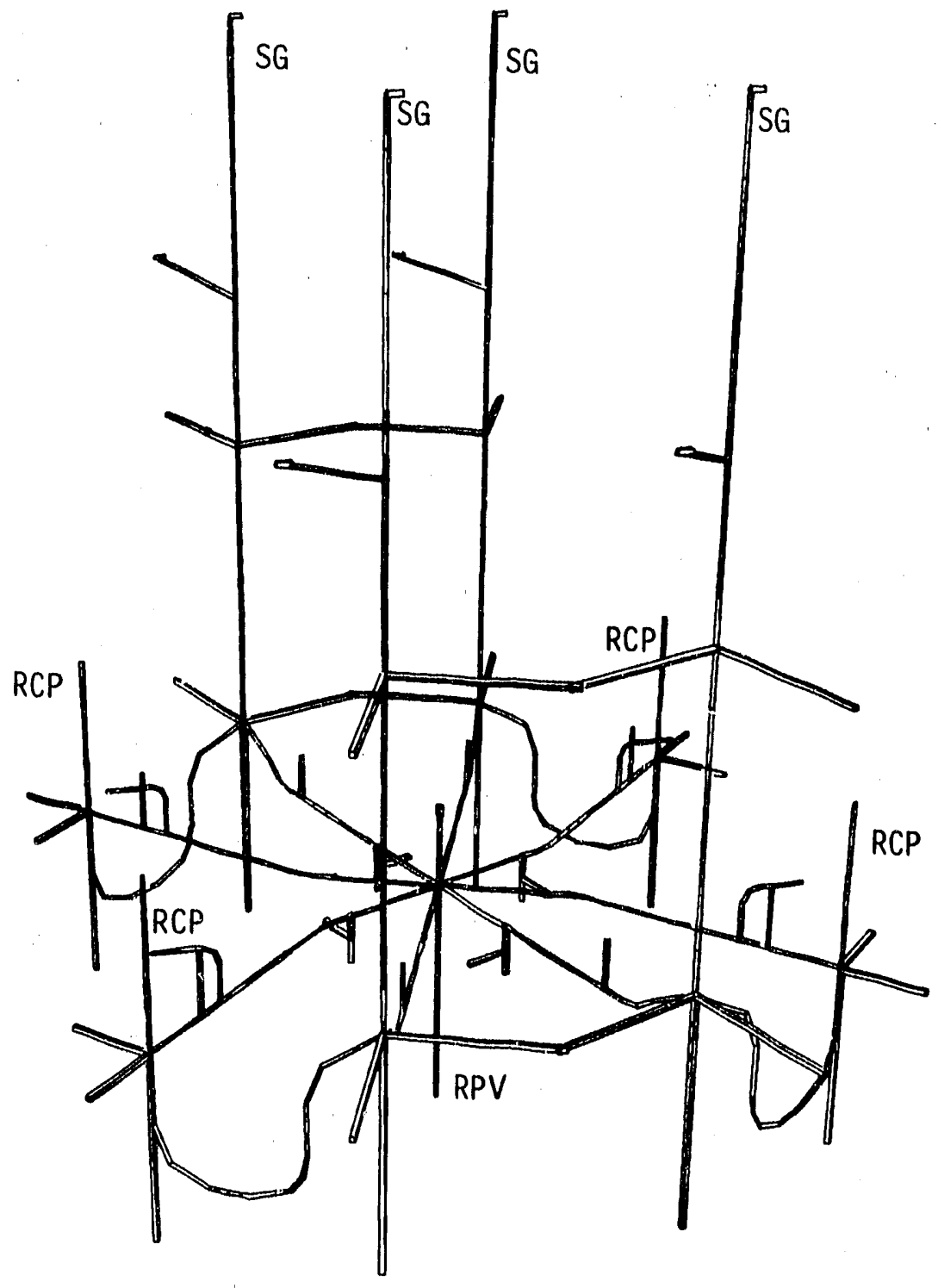

Figure A8-2 RCL model with safety injection lines. 


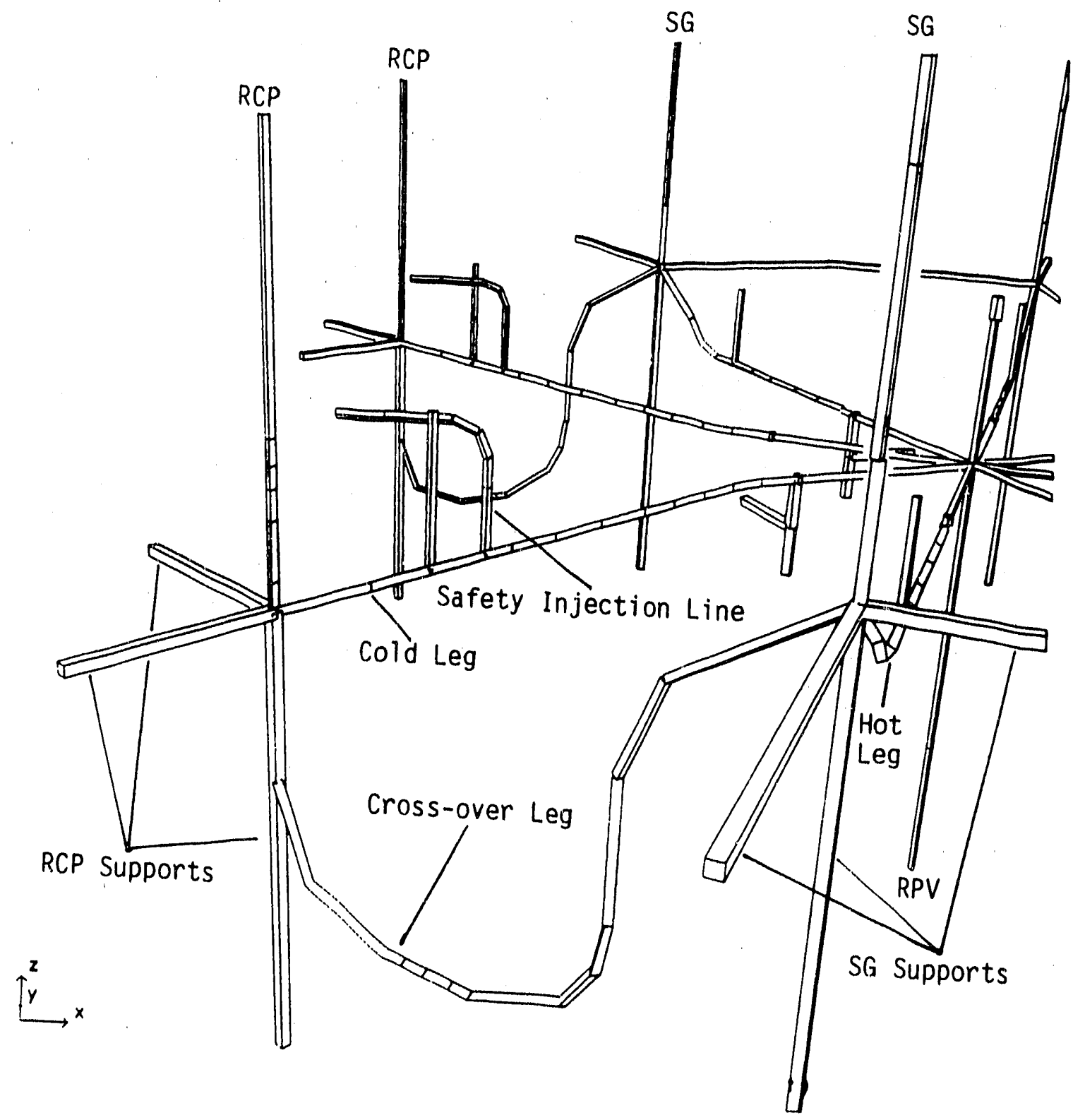

Figure A8-3 Close-up of the RCL model with safety injection lines. 


\begin{abstract}
Attachment
Preliminary Structural Evaluation of Trojan

RCL subject to postulated RPV support failure
\end{abstract}




\begin{abstract}
This report describes a preliminary structural evaluation made to determine whether the reactor coolant loop ( $R C L)$ piping of the Trojan nuclear power plant is capable of transferring the loads normally carried by the reactor pressure vessel (RPV) supports to other component supports in the RCL system if the RPV supports should fail, say from radiation damage. For the evaluation, we use the computer model of the RCL system of Unit 1 of the Zion nuclear power plant because it is readily available; the RCL systems of these two plants closely resemble each other. As a bounding case in the evaluation we postulate that all four RPV supports have failed. Two load combinations are evaluated: (1) the combination of dead weight, operating pressure, and the safe-shutdown earthquake, and (2) the combination of dead weight, operating pressure, and a loss-of-coolant accident. Both load combinations are classified as Level D Service Linvits in accordance with the ASME Boiler and $\mathrm{P}$ essure Vessel $\mathrm{C}$-je. Static and dynamic linear elastic analyses are conducted to comply with rules pecified by Subsection NB in conjunction with Appendix F, Division 1, Section III of the ASME Code. Results of this preliminary evaluation indicate that ASME Code Appendix $\mathrm{F}$ requirements are satisfied by each of the load combinations considered in the analysis, leading to the conclusion that the Trojan RCL piping is capable of transferring the RPV support loads to the steam generator and reactor coolant pump supports.
\end{abstract}


TABLE OF CONTENTS

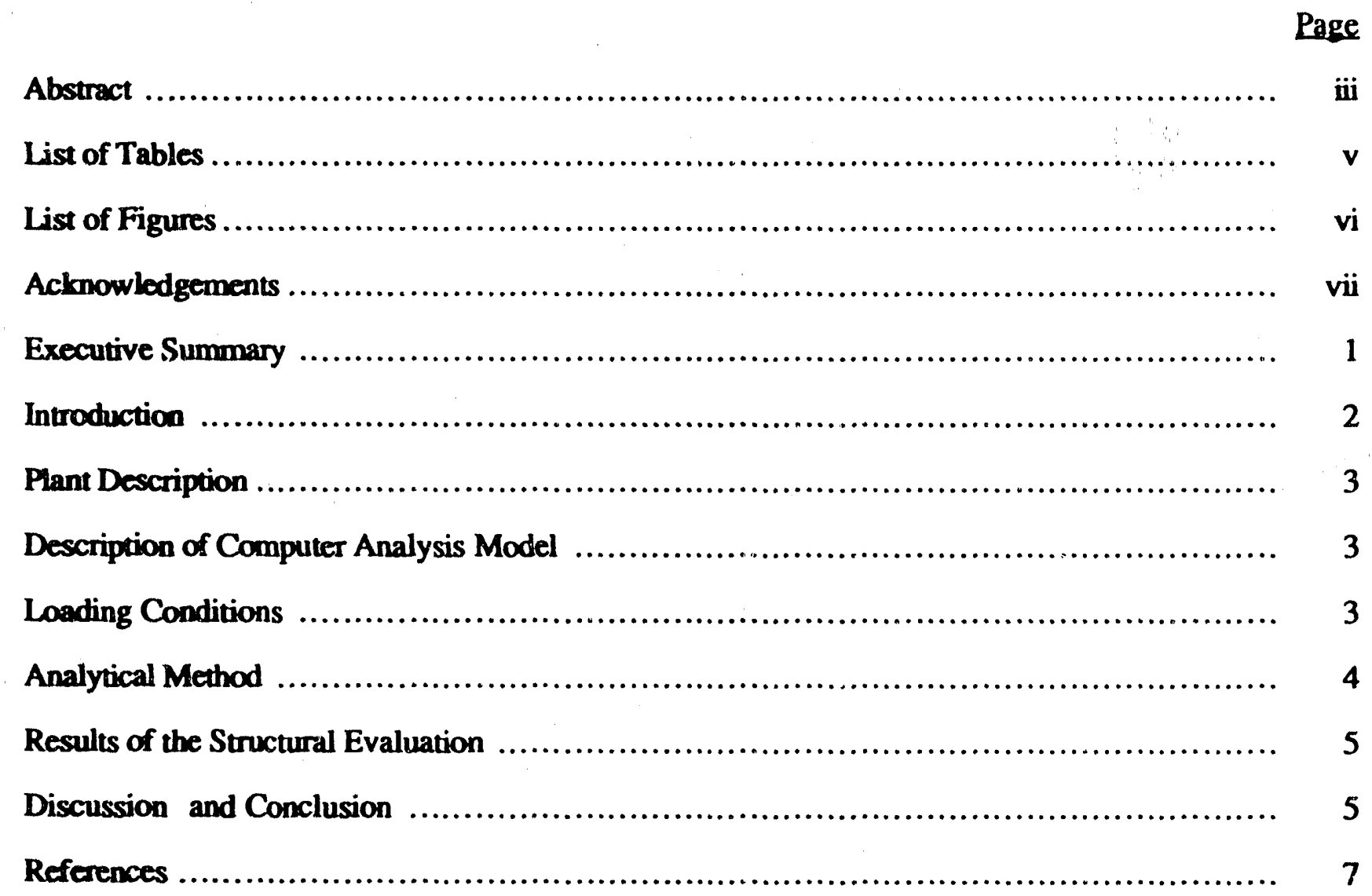




\section{LIST OF TABLES}

Page

Table 1 Comparison of Trojan and Zion RCL Systems .................................... 8

Table 2 Frequencies of First 30 Modes of Zion RCL Model ..................................

Table 3 Vertical Fonces in RPV Supports ............................................... 10

Table 4 Vertical Displacements at RPV Outlet Nozzles ...................................... 11

Table 5 Vertical Forces in SG Supports ................................................ 12

Table 6 Overturning Moments in SG Supports ........................................... 13

Table 7 Bending Stresses in RCL Piping at RPV Outlet Nozzles ............................ 14

Table 8 ASME Code Equation (9) Evaluation .............................................. 15 


\section{LIST OF FIGURES}

Page

Figure 1 A Typical Westinghouse PWR NSSS ...................................... 16

Figure 2 A Plan View of Zion 1 NSSS ........................................... 17

Figure 3 Typ $₫$ 4G PWR Reactor Vessel Support .......................................... 18

Figure 4 Type 4A PWR Reactor Vessel Support ......................................... 19

Figure 5 Zion 1 Reactor Coolant Loop Model ............................................ 20

Figure 6 Zion 1 RCL Floor Response Spectra ............................................ 21

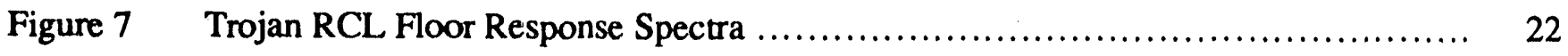

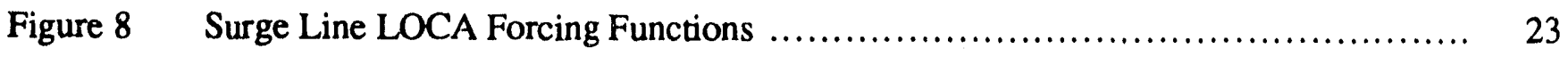

Figure 9 RCL Model First Vibration Mode (No RPV Supports) ............................ 24

Figure 10 RCL Model Second Vibration Mode (No RPV Supports) ....................... 25

Figure 11 RCL Model Third Vibration Mode (No RPV Supports) ....................... 26

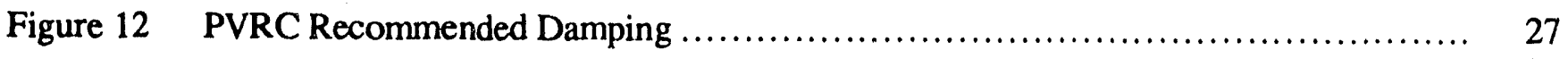




\section{ACKNOWLEDGMENTS}

The author wishes to acknowledge the Office of Nuclear Regulatory Research, U.S. Nuclear Regulatory Commission (NRC), for providing the funding, Dr. John O'Brien, the NRC Project Manager, for his technicai direction, and Dr. John Stevenson of Stevenson and Associates and Mr. Garry Holman of LLNL for providing technical input to this work. 


\section{EXECUTIVE SUMMARY}

In order to evaluate the consequences of potential failure of reactor pressure vessel (RPV) supports in pressurized water reactor nullear power plants due to effects of irradiation embrittlement, the Nuclear Regulatory Commission ras selected the Trojan nuclear power plant for a pilot study. The evaluation starts with the structimo integrity assessment of the reactor coolant loop (RCL) system to de termine whether the RCL piping is capable of transferring (or redistributing) RPV support loads to other component supports in the RCL system. Because of its close resemblance to the Trojan RCL design and because there is a readily available computer model for it, the RCL system of Unit 1 of Zion nuclear plant has been analyzed to demonstrate the methodology as well ass to obtain preliminary results regarding the structural evaluation.

As a bounding case in the evaluation, it is postulated that all four RPV supports have initially failed. Two load combinations are evaluated: (1) the combination of dead weight, operating pressure, and the safe shutdown earthquake, and (2) the combination of dead weight, pressure, and a loss-of-coolant-accident. Both load combinations are classified as Level D Service Limits in accordance with the ASME Boiler and Pressure Vessel Code, and rules contained in Subsection NB in conjunction with Appendix F, Division 1, Section III of the ASME Code, which permit linear elastic analyses, are followed by the evaluation.

Results of the evaluation indicate that the ASME Code Appendix F requirements are satisfied by both load combinations considered in the analysis, leading to the conclusion that the Zion RCL piping is capable of transferring RPV loads to steam generator (SG) and reactor coolant pump (RCP) supports. The same conclusion also appears to be applicable to the Trojan RCL design because (1) the two RCL systems are very similar and (2) both Zion and Trojan seismic input motions are considered by the analysis. It is cautioned that RPV movements may be considerably underestimated because of the linear elastic nature of the analysis. Additionally, the ability of SG and RCP supports to carry the additional loads transferred by the RCL piping has not been evaluated by the current study. However, it is felt that these supports should have sufficient design margins to accommodate the additional loads. 


\subsection{INTRODUCTION}

The reactor pressure vessel (RPV) support embrittlement problem associated with pressurized water reactors (PWRs) in nuclear power plants was identified by the Nuclear Regulatory Commission (NRC) in 1978, designated as a candidate Unresolved Safety Issue in 1981, but assigned a LOW priority in 1983. Based on data and analyses developed by the Oak Ridge National Laboratory (ORNL) in April 1988 [1], the NRC staff concluded that the potential for RPV support embrittlement from neutron radiation damage could be greater than predictions based on pre- 1988 data. A reevaluation of the issue conducted by the NRC finally concluded in December 1988 that this issue should be given a HIGH priority ranking.

The potential safety significance of this problem is that low-temperature irradiation of structural materials can result in RPV support structure embrittlement, increasing the potential for unstable propagation of flaws that might exist in the materials. The radiation-induced embrittlement may result in failure of the RPV supports and consequent movement of the reactor vessel, given the occurrence of a transient stress or shock such as could be experienced in a loss-of-coolant- accident (LOCA) or severe earthquake. A number of actions are currently funded by the NRC to resolve this generic safety issue. One of the actions is to conduct a consequence evaluation of embrittled RPV support failure.

The objective of the consequence evaluation of embrittled RPV support failure is to provide a sound technical basis for determining whether the failure of RPV supports could prevent safe shutdown or lead to unacceptable consequences during or following the design basis earthquake or pipe rupture. The work is sponsored by the Division of Engineering of the Office of Nuclear Regulatory Research of the NRC and executed by Lawrence Livermore National Laboratory (LLNL) under an interagency agreement between the NRC and the U.S. Department of Energy.

The evaluation is divided into two phases. Phase 1 is a pilot study on a selected nuclear plant. Phase 2 is a parametric study of critical variables undertaken in an attempt to generalize the pilot results to other nuclear units susceptible to neutron embrittlement damage. The Trojan nuclear power plant has been selected for the pilot study because its RPV supports are located in the high radiation zone and are subject to high tensile stresses.

The pilot study comprises a structural evaluation and an effects evaluation for postulated failure of one or more RPV supports. Failure of an RPV support herein means the support has completely lost its load-bearing capacity. The structural evaluation determines (1) the ability of the reactor coolant loop (RCL) piping to transfer (or redistribute) the RPV support loads to steam generator (SG) supports, reactor coolant pump (RCP) supports, and, if applicable, the concrete shield wall, and (2) the ability of SG and RCP supports to carry the additional loads transferred by the RCL piping.

The effects evaluation will be conducted if the structural evaluation shows that the RPV support loads can be redistributed from the failed supports and that the SG and RCP supports are capable of carrying the additional loads. The effects evaluation will then (1) calculate the motions (translations and rotations) of the RPV associated with failure of specified RPV supports, and (2) assess consequences of the RPV motions such as, but not limited to, the ability to insert control rods for achieving hot shutdown and the ability of the reactor coolant pumps and any instrument lines and small-diameter piping attached to the RPV to maintain their integrity.

As a bounding case in the Phase 1 study, all four supports of the Trojan reactor pressure vessel are assumed to have initially failed. If it is shown that the RPV loads cannot be redistributed from the failed vessel supports, this bounding case will be abandoned and only one of the four supports will be assumed to have failed. The structural evaluation is based on a linear analysis following nules 
provided by Subsection NB and Appendix F, Division 1, Section III of the ASME Boiler and Pressure Vessel Code [2].

This report summarizes the structural evaluation of the bounding case for the Zion Unit 1 (Zion 1) nuclear plant. The reasons for doing this exercise are (1) the close resemblance between Zion 1 and Trojan (both are four-loop Westinghouse PWR plants), and (2) the existence of an RCL computer analysis model for Zion 1 . The objectives of this evaluation are to demonstrate the methodology used in the structural evaluation and to obtain some quick and preliminary indications with regard to the structural integrity of the Trojan RCL system when all four RPV supports have failed. The analysis will be repeated when the development of the actual Trojan model is completed.

\subsection{PLANT DESCRIPTION}

The Zion 1 nuclear power plant utilizes a four-loop Westinghouse PWR nuclear steam supply system (NSSS). A typical four-loop Westinghouse NSSS is shown in Figure 1. The NSSS consists of the reactor pressure vessel, steam generators, reactor coolant pumps, the pressurizer, and the piping. The piping in each of the main loops of the NSSS contains the hot leg (RPV to $\mathrm{SG}$ ), the cross- over leg (SG to RCP), and the cold leg (RCP to RPV). The surge line piping connects the pressurizer to the hot leg in one of the four loops. Figure 2 shows the plan view of tie reactor coolant loops for the Zion 1 plant.

The Zion 1 RPV has four Type 4G supports (see Fig. 3) located at alternate nozzles according to the classification system described in [1]. Zion Unit 1 bears a great deal of resemblance to the Trojan plant in terms of the NSSS design. Table 1 presents a close comparison between the two NSSS systems based on [3] and [4]. Figure 4 shows the Type 4A RPV support design used by the Trojan plant.

\subsection{DESCRIPTION OF COMPUTER ANALYSIS MODEL}

The Zion Station RCL model was originally developed for LLNL's Load Combination Program [5] to be used to perform linear elastic analyses of the RCL system subject to either earthquake input motions or static loads such as dead weight, thermal loads, and internal pressure. The input format of the model is compatible with the finite-element computer code SAP4 [6] or GEMINI [7].

The original model has 339 nodes. The model utilizes beam elements to model component supports, stiffness elements to represent nozzle effects, and pipe elements to simulate piping, steam generators, reactor coolant pumps, the reactor pressure vessel, and the pressurizer. For the present analysis, the original model has been reduced by removing the surge line and the pressurizer. The reduced model has 282 nodes ( 234 unconstrained and 48 constrained), 33 beam elements for static analyses or 37 for dynamic analyses, 16 stiffness elements, and 224 straight and bent pipe elements. The reduced model is shown by Figure 5.

\subsection{LOADING CONDITIONS}

Two load combinations are evaluated in the analyses: load combination 1 consists of dead weight, operating pressure, and the safe shutdown earthquake (SSE), and load combination 2 consists of dead weight, operating pressure, and a loss-of-coolant-accident (LOCA) load due to a small pipe break. Both load combinations are classified as Level D Service Limits in accordance with ASME Code definitions, and rules contained in Appendix F in conjunction with Subsection NB of the Code are to be used in evaluating the Service Loadings. 
The operating pressure for Trojan is $2,235 \mathrm{psi}$. An operating temperature of $600^{\circ} \mathrm{F}$ is conservatively chosen to determine temperature-dependent material properties for the pipe, but thermally induced stresses are not considered in the piping evaluation because thermal stresses are classified as secondary stresses by the ASME Code and are not required to be considered by Appendix F evaluations. However, thermal effects due to the operating temperature are included in determinations of the RPV support forces (with supports intact) and the RPV vertical motion (with no RPV supports).

SSE loading is evaluated by the response spectrum method. The floor response spectra for Zion 1 with a base ground acceleration of $0.17 \mathrm{~g}$ horizontally and $0.11 \mathrm{~g}$ vertically are shown by Figure 6 [4]. The SSE at Trojan has a base ground acceleration of $0.25 \mathrm{~g}$ horizontally and $0.17 \mathrm{~g}$ vertically. The floor response spectra needed for the analyses were obtained from the PGE [8] and are shown in Figure 7.

A small-break loss-of-coolant-accident (SBLOCA) is assumed to occur in one of the auxiliary pipe lines attached to one reactor coolant loop. The specific auxiliary line to be considered by the evaluation was specified by the NRC to be the surge line. The location of the pipe break is assumed to occur at the joint between surge line and hot leg, although further studies may be required to determine whether this is the most unfavorable location.

Forcing functions for the thrust force induced by the pipe break at the break location were developed by Stevenson [9] and Holman [10]. Both results are based on double-ended guillotine break (DEGB), although the thrust force is applied vertically at the break location in the analyses to simulate the more unfavorable condition resulting from a slot break. The forcing function developed by Stevenson, shown by the curve identified as SBLOCA(DEGB1) in Figure 8, was based on simplified considerations, whereas that developed by Holman, shown by the curve identified as SBLOCA(DEGB2) in Figure 8, was based on a much more elaborate analysis conducted by Fletcher [11] of the Idaho National Engineering Laboratory (INEL) using the thermohydraulic computer code RELAP5. Fletcher has also performed a RELAP5 analysis to simulate a slot break in the surge line [12]. The forcing function for the slot break is shown by the curve SBLOCA(SLOT) in Figure 8.

\subsection{ANALYTICAL METHOD}

Rules contained in Appendix F and Subsection NB are provided for limiting the consequences of the specified events. They are intended to assure that violation of the pressure-retaining boundary will not occur, but are not intended to assure operability of components either during or following the specified event. Only limits on primary stresses are prescribed. Unless specifically required by the Appendix, self-relieving stresses (stch as thermally induced stresses) resulting from loads for which Level D Service Limits are specified need not be considered. Linear analyses are permitted by Appendix F in perform ng the structural evaluation. For piping, Appendix F requires that Equation (9) of NB-3652 shall be satisfied using a stress limit of $3 \mathrm{~S}_{\mathrm{m}}$, i.e.,

$$
B_{1}\left(P D_{0} / 2 t\right)+B_{2}\left(D_{0} M_{i} / 2 l\right)<3 S_{m}
$$

where $B_{1}, B_{2}=$ primary stress indices which are given the values of 0.5 and 1.0 , respectively, in accordance with NB-3680,

$\mathbf{P}=$ pressure,

$D_{0}=$ outside diameter,

$\mathrm{t}=$ pipe wall thickness,

$I=$ moment of inertia of the pipe section,

$\mathbf{M}_{\mathbf{i}}=$ resulting moment due to a combination of mechanical loads,

$S_{m}=$ ailowabie stress intensity value per Table I-1.0 of the ASME Code. 
It can be seen from the above equation that, in order to carry out the structural evaluation, we need to calculate bending moments in the pipe due to dead weight, SSE, and SBLOCA, individually, and then combine them appropriately.

For SG and RCP supports, it is tentatively assumed that they are capable of carrying the additional loads without failure. Appropriate failure criteria for component supports, however, will be developed for the structural evaluation of the Trojan plant.

Bending moments in the RCL piping are obtained by static analyses resulting from GEMINI, which is a computer program for calculation of static and dynamic response of linear elastic structures by the finite-element method.

Bending moments due to the SSE are obtained by floor response spectrum analysis. Fundamental frequencies of fre $\epsilon$ vibration modes of the RCL model are calculated because they are required by the response spectrum analysis. The frequencies of the first 30 modes are given in Table 2 , and the first three vibration modes are shown in Figures 9, 10, and 11. In the seismic evaluation, both Zion 1 floor response input (Figure 6) and the Trojan input (Figure 7) are analyzed. Variable and frequency-dependent modal damping ratios as depicted by Figure 12 are used in the current analysis. The variable damping ratios were developed by the Pressure Vessel Research Committee (PVRC) and recommended by the Seismic Design Task Group of the NRC Piping Review Committee [13] following ASME Code Case N-411.

Structural analysis of the SBLOCA load due to the surge line break is carried out by the modal time history integration method available in GEMINI. The analysis considers all three forcing functions of the thrust force induced by the SBLOCA, as shown by Figure 8, and determines the most critical one to be used.

\subsection{RESULTS OF THE STRUCTURAL EVALUATION}

Although the current evaluation deals mainly with the RCL system subject to posiulated RPV support failure, the original RCL system with no RPV support failure is also analyzed in order to generate some useful information, such as RPV support forces resulting from various loading conditions as shown by Table 3. I is noted that both SBLOCA(DEGB2) and SBLOCA(SLOT) forcing functions produce almost intical RPV support forces, which are slightly higher than those produced by SBLOCA(DE JB1). Consequently, SBLOCA(SLOT) is selected as the small-pipe-break forcing function to be used throughout this evaluation.

Vertical displacements at locations of RPV outlet nozzles are listed in Table 4. Vertical support forces and overturning moments are listed in Tables 5 and 6, respectively, for steam generator supports. Table 7 shows stresses in the RCL piping at RPV outlet (or hot leg) nozzles calculated from bending moments.

\subsection{DISCUSSION AND CONCLUSION}

The results of the free vibration analysis (Table 2 ) indicate that the first three vibration modes, having frequencies of $3.76,4.26$, and $5.89 \mathrm{~Hz}$, of the RCL model with postulated RPV support failure are clearly lower than all the frequencies associated with the vibration modes of the RCL. model without RPV support failure. As anticipated, the first vibration mode, as shown by Figure 9, is dominated by the up-and-down motion of the reactor vessel whereas the other two modes, as shown by Figures 10 and 11 , are basically rocking modes in two perpendicular directions. 
Table 8, which summarizes the results of the ASME Code Equation (9) evaluation, shows that the Appendix $F$ requirement is easily satisfied by each of the load combinations considered by the current structural evaluation, leading to the conclusion that Zion 1 RCL piping is capable of transferring the RPV support loads to the SG and RCP supports. The same conclusion appears to be applicable also to the Trojan RCL system because the RCL systems of the two plants are so much alike. The fact that the Trojan RCL pipe thicknesses are slightly less than those of Zion 1 probably will be compensated by the shorter distance between the RPV and the SG and the higher value for $S_{m}$ associated with the Trojan plant. Table 8 also reveals that Load Combination 1 (with SSE) is more damaging than Load Combination 2 (with SBLOCA) for plants located in high seismic zones, such as in the case of the Trojan plant. However, just the opposite is true for Zion.

Displacements in Table 4 are listed simply for reference purposes, since they could be considerably underestimated by the linear analysis. The displacements will be rigorously assessed by a nonlinear analysis for the Trojan model at a later date.

Table 5 indicates that the maximum steam generator vertical support force shows an increase of $37 \%$ (based on the Load Combination 1 for Zion or 48\% for Trojan SSE input) as the RPV loses all four supports. The increase in the maximum overturning moment, however, is much higher, i.e., $114 \%$ for Zion or $110 \%$ for Trojan, as indicated by Table 6 . A study of the ultimate load capacity of component support structures is required in order to determine the ability of component supports to carry the additional loads transferred to them due to the postulated failure of the RPV supports. However, it is noted that SG or RCP supports were designed for a large-break LOCA which is now viewed as extremely unlikely. Large margins therefore exist to accommodate RPV support failure because the large-break LOCA load is now replaced by the SBLOCA load.

To conclude the conscruence evaluation for the Trojan plant we will finish the following work:

- Structural Evaluation:

- Complete the development of Trojan RCL model.

- Conduct the structural evaluation including both the piping and the SG and RCP supports.

- Include a study to determine the most unfavorable pipe break location along the length of the surge line.

- Effects Evaluation:

- Identify critical components, instrument lines, and small pipes which are required for safe shutdown of the plant and are also affected by the RCL motions.

- Determine the movements of the RCL system by a nonlinear structural analysis or other methods to evaluate the functionality or operability of the critical components, instrument lines and pipes. 


\subsection{RERERTNCES}

1. R. D. Cheverton, J. G. Merkle, and R. K. Nanstad, "Evaluation of HFIR Pressure Vessel Integrity Considering Radiation Embrittlement," Report ORNL/TM-10444, Oak Ridge National Laboratory, April 1988.

2. ASME Boiler and Pressure Vessel Code, 1986 Edition.

3. Trojan Nuclear Plant Final Safety Analysis Report, Docket No. 50-344, Portland General Electric Company.

4. Zion Station Final Safety Analysis Report, Commonwealth Edison Company.

5. A. C. Eberhardt, "Probability of Pipe Fracture in the Primary Coolant Loop of a PWR Plant, Volume 2: Primary Coolant Loop Model," NUREG/CR-2189, Vol. 2, September 1981.

6. S. J. Sackett, "Users Manual for SAP4, A Modified and Extended Version of the U. C. Berkeley SAPIV Code," UCID- 18226, Lawrence Livermore National Laboratory, May 1979.

7. R. C. Murray, "GEMINI - A Computer Program for Two and Three Dimensional Linear Static and Seismic Structural Analysis," UCID-20338, Lawrence Livermore National Laboratory, October 1984.

8. Informal Technical Transmittal, PGE to LLNL, June 1989.

9. Letter from J. D. Stevenson, Stevenson and Associates, to J. A. O'Brien, the Nuclear Regulatory Commission, July 12, 1989.

10. Letter from G. S. Holman, LLNL to J. A. O'Brien, NRC, August 14, 1989.

11. C. D. Fletcher, "Data Supporting Calculation of Thrust Load Imposed by a Pressurizer Surge Line Break," CDF-07- 89, INEL Letter Report to J. A. O'Brien of NRC, July 28, 1989.

12. C. D. Fletcher, "Data Supporting Calculation of Thrust Load Imposed by a Hot Leg Break," CDF-12-89, INEL Letter Report to J. A. O'Brien of NRC, August 15, 1989.

13. The Seismic Design Task Group of the NRC Piping Review Committee (S. Hou, Chairman), "Report of the U.S. Nuclear Regulatory Commission Piping Review Committee, Volume 2: Evaluation of Seismic Designs - A Review of Seismic Design Requirements for Nuclear Power Plant Piping," NUREG-1061, Volume 2, April 1985. 
Table 1 Comparison of Trojan and Zion RCL Systems

Trojan

Core heat output

No. of fuel rods

Core diameter

Core height

RPV total height

RPV shell ID

RPV belt-line thickness

RPV support type

RPV dead load

SG model type

$\mathrm{RCP}$ capacity

RCP height

$\mathrm{RCP}$ dry weight

RCP motor power

Main piping material

Surge line material

Hot leg ID

Hot leg OD

Hot leg thickness

Crossover leg ID

Crossover leg OD

Crossover leg thickness

Cold leg ID

Cold leg OD

Cold leg thickness

Surge line ID

Surge line OD

Surge line thickness

RPV to SG distance

RPV to RCP distance

$\mathrm{RCP}$ to $\mathrm{SG}$ distance
3,411 MWt

39,372

$132.7 \mathrm{in.}$

$144.0 \mathrm{in.}$

$43 \mathrm{ft}-10$ in.

173 in.

8.5 in.

$4 \mathrm{~A}$

2,120 kips

51

$88,500 \mathrm{gpm}$

$28 \mathrm{ft}-6.6 \mathrm{in}$.

$188,200 \mathrm{lb}$

$6,000 \mathrm{hp}$

ASTM A351 Grade CF8A

ASTM A376 Type 316

29.00 in.

33.90 in.

$2.45 \mathrm{in}$.

31.00 in.

36.20 in.

$2.60 \mathrm{in.}$

27.50 in.

32.14 in.

2.32 in.

11.188 in.

$14.000 \mathrm{in}$.

1.406 in.

$31.250 \mathrm{ft}$

$34.502 \mathrm{ft}$

$17.472 \mathrm{ft}$
Zion

3,250 MWt

39,372

132.7 in

$143.4 \mathrm{in}$.

$43 \mathrm{ft}-9.72 \mathrm{in}$.

173 in.

8.44 in.

$4 \mathrm{G}$

1,990 kips

51

$87,500 \mathrm{gpm}$

$25 \mathrm{ft}-5.05$ in

$169,200 \mathrm{lb}$

$6,000 \mathrm{hp}$

ASTM A376 Type 316

ASTM A376 Type 316

29.00 in.

34.00 in.

$2.50 \mathrm{in}$.

$31.00 \mathrm{in.}$

36.32 in.

$2.66 \mathrm{in}$.

$27.50 \mathrm{in.}$

32.26 in.

$2.38 \mathrm{in}$.

11.188 in.

14.000 in.

1.406 in.

$32.333 \mathrm{ft}$

$36.500 \mathrm{ft}$

$17.445 \mathrm{ft}$ 
Table 2 Frequencies of First 30 Modes of Zion RCL Model

\begin{tabular}{|c|c|c|}
\hline \multirow[b]{2}{*}{ Mode No. } & \multicolumn{2}{|c|}{ Frequency $(\mathrm{Hz})$} \\
\hline & $\begin{array}{c}\text { With RPV } \\
\text { Support Failure }\end{array}$ & $\begin{array}{l}\text { Without RPV } \\
\text { Support Failure }\end{array}$ \\
\hline 1 & 3.76 & 7.26 \\
\hline 2 & 4.26 & 7.29 \\
\hline 3 & 5.89 & 7.29 \\
\hline 4 & 7.10 & 7.31 \\
\hline 5 & 7.19 & 9.09 \\
\hline 6 & 7.29 & 9.09 \\
\hline 7 & 7.31 & 9.09 \\
\hline 8 & 9.08 & 9.10 \\
\hline 9 & 9.09 & 9.47 \\
\hline 10 & 9.09 & 9.48 \\
\hline 11 & 9.11 & 9.49 \\
\hline 12 & 9.30 & 9.49 \\
\hline 13 & 9.40 & 9.90 \\
\hline 14 & 9.49 & 9.93 \\
\hline 15 & 9.51 & 9.96 \\
\hline 16 & 9.66 & 9.97 \\
\hline 17 & 9.83 & 13.89 \\
\hline 18 & 9.96 & 13.92 \\
\hline 19 & 10.07 & 13.94 \\
\hline 20 & 10.51 & 13.94 \\
\hline 21 & 12.89 & 15.91 \\
\hline 22 & 13.51 & 16.23 \\
\hline 23 & 13.94 & 18.71 \\
\hline 24 & 13.95 & 19.54 \\
\hline 25 & 13.96 & 19.54 \\
\hline 26 & 14.01 & 19.54 \\
\hline 27 & 19.54 & 19.56 \\
\hline 28 & 19.54 & 20.24 \\
\hline 29 & 19.54 & 20.77 \\
\hline 30 & 19.56 & 20.96 \\
\hline
\end{tabular}


Table 3 Vertical Forces in RPV Supports

\begin{tabular}{|c|c|c|c|c|}
\hline \multirow[b]{2}{*}{ Load Case } & \multicolumn{4}{|c|}{ Support Force (kips) } \\
\hline & Loop 1 & Loop 2 & Loop 3 & Loop 4 \\
\hline Pres + Weight & 556 & 550 & 556 & 549 \\
\hline SSE (Zion) & 130 & 118 & 130 & 118 \\
\hline SSE (Trojan) & 380 & 348 & 380 & 348 \\
\hline SBLOCA (DEGB1) & 92 & 84 & 129 & 121 \\
\hline SBLOCA (DEGB2) & 97 & 88 & 138 & 128 \\
\hline SBLOCA (SLOT) & 98 & 88 & 138 & 128 \\
\hline Thermal & 94 & 61 & 108 & 92 \\
\hline PWT* + SSE (Zion) & 780 & 729 & 794 & 759 \\
\hline PWT + SSE (Troj) & ${ }^{\top}, 030$ & 959 & 1,044 & 989 \\
\hline PWT + SBLOCA (SLOT) & 748 & 699 & 802 & 769 \\
\hline
\end{tabular}

*PWT $=$ Pressure + Weight + Thermal . 
Table 4 Vertical Displacements at RPV Outlet Nozzles

\begin{tabular}{|c|c|c|c|c|}
\hline \multirow[b]{2}{*}{ Load Case } & \multicolumn{3}{|c|}{ Displacement (inches) } & \multirow[b]{2}{*}{ Loop 4} \\
\hline & Loop 1 & Loop 2 & Loop 3 & \\
\hline Pres + Weight & $\begin{array}{l}0.828 \\
(0.010)^{*}\end{array}$ & $\begin{array}{c}0.828 \\
(0.012)\end{array}$ & $\begin{array}{c}0.828 \\
(0.010)\end{array}$ & $\begin{array}{c}0.828 \\
(0.012)\end{array}$ \\
\hline Thermal & $\begin{array}{l}0.136 \\
(0.004)\end{array}$ & $\begin{array}{c}0.133 \\
(0.005)\end{array}$ & $\begin{array}{c}0.138 \\
(0.004)\end{array}$ & $\begin{array}{c}0.142 \\
(0.006)\end{array}$ \\
\hline SSE (Zion) & $\begin{array}{c}0.128 \\
(0.002)\end{array}$ & $\begin{array}{c}0.128 \\
(0.003)\end{array}$ & $\begin{array}{c}0.129 \\
(0 .(02)\end{array}$ & $\begin{array}{c}0.128 \\
(0.003)\end{array}$ \\
\hline SSE (Trojan) & $\begin{array}{c}0.232 \\
(0.007)\end{array}$ & $\begin{array}{c}0.232 \\
(0.008)\end{array}$ & $\begin{array}{c}0.232 \\
(0.007)\end{array}$ & $\begin{array}{c}0.232 \\
(0.008)\end{array}$ \\
\hline $\mathrm{PWT}^{* *}+\mathrm{SSE}$ (Zion) & $\begin{array}{c}1.092 \\
(0.016)\end{array}$ & $\begin{array}{c}1.089 \\
(0.020)\end{array}$ & $\begin{array}{c}1.094 \\
(0.016)\end{array}$ & $\begin{array}{l}1.098 \\
(0.021)\end{array}$ \\
\hline PWT $^{* *}+$ SSE (Troj) & $\begin{array}{c}1.196 \\
(0.021)\end{array}$ & $\begin{array}{c}1.193 \\
(0.025)\end{array}$ & $\begin{array}{c}1.198 \\
(0.021)\end{array}$ & $\begin{array}{l}1.202 \\
(0.026)\end{array}$ \\
\hline SBLOCA (SLOT) & $\begin{array}{c}0.119 \\
(0.002)\end{array}$ & $\begin{array}{c}0.098 \\
(0.003)\end{array}$ & $\begin{array}{c}0.136 \\
(0.003)\end{array}$ & $\begin{array}{c}0.160 \\
(0.004)\end{array}$ \\
\hline PWT $^{* *}+$ SBLOCA & $\begin{array}{c}1.083 \\
(0.016)\end{array}$ & $\begin{array}{c}1.059 \\
(0.020)\end{array}$ & $\begin{array}{c}1.102 \\
(0.017)\end{array}$ & $\begin{array}{c}1.130 \\
(0.022)\end{array}$ \\
\hline
\end{tabular}

* Displacements without RPV support failure are shown inside parentheses. Numbers above parentheses are displacements with RPV support failure.

** $\mathrm{PWT}=$ Pressure + Weight + Thermal. 
Table 5 Vertical Forces in SG Supports

\begin{tabular}{lcccc} 
Load Case & Loop 1 & Loop 2 & Loop 3 & Loop 4 \\
\hline Pres + Weight & 1,267 & 1,262 & 1,266 & 1,256 \\
& $(853)^{*}$ & $(853)$ & $(851)$ & $(856)$ \\
Thermal & 7 & 8 & 10 & 4 \\
& $(57)$ & $(23)$ & $(32)$ & $(110)$ \\
SSE (Zion) & 151 & 163 & 163 & 126 \\
& $(110)$ & $(102)$ & $(131)$ & $(82)$ \\
SSE (Troj) & 497 & 550 & 549 & 374 \\
& $(294)$ & $(275)$ & $(353)$ & $(221)$ \\
PWT** + SSE (Zion) & 1,425 & 1,433 & 1,439 & 1,386 \\
& $(1,020)$ & $(978)$ & $(1,014)$ & $(1,048)$ \\
PWT + SSE (Troj) & 1,771 & 1,820 & 1,825 & 1,634 \\
& $(1,204)$ & $(1,151)$ & $(1,236)$ & $(1,187)$ \\
SBLOCA (SLOT) & 86 & 65 & 107 & 317 \\
& $(6)$ & $(11)$ & $(7)$ & $(238)$ \\
PWT + SBLOCA & 1,360 & 1,335 & 1,383 & 1,577 \\
& $(916)$ & $(887)$ & $(890)$ & $(1,204)$ \\
\hline
\end{tabular}
* Forces without postulated RPV support failure are shown in parentheses. Numbers above parentheses
are forces with RPV support failure.

** PWT $=$ Pressure + Weight + Thermal. 
Table 6 Overturning Moments in SG Supports

\begin{tabular}{lcccc} 
Load Case & \multicolumn{4}{c}{ Overturning Moment (kips-in.) } \\
Loop 1 & Loop 2 & Loop 3 & Loop 4 \\
\hline Pres + Weight & 51,040 & 52,660 & 51,880 & 52,900 \\
& $(490)^{*}$ & $(320)$ & $(410)$ & $(660)$ \\
Thermal & 23,790 & 25,440 & 28,460 & 9,320 \\
& $(32,270)$ & $(33,790)$ & $(36,560)$ & $(18,090)$ \\
SSE (Zion) & 1,940 & 2,110 & 1,970 & 2,160 \\
& $(1,140)$ & $(1,780)$ & $(1,420)$ & $(2,100)$ \\
SSE (Trojan) & 5,100 & 5,570 & 5,200 & 5,700 \\
& $(3,020)$ & $(4,700)$ & $(3,750)$ & $(5,520)$ \\
PWT** + SSE (Zion) & 76,770 & 80,210 & 82,310 & 64,380 \\
& $(33,900)$ & $(35,890)$ & $(38,390)$ & $(20,850)$ \\
PWT + SSE (Trojan) & 79,930 & 83,670 & 85,540 & 67,920 \\
& $(35,780)$ & $(38,810)$ & $(40,720)$ & $(24,270)$ \\
SBLOCA (SLOT) & 950 & 800 & 1,490 & 1,720 \\
& $(260)$ & $(170)$ & $(50)$ & $(560)$ \\
PWT + SBLOCA & 75,780 & 78,900 & 81,830 & 63,940 \\
& $(33,020)$ & $(34,280)$ & $(37,020)$ & $(19,310)$ \\
\hline
\end{tabular}

* Overturning moments without RPV support failure are shown in parentheses. Numbers above parentheses are overturning moments with RPV failure.

** PWT $=$ Pressure + Weight + Thermal. 
Table 7 Bending Stresses in RCL Piping at RPV Outlet Nozzles

\begin{tabular}{lcccc} 
Load Case & Loop 1 & Loop 2 & Lonp 3 & Loop 4 \\
\hline Dead Weight & 22,580 & 22,490 & 22,570 & 22,510 \\
& $(1,630)$ & $(1,440)$ & $(1,630)$ & $(1,420)$ \\
Thermal & 1,380 & 1,570 & 1,270 & 1,780 \\
& $(5,080)$ & $(5,100)$ & $(4,920)$ & $(5,890)$ \\
SSE (Zion) & 4,830 & 4,830 & 4,830 & 4,830 \\
& $(330)$ & $(350)$ & $(350)$ & $(330)$ \\
SSE (Trojan) & 9,260 & 9,280 & 9,280 & 9,230 \\
& $(930)$ & $(980)$ & $(970)$ & $(950)$ \\
SBLOCA (DEGB1) & $* *$ & $* *$ & $* *$ & $* *$ \\
& $(180)$ & $(210)$ & $(130)$ & $(210)$ \\
SBLOCA (DEGB2) & $* *$ & $* *$ & $* *$ & $*$ \\
& $(200)$ & $(280)$ & $(160)$ & $(310)$ \\
SBLOCA (SLOT) & 4,210 & 3,390 & 5,700 & 7,320 \\
& $(200)$ & $(280)$ & $(160)$ & $(310)$ \\
& & & & \\
\hline
\end{tabular}

* Stresses in parentheses are without RPV support failure. Numbers above parentheses are stresses with RPV support failure.

** Not calculated. 
Table 8 ASME Code Equation (9) Evaluation

\begin{tabular}{lccccc}
\multicolumn{7}{c}{$\mathrm{B}_{1}\left(\mathrm{PD}_{0} / 2 \mathrm{~T}\right)+\mathrm{B}_{2}\left(\mathrm{M}_{\mathrm{i}} \mathrm{D}_{\mathrm{o}} / 2 \mathrm{I}\right),(\mathrm{ksi})$} \\
Load Combination* & Loop 1 & Loop 2 & Loop 3 & Loop 4 & $3 \mathrm{~S}_{\mathrm{m}}(\mathrm{ksi})$ \\
\hline Load Comb. 1 (Zion) & 35.0 & 34.9 & 35.0 & 34.9 & 51.0 \\
& $(9.6)^{*}$ & $(9.4)$ & $(9.6)$ & $(9.4)$ & \\
Load Comb. 2 (Zion) & 34.4 & 33.5 & 35.9 & 37.3 & 51.0 \\
& $(9.4)$ & $(9.4)$ & $(9.4)$ & $(9.3)$ & \\
Load Comb. 1 (Trojan) & 39.4 & 39.4 & 39.5 & 39.3 & 57.9 \\
& $(10.2)$ & $(10.0)$ & $(10.2)$ & $(10.0)$ & \\
Load Comb. 2 (Trojan) & 34.4 & 33.5 & 35.9 & 37.3 & 57.9 \\
& $(9.4)$ & $(9.4)$ & $(9.4)$ & $(9.3)$ & \\
\hline
\end{tabular}

* See Section 4, Loading Conditions, for definitions of load combinations, i.e., Load Comb. 1 = DW + Pressure + SSE Load Comb. 2 = DW + Pressure + SBLOCA

** Numbers in parentheses are stresses without postulated RPV support failure. Numbers above parentheses are stresses with RPV support failure. 


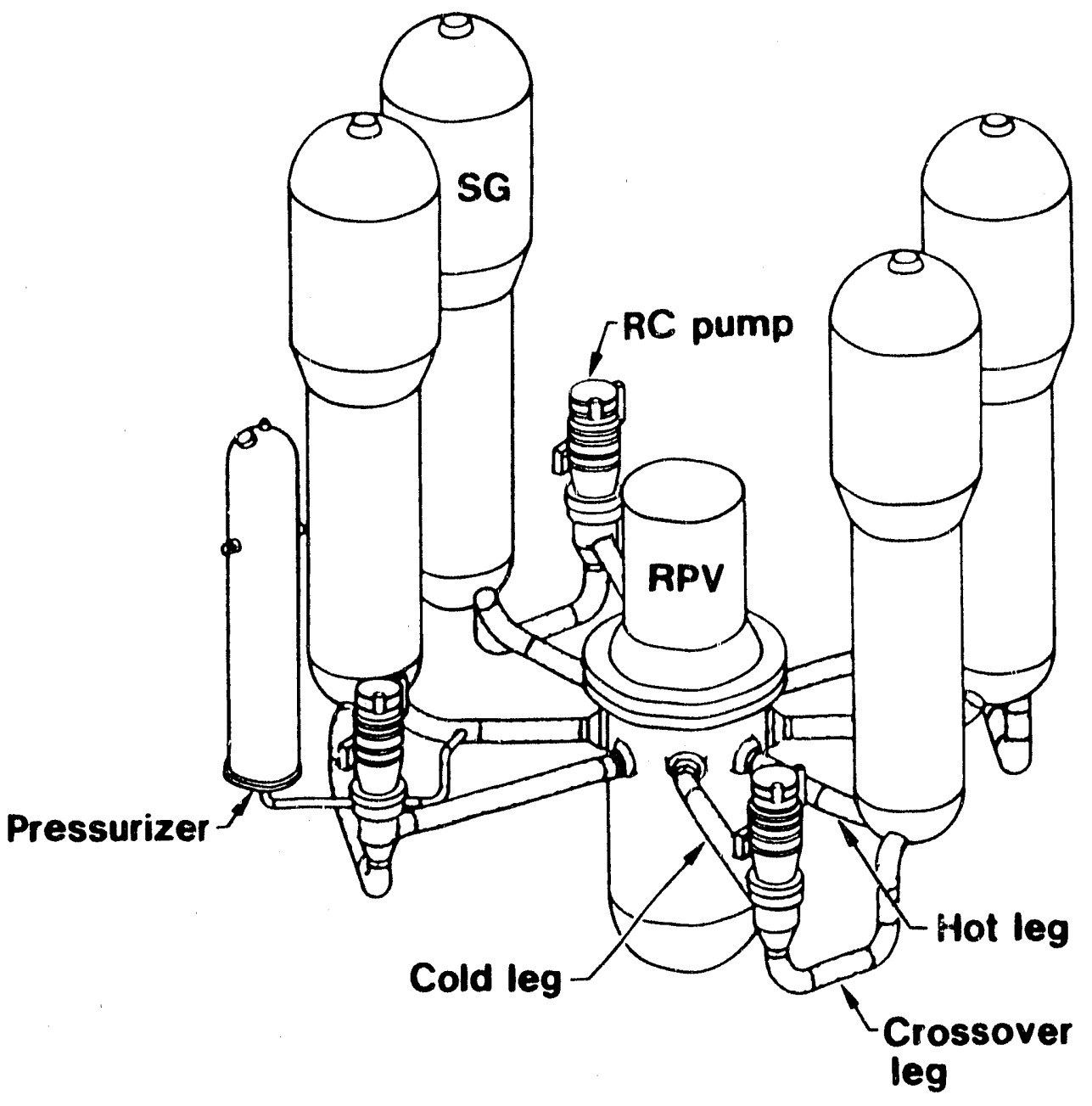

Figure 1 A Typical Westinghouse PWR NSSS. 


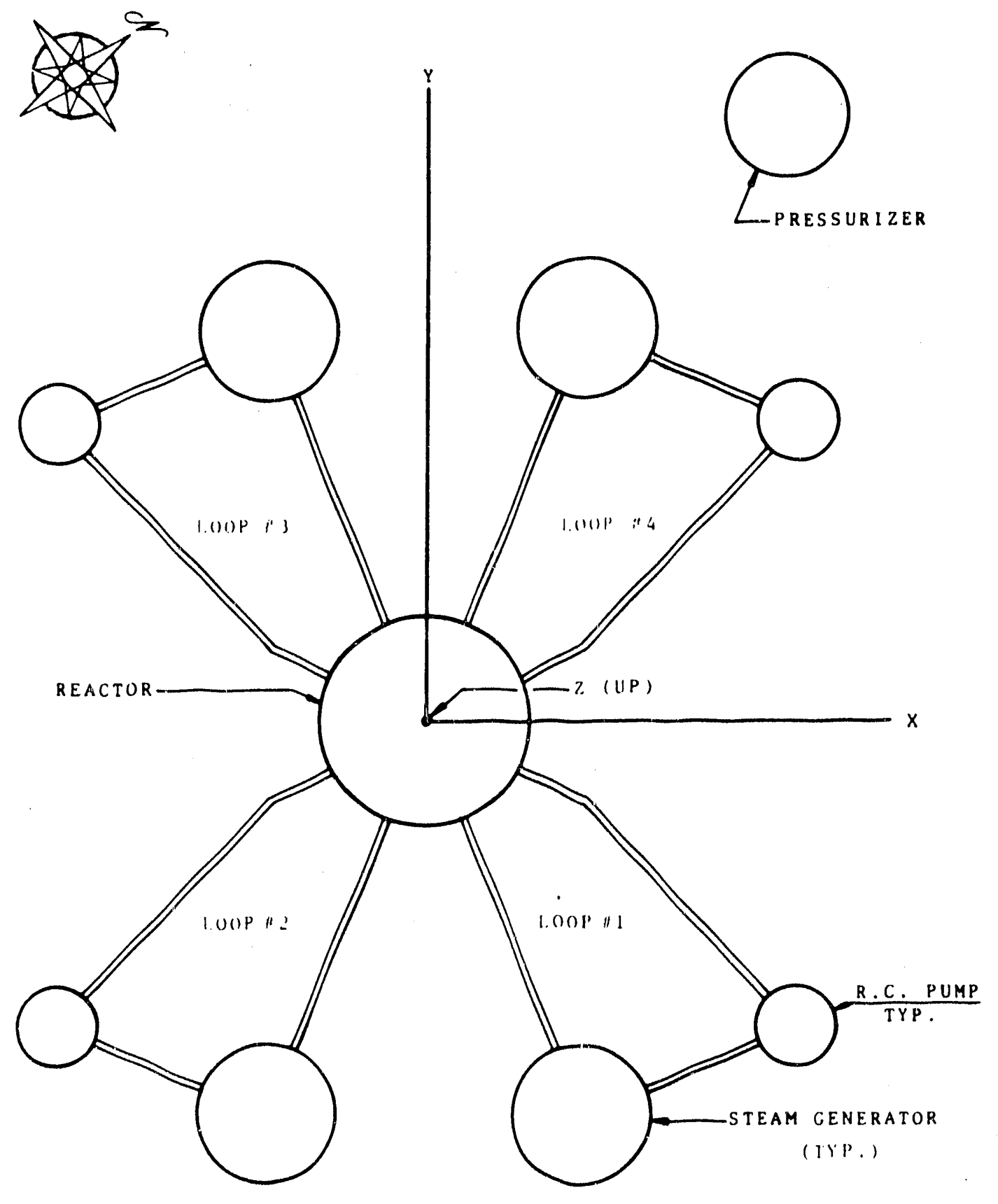

Figure 2 A Plan View of Zion 1 NSSS. 


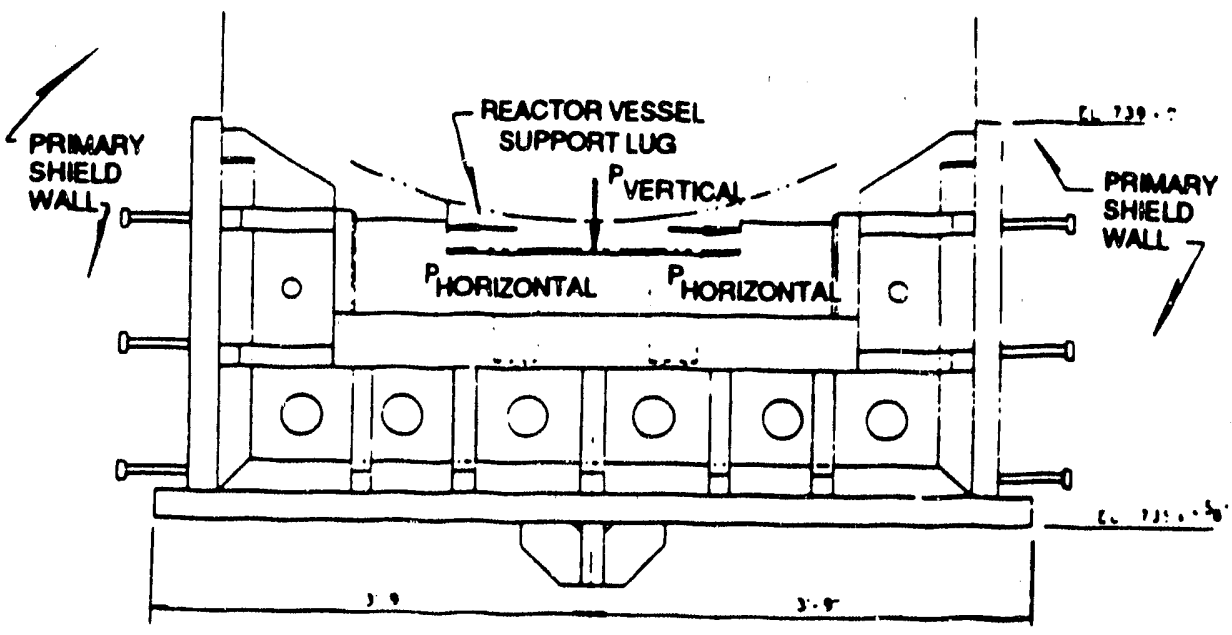

Figure 3 Type 4G PWR Reactor Vessel Support. 


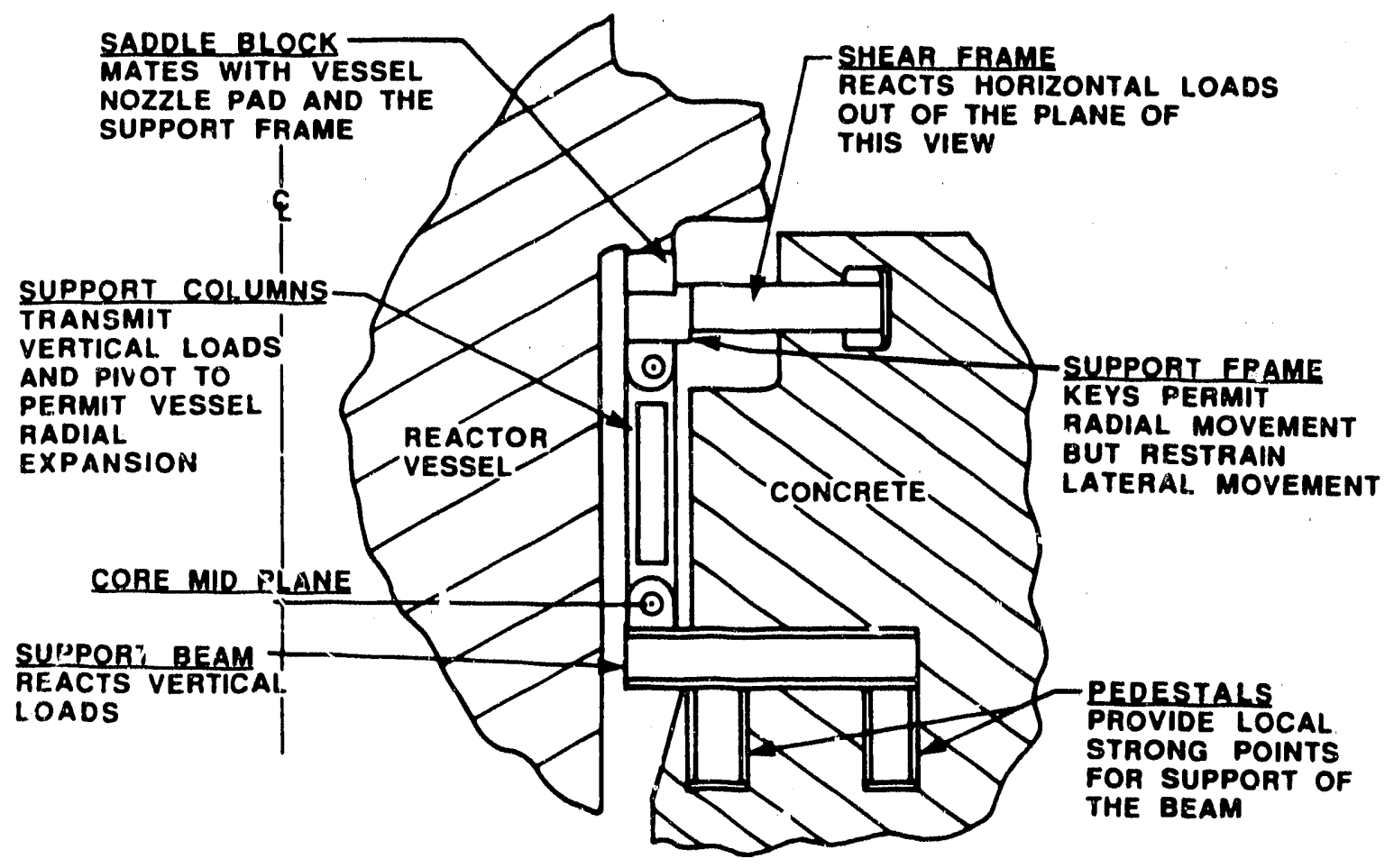

Figure 4 Type 4A PWR Reactor Vessel Support. 


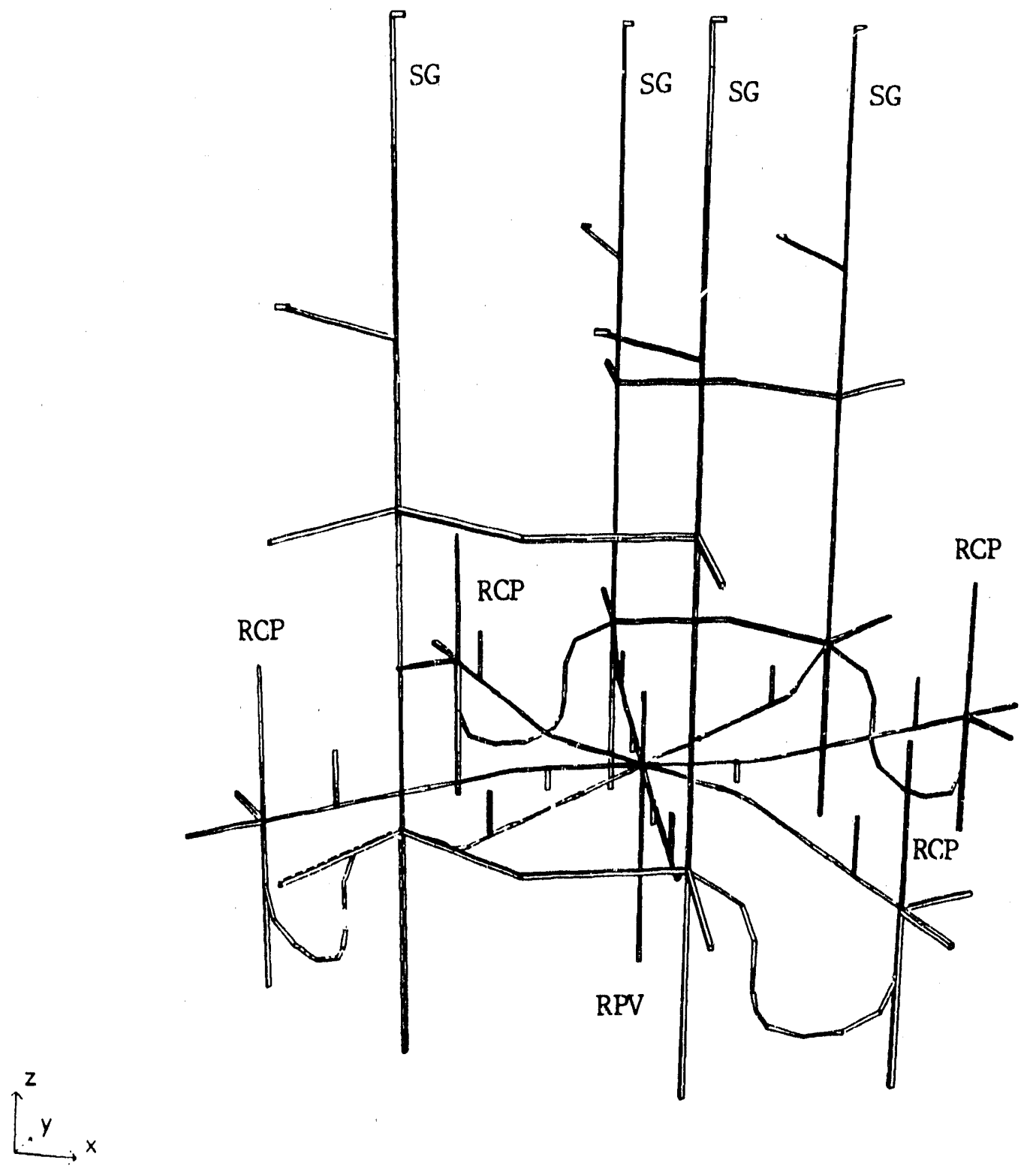

Figure 5 Zion 1 Reactor Coolant Loop Model. 


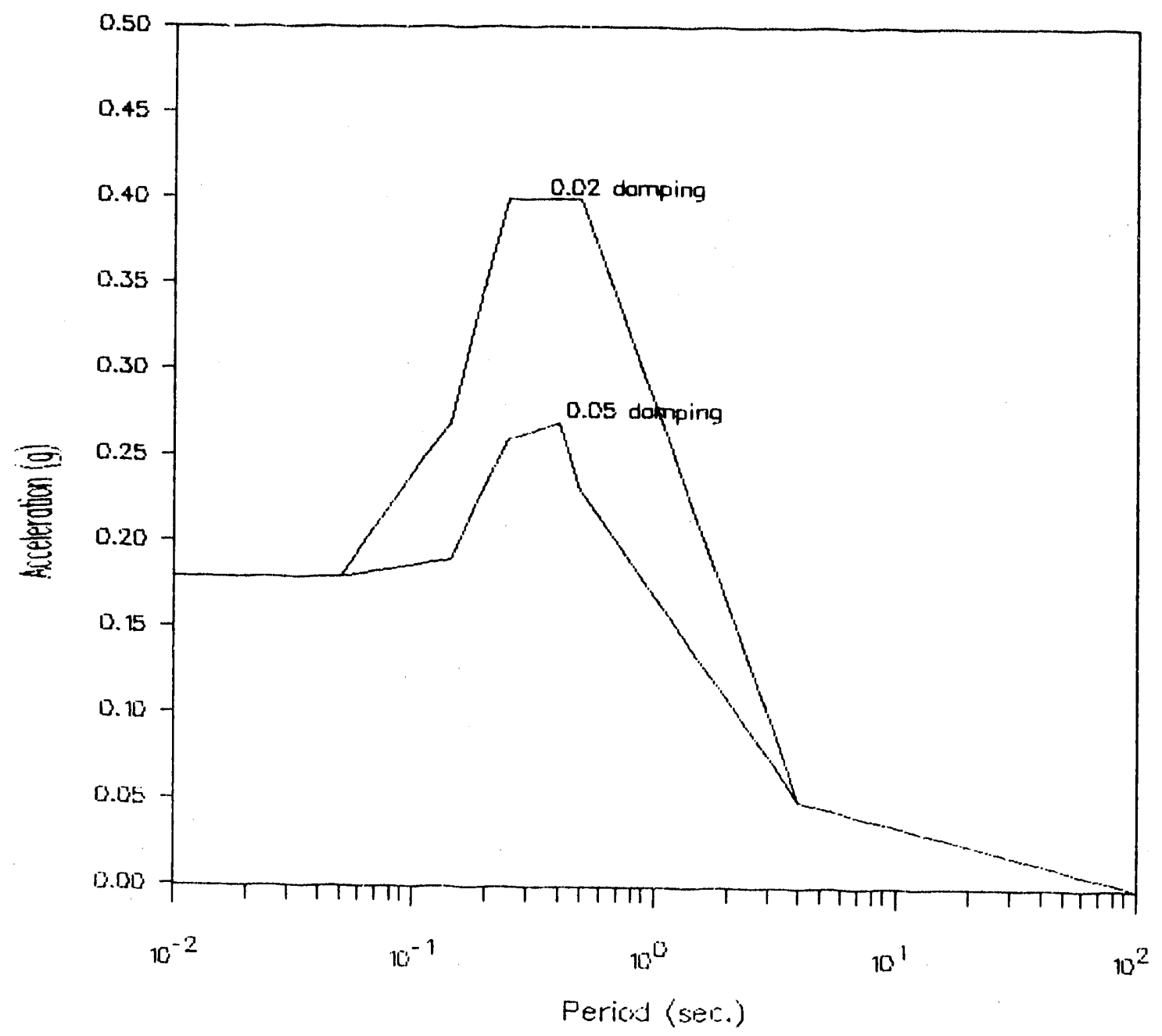

Figure 6 Zion 1 RCL Floor Response Spectra. 


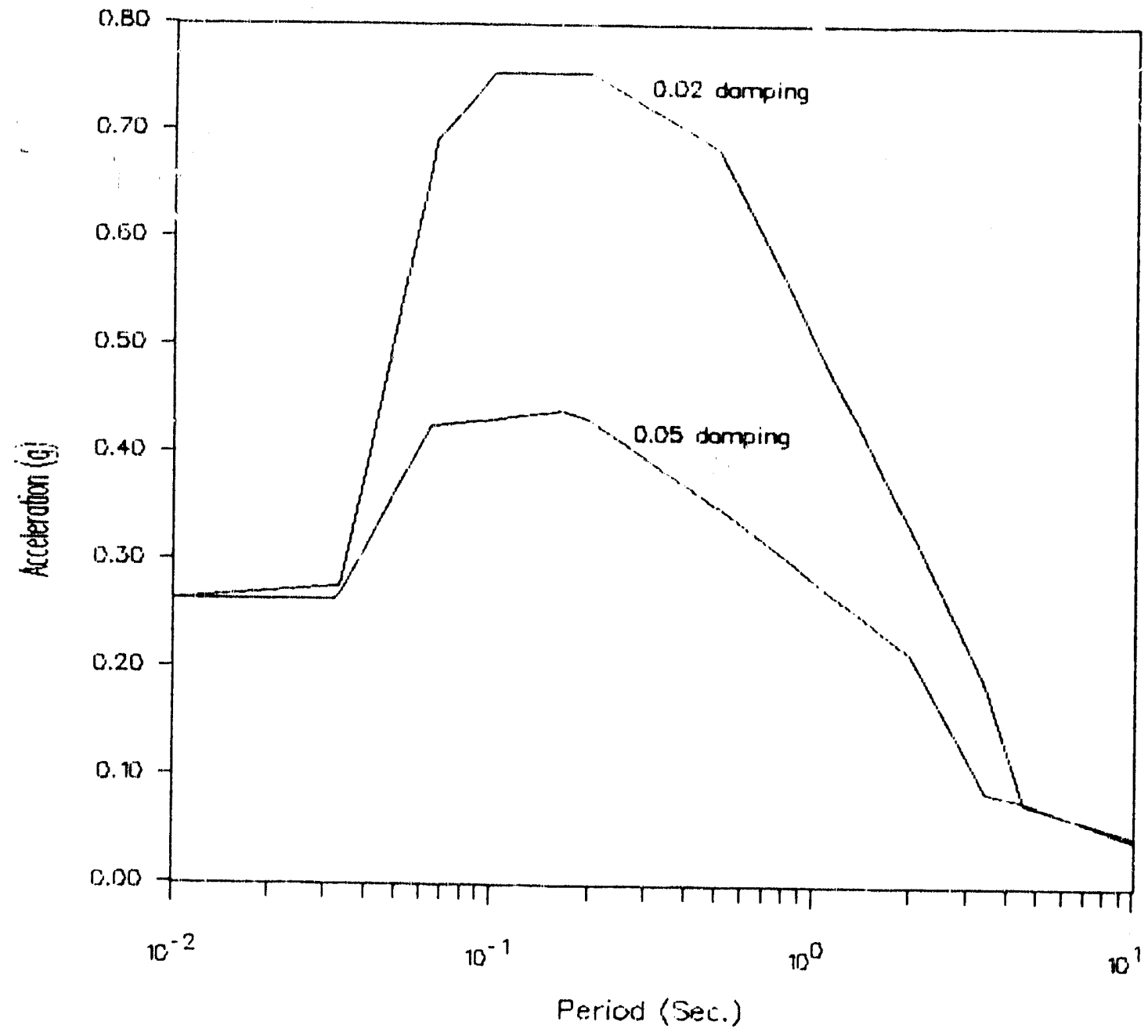

Figure 7 Trojan RCL Floor Response Spectra.

-22 . 


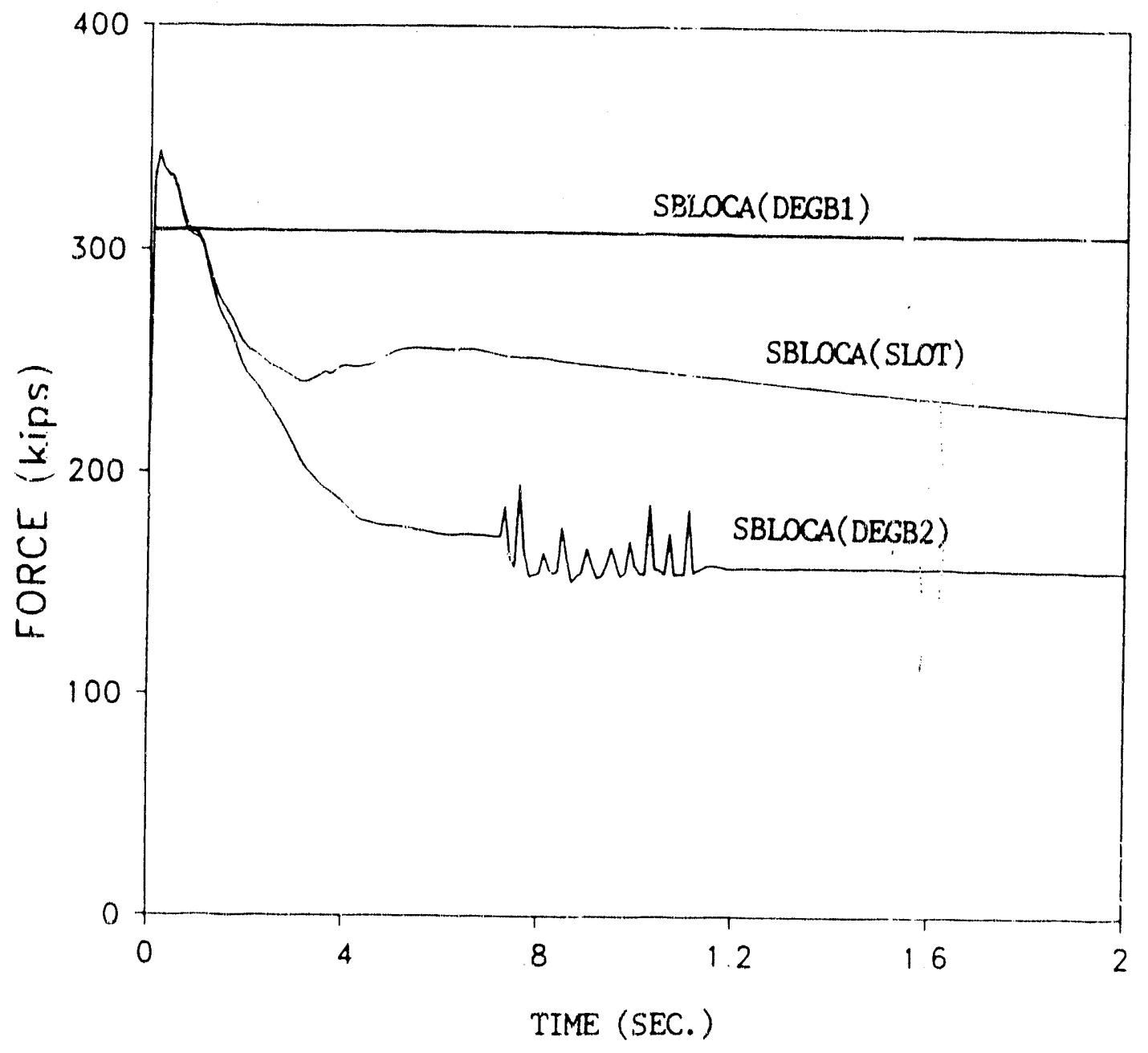

Figure 8 Surge Line LOCA Forcing Functions. 


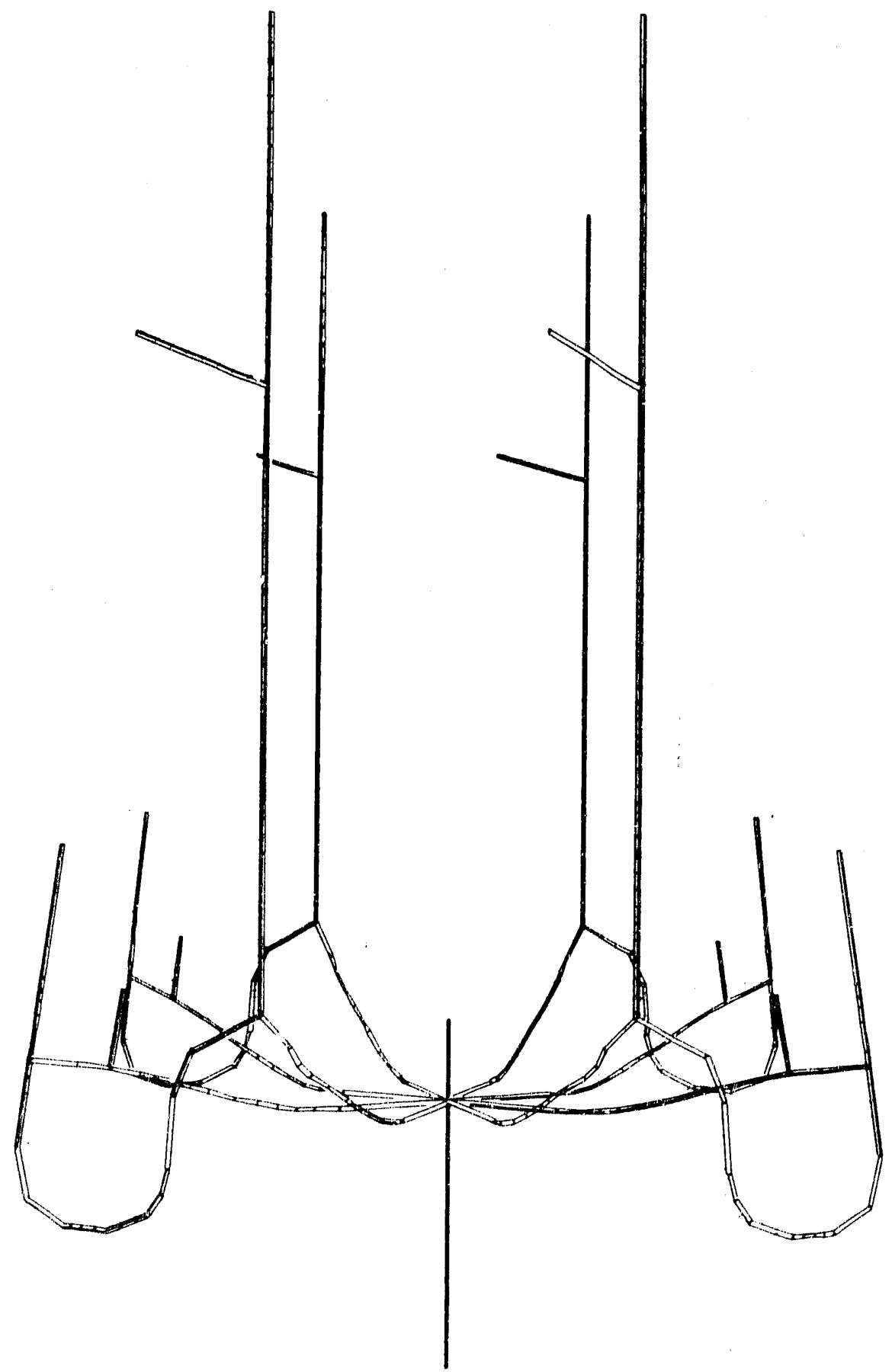

Frequency $=3.76 \mathrm{~Hz}$.

Figure 9 RCL Model First Vibration Mode (No RPV Supports).

.24 . 


$$
\mathbb{H}
$$




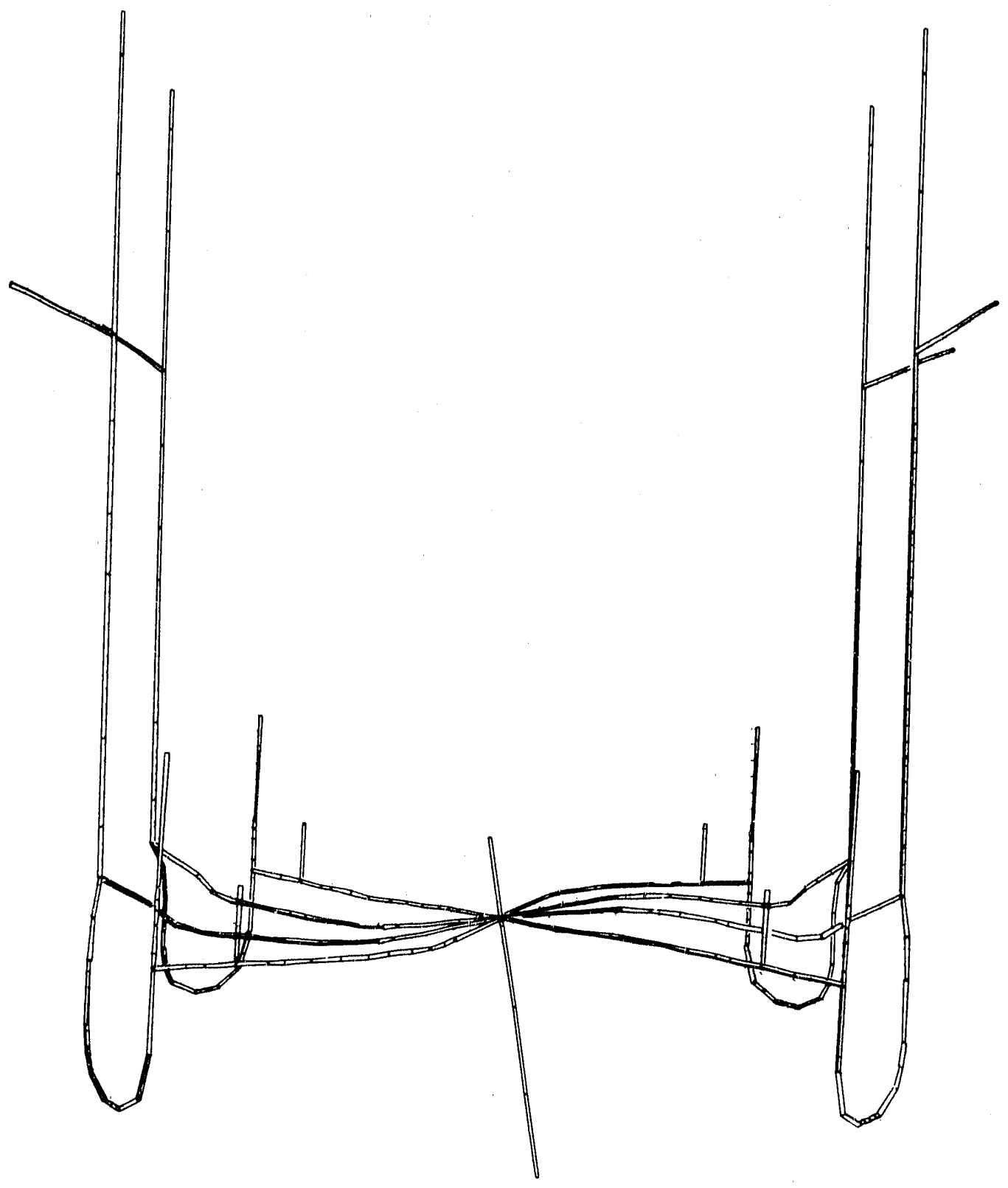

Frequency $=5.89 \mathrm{~Hz}$.

Figure 11 RCL Model Third Vibration Mode (NO RPV Supports).

$$
-26 \text {. }
$$




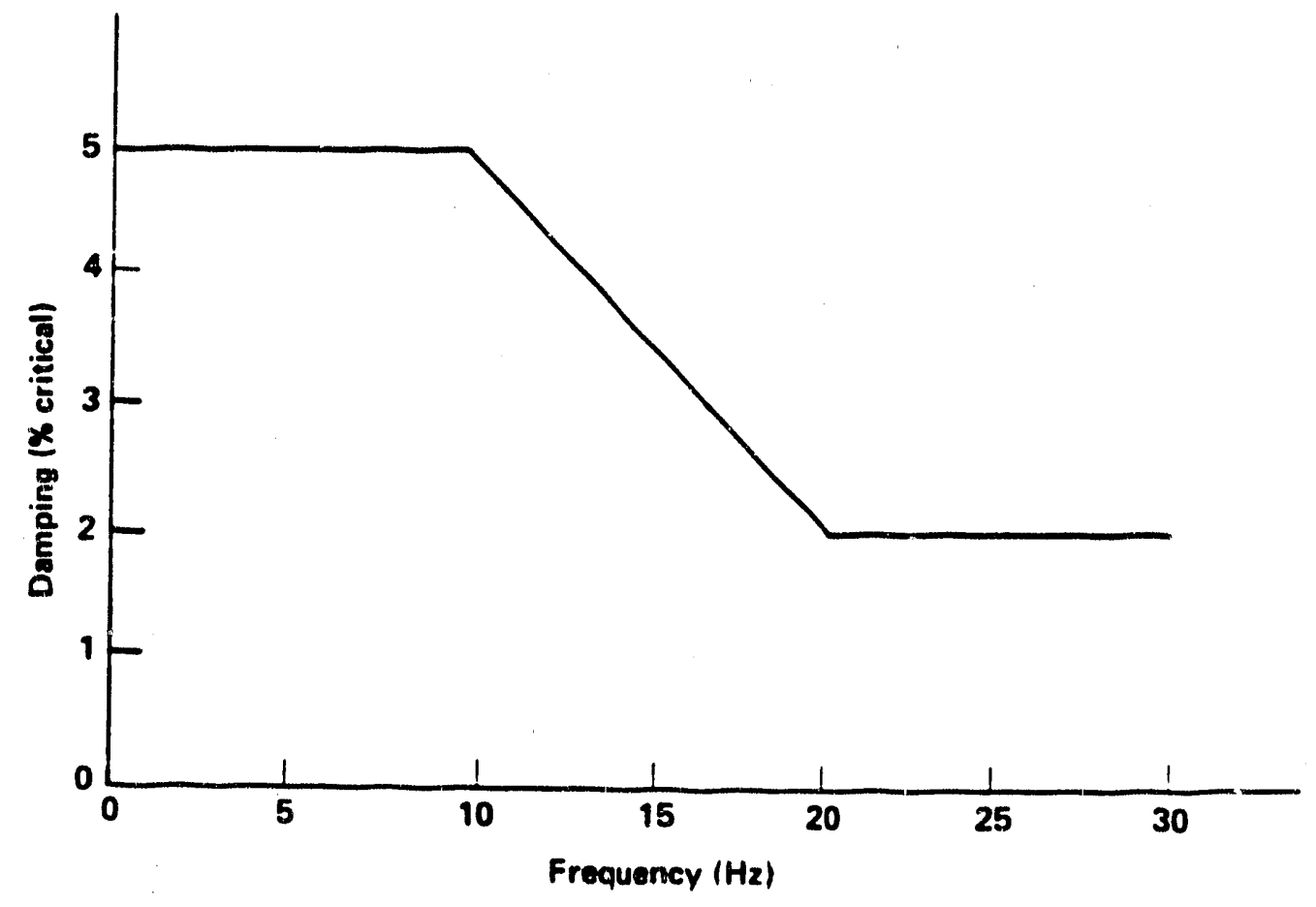

Figure 12 PVRC Recommended Damping. 


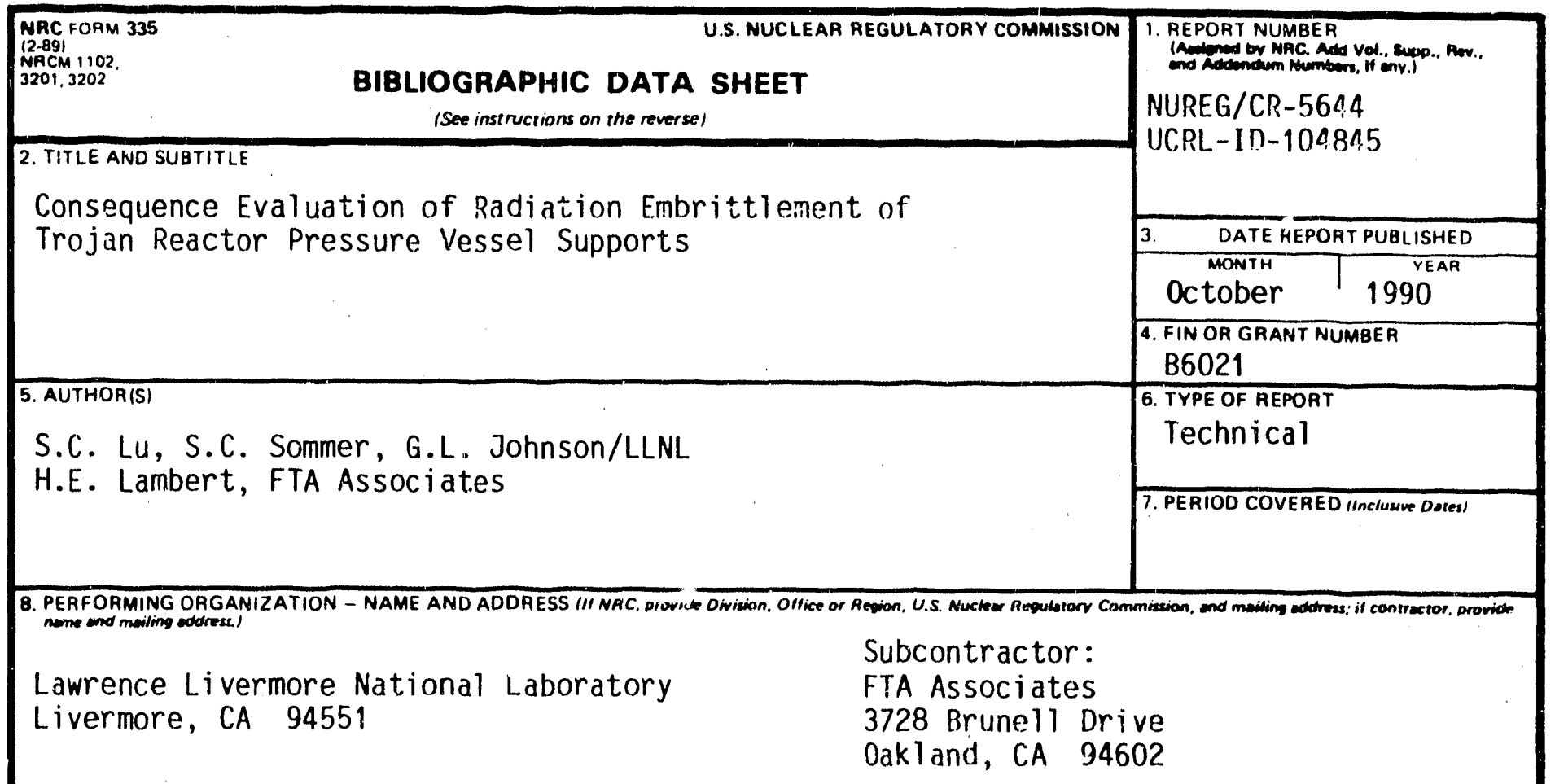

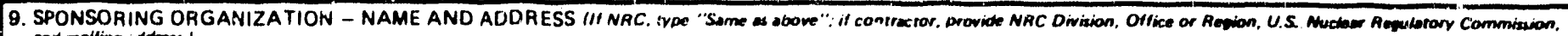
and melling nodress.

Division of Engineering

Office of Nuclear Regulatory Research

U.S. Nuclear Regulatory Commission

Washington, DC 20555

10. SUPPLEMENTARY NOTES

11. ABSTRACT 1200 words or test

This report describes a consequence evaluation to address safety concerns raised by the radiation embrittlement of the reactor p essure vessel (RPV) supports for the Trojan nuclear power plant. The study comprises a structural evaluation and an effects evaluation and assumes tha: all four reactor vessei supports have completely lost the load carrying capability.

The structural evaluation indicates that the Trojan reactor coolant loop (RCL) piping is capable of transferring loads to the steam generator (SG) supports and the reactor coolant pump (RCP) supports. A subsequent analysis further demonstrates that the SG supports and the RCP supports have sufficient design margins to accommodate additional loads transferred to them through the RCL piping.

The effects evaluation, employing a systems analysis approar $h$, investigates initiating events and the reliability of the engineered safeguard systems as the RPV is subject to movements caused by the RPV support failure. The study concludes that a hypothetical failure of the Trojan RPV supports due to radiation embrittlement will not result in consequences of significant safety concerns. 

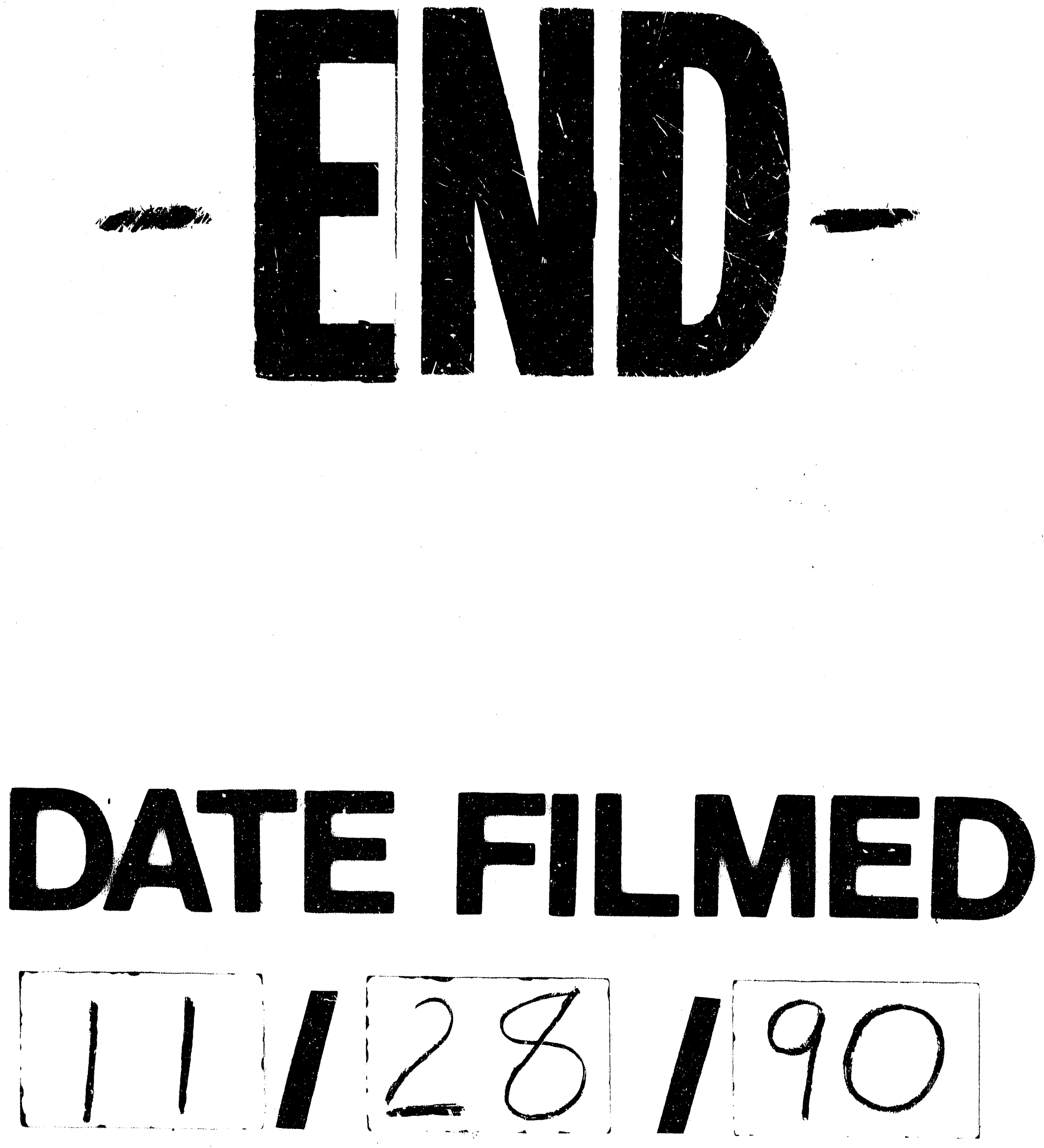
